\title{
Indicadores Formativos em Modelos de Equações Estruturais
}

\author{
Marcos Rogério Sanches
}

DISSERTAÇÃO APRESENTADA

$A O$

INSTITUTO DE MATEMÁTICA E ESTATÍSTICÃ DÁ UNIVERSIDADE DE SÃO PAULO

PARA

OBTENÇÃO DO GRAU

DE

MESTRE EM ESTATÍSTICA

Área de Concentração: Estatística

Orientadora: Profa. Dra. Lúcia Pereira Barroso

São Paulo, dezembro de 2005 


\section{Indicadores Formativos em Modelos de Equações Estruturais}

Este exemplar corresponde à redação

final da dissertação de Marcos Rogério Sanches

São Paulo, 9 de dezembro de 2005

Banca Examinadora:

- Profa. Dra. Lúcia Pereira Barroso (orientadora) - IME/USP

- Prof. Dr. Wilton de Oliveira Bussab - IME/USP

- Prof. Dr. Francisco José Espósito Aranha Filho - EAESP/FGV 


\section{Agradecimentos}

Dedico este trabalho a todos que me apoiaram nesse periodo, em especial a meus pais. Agradecimentos especiais a minha noiva Lilian Satake pela ajuda na digitação e correção e pelo apoio, a Sérgio Litvac pela compreensão e incentivo que tantas vezes precisei, aos irmãos Sergio e Valéria Negrini pela grande torcida e preocupação, e principalmente a minha orientadora $\mathrm{Dr}^{\mathrm{a}}$. Lúcia Barroso, que percorreu comigo cada passo desta jornada e foi essencial para o sucesso deste trabalho. 


\section{Resumo}

Os Modelos de Equações Estruturais vêm sendo cada vez mais usados em situações práticas como forma de confirmar modelos teóricos de eventos estudados. Nos Estados Unidos, a técnica se apresenta bastante disseminada, ao contrário do que acontece no Brasil, onde estas equações passaram a ser usadas mais recentemente. Como a utilização de modelos estruturais envolve uma certa quantidade de subjetividade, é importante que seus aspectos teóricos não subjetivos estejam bem fundamentados. Um dos principais pontos que definem as equações estruturais são as relações causais entre as variáveis, cuja direção muitas vezes é ou precisa ser especificada de forma subjetiva, com base apenas em conhecimentos do pesquisador sobre o assunto estudado. Além disso, os pesquisadores que trabalham com Modelos de Equações Estruturais carregam consigo um viés da Análise Fatorial, que é um tipo especial de modelo estrutural: o constructo sempre sendo a causa da variável observada. Diante disso, o objetivo deste texto foi acima de tudo estudar a direção causal em equações estruturais, dando ênfase à variável observada que causa o constructo latente, comumente chamada de indicador formativo. A motivação foi a escassez da literatura estatística específica sobre o assunto e principalmente o possivel uso amplamente disseminado da direção causal especificada incorretamente, visto que na grande maioria dos casos a direção especificada da causa é sempre do constructo para o indicador. Tentamos então fazer um apanhado geral desta escassa literatura e ainda obter dados sobre os efeitos da especificação incorreta da direção causal por meio de simulações. 


\section{Índice}

1. Breve Introdução aos Modelos de Equações Estruturais.........................1

1.1. História dos Modelos de Equações Estruturais ...........................2

1.2. Uma Introdução Geral aos Modelos de Equações Estruturais......4

1.2.1. Convenções Usadas neste Texto....................................4

1.2.2. Os Diagramas de Caminho.............................................6

1.2.3. Validade e Confiabilidade.............................................. 9

1.2.4. Relações entre as Variáveis...........................................12

1.2.5. Matriz de Covariância Implicada .....................................22

1.2.6. Identificação do Modelo................................................ 25

1.2.7. Estimação dos Parâmetros...............................................27

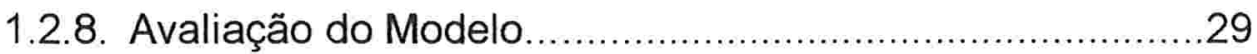

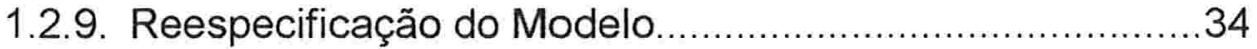

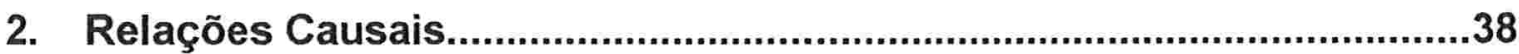

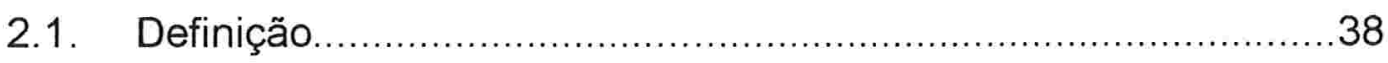

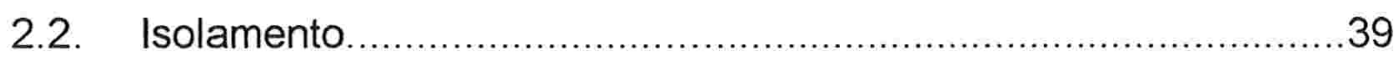

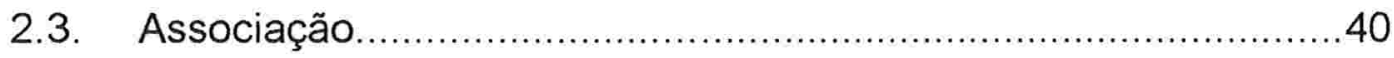

2.4. Direção da Causa......................................................... 42

3. Breve Relato das Principais Referências sobre Indicadores

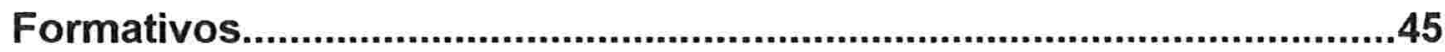

4. Indicadores Formativos e Reflexivos: Uma Comparação.................... .52

4.1. Definição de Variável Latente...................................................53

4.2. O Princípio da Consistência Interna ............................................54

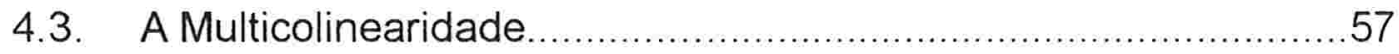

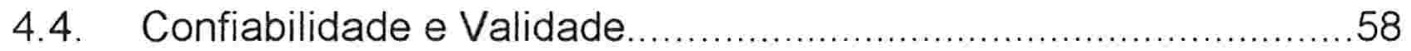

4.5. Representação Amostral da Variável Latente.............................59

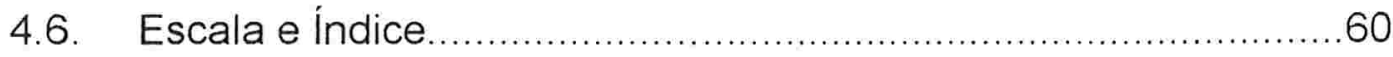


5. Indicadores Formativos e Principais Aspectos Teóricos.......................63

5.1. Identificação

5.2. Regras para Identificação de Modelos com Indicadores Formativos. 64

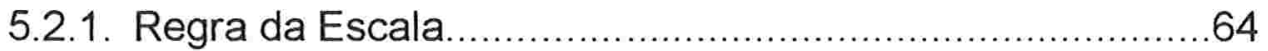

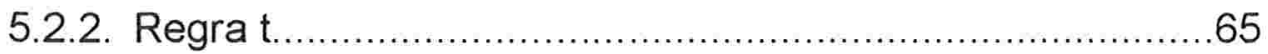

5.2.3. Regra dos Dois Caminhos Emitidos.................................66

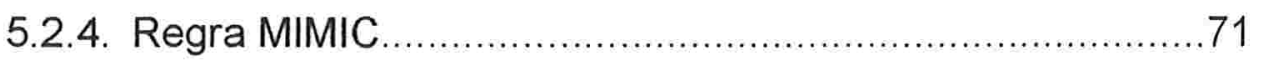

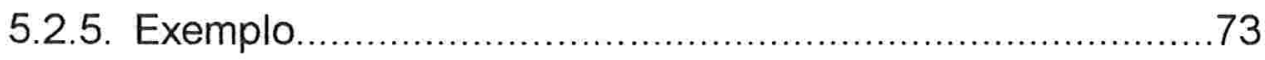

5.3. Modelos com Indicadores Formativos não Identificados..............79

5.4. A Restrição de Proporcionalidade ............................................ 84

6. Especificação da Direção da Causa..........................................................87

6.1. O Uso de Tétrades para a Especificação da Direção Causal.......88

6.2. Modelos para o Relacionamento entre Constructo e Indicador...997

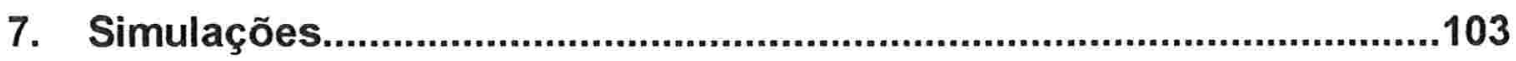

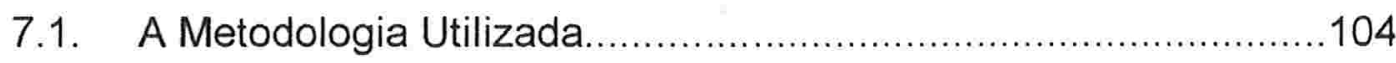

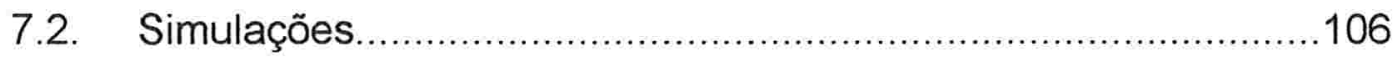

7.2.1. O Modelo MIMIC com Três Indicadores Formativos e Três Indicadores Reflexivos.................................................107

7.2.2. O Modelo MIMIC com Três Indicadores Formativos e Cinco Indicadores Reflexivos...............................................118

7.2.3. O Modelo MIMIC com Cinco Indicadores Formativos e Três Indicadores Reflexivos..................................................119

7.2.4. O Modelo MIMIC com Indicadores Formativos

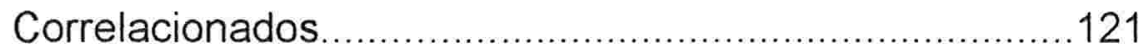

7.2.5. Modelo com Dois Constructos, sendo um sem Indicador Formativo e Causado pelo Outro.....................................126

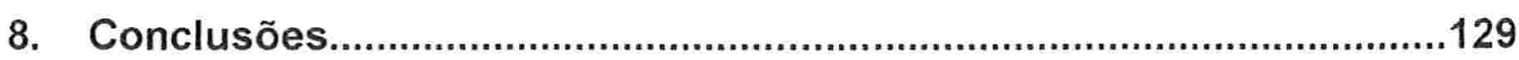

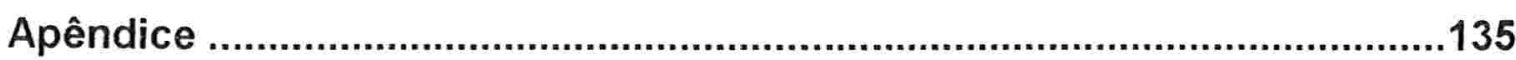

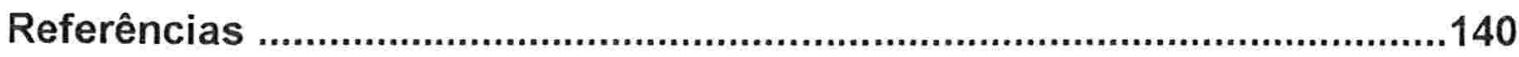




\section{Capítulo 1 - Breve Introdução aos Modelos de Equações Estruturais}

O presente texto discorre sobre um tipo de técnica estatística que vem se tornando muito comum, principalmente por causa da grande quantidade de softwares que têm sido desenvolvidos na área. São os chamados Modelos de Equações Estruturais que podem ser considerados como uma generalização de várias técnicas estatísticas mais conhecidas e usadas, como por exemplo a Análise de Regressão Simples, Múltipla e Multivariada, a Análise de Variância e de Covariância e a Análise Fatorial. A possibilidade de se estudar relações de causa-efeito entre variáveis que a princípio não podemos mensurar é um dos motivos que faz com que os modelos estruturais sejam uma técnica mais geral que as citadas anteriormente. Outro motivo é a possibilidade de se incluir múltiplas relações de causa-efeito entre as variáveis, isto é, em um modelo estrutural uma variável $Y_{1}$ pode ser causada por $X_{1}$, mas pode também causar $Y_{2}$. Podemos até postular uma relação recíproca do tipo $Y_{1}$ causa $Y_{2}$ que por sua vez causa $Y_{1}$. Esta generalidade de relações não pode ser representada em um único modelo usual de regressão, e então os modelos estruturais podem ser tidos como um conjunto de regressões simultâneas.

Suponha o seguinte exemplo aplicado à análise de criminalidade: queremos explicar o número de roubos de veículos nos setores censitários da cidade de São Paulo. Para isso podemos usar um modelo de regressão com variáveis explicativas relacionadas ao perfil sócio-econômico dos habitantes de cada setor, como idade, renda familiar, número de domicílios, número de habitantes por domicílio, número de estabelecimentos comerciais, etc. Usando modelos estruturais podemos ir mais adiante, por exemplo, a renda familiar pode ter uma relação de causa com o número de habitantes por domicílio e com o próprio número de domicílios do setor censitário. O número de estabelecimentos comerciais nos setores pode ser determinado pelo potencial comercial nestes setores, este potencial pode não ser uma variável diretamente mensurável, mas outras variáveis mensuráveis, como número de vias de acesso, distância do setor 
ao centro da cidade, nível de infra-estrutura existente, movimento de pessoas e a própria renda familiar podem ser supostos indicadores deste potencial. Todas estas relações são suposições que podem ser testadas em um único modelo estrutural com base nos dados.

Uma outra característica que vale ressaltar nos modelos estruturais é que eles sempre podem ser representados através de um diagrama, o que os tornam bem simples de serem entendidos. Estes diagramas são chamados de diagramas de caminho e serão definidos com mais detalhes na Seção 1.2.2.

Ao contrário da maioria das técnicas de Análise Multivariada, os modelos estruturais têm uma característica muito mais confirmatória, embora possamos usá-los também em estudos exploratórios. Geralmente quando pensamos em usar um modelo estrutural já temos uma hipótese formulada para ser testada, a qual quase sempre consiste de relações que supomos existir e queremos evidências que as confirmem. No exemplo anterior postulamos todo um conjunto de relações entre variáveis, com base apenas no nosso conhecimento sobre o assunto - o modelo estrutural resultante validará ou não estas relações.

Mais adiante faremos uma breve revisão dos principais pontos relacionados com os modelos estruturais, antes porém vamos passar por um breve relato sobre o contexto histórico em que se encaixam estes modelos.

\section{1 - História dos Modelos de Equações Estruturais}

Como vimos anteriormente os modelos estruturais unem em um único conjunto de equações (regressões) variáveis latentes, que também são chamadas de fatores ou constructos, e variáveis observadas, que também podem ser chamadas de indicadores. Podem ainda ser representados por diagramas, chamados diagramas de caminho. O desenvolvimento de toda esta estrutura não se deu em conjunto e não terminou ainda. Novos métodos de estimação, de estudo de relações mais complexas como as não lineares, inclusão de variáveis categorizadas, etc, vêm sendo continuamente aperfeiçoadas, contribuindo para a evolução dos modelos estruturais. 
Wright $(1918,1921,1934,1960)$ foi o pioneiro no estudo de modelos que incluem diagramas de caminho, na associação de sistemas de equações a estes modelos pictóricos e na relação dos elementos da matriz de covariância com os parâmetros do modelo. Contudo Wright não usava na representação dessas relações a notação matricial comum hoje em dia, mas sim as próprias equações de regressão presentes nos diagramas de caminho.

Embora Wright tenha chegado a usar variáveis latentes em seus trabalhos, a primeira publicação relacionada à Análise Fatorial é devida a Spearman (1904), que tratou do estudo da performance de crianças em línguas. $\mathrm{Na}$ ocasião Spearman notou que a performance em várias línguas podia ser explicada em parte por um fator comum. Depois o conceito de variável latente foi mais desenvolvido por Spearman e Karl Pearson na tentativa de se estudar a Inteligência. Por causa dessa ligação inicial da Análise Fatorial com a Inteligência, essa técnica foi muito mais desenvolvida e utilizada nas ciências sociais e psicologia, e sempre houve também muita controvérsia em relação à validade destes modelos principalmente porque os primeiros trabalhos tinham muita intuição e nem tanta inferência.

Até os anos 60 não se deu muita atenção ao trabalho de Wright, e nesta fase os diagramas de caminho não evoluíram muito. A Análise Fatorial ganhou uma sólida base estatística no começo dos anos $40 \mathrm{com} 0$ desenvolvimento da estimação por máxima verossimilhança por Lawley (1940) e então foi bastante ignorada até os anos 60 devido às dificuldades computacionais. No final dos anos 60 a Análise Fatorial reapareceu forte com os trabalhos de Jöreskog (1967) e Jöreskog e Lawley (1968) que desenvolveram procedimentos para a estimação por máxima verossimilhança através de um algoritmo computacional. Nos anos 60 houve alguns artigos a respeito da utilização de variáveis latentes em modelos de causa-efeito onde se sugeria que elas causavam ou eram causadas por variáveis observáveis, mas foi só no começo dos anos 70 com Jöreskog (1973), Keesling (1972) e Wiley (1973) que os modelos estruturais ganharam sua forma geral com uma teoria abrangente que os estudava divididos em duas partes: o modelo de variáveis latentes - parte estrutural - que 
compreende as relações dos fatores entre si e o modelo de mensuração que relaciona as variáveis latentes a seus indicadores.

A partir de então o programa LISREL (Linear Structural Relations), desenvolvido por Jöreskog e Sörbom, e vários artigos de Jöreskog e outros sobre o assunto fizeram com que os modelos estruturais se tornassem muito populares. O software LISREL foi tão disseminado e usado que muitas pessoas chamam os modelos estruturais de LISREL. Hoje temos muitos programas computacionais desenvolvidos para estimação de parâmetros em modelos estruturais, e além do LISREL (Jöreskog e Sörbom (1989)) encontramos ainda o AMOS (Arbuckle (1999)) e o EQS (Bentler (1985)) que são largamente utilizados. Softwares tradicionais de análise estatística como o SAS, o SPSS (AMOS) e o S-Plus também têm seus módulos para trabalhar com modelos estruturais.

\section{2 - Uma Introdução Geral aos Modelos de Equações Estruturais}

Nesta seção descrevemos de uma forma resumida e direta os pontos principais da teoria estatística que envolve os modelos estruturais. Primeiramente incluímos uma seção explicativa que introduz símbolos e notações envolvidas com este tipo de modelo, bem como explicações sobre a interpretação dos diagramas de caminho. Depois falamos sobre relações entre variáveis, identificação, estimação, validação e reespecificação do modelo nesta ordem.

\subsection{1 - Convenções Usadas neste Texto}

Como os modelos estruturais envolvem uma grande diversidade de parâmetros e variáveis, torna-se necessário adotar um padrão de notação que seja obedecido durante todo o texto a fim de facilitar a compreensão e evitar ambigüidades. Usamos aqui a mesma notação encontrada em Bollen (1989a), que pode ser verificada na Tabela 1.1. Alguns termos desta tabela serão explicados no decorrer do texto, quando se fizer necessário. 
Tabela 1.1 - Relaçäo dos símbolos utilizados no texto e seus significados.

\begin{tabular}{|c|c|}
\hline Símbolo & Significado \\
\hline $\mathrm{X}, \mathrm{x}$ & $\begin{array}{l}\text { Variável mensurável, indicador de variáveis latentes exógenas*, ou variável mensurável } \\
\text { exógena em modelos sem variáveis latentes. O termo minúsculo, em negrito refere-se a } \\
\text { um vetor de variáveis }\end{array}$ \\
\hline$Y, y$ & $\begin{array}{l}\text { Variável mensurável, indicador de variáveis latentes endógenas*, ou variável mensurável } \\
\text { endógena em modelos sem variáveis latentes. O termo minúsculo, em negrito refere-se a } \\
\text { um vetor de variáveis }\end{array}$ \\
\hline$\xi$ & Variável latente exógena \\
\hline$\eta$ & Variável latente endógena \\
\hline$\delta$ & Erro associado aos indicadores das latentes exógenas \\
\hline$\varepsilon$ & Erro associado aos indicadores das latentes endógenas \\
\hline$\Sigma$ & Matriz de variâncias e covariâncias populacionais \\
\hline $\mathbf{S}$ & Matriz de variâncias e covariâncias amostrais \\
\hline$\theta$ & Vetor de parâmetros \\
\hline$\gamma$ & $\begin{array}{l}\text { Coeficiente entre variável latente exógena e latente endógena. Em modelos sem variáveis } \\
\text { latentes, é o coeficiente entre } \mathrm{X} \text { e Y. Em modelos do tipo MIMIC }{ }^{* \star} \text { é o coeficiente entre } X \text { e } \\
\text { a variável latente }\end{array}$ \\
\hline$\zeta$ & $\begin{array}{l}\text { Erro associado a variáveis latentes endógenas ou erro associado a modelos com variáveis } \\
\text { observadas }\end{array}$ \\
\hline$\phi$ & Covariância entre variáveis exógenas \\
\hline$\psi$ & Covariância entre erros \\
\hline$\lambda$ & Coeficiente da variável latente em seu indicador \\
\hline$\beta$ & $\begin{array}{l}\text { Coeficiente do efeito de uma latente endógena em outra latente endógena. Em modelos } \\
\text { sem varáveis latentes é o coeficiente de } Y \text { em outro } Y\end{array}$ \\
\hline$\Theta_{\varepsilon}$ & Matriz de covariância dos erros dos Y's \\
\hline$\Theta_{\delta}$ & Matriz de covariância dos erros dos X's \\
\hline$\Lambda_{\mathrm{X}}$ & Matriz dos coeficientes entre as latentes e $X$ \\
\hline$\Lambda_{Y}$ & Matriz dos coeficientes entre as latentes e $Y$ \\
\hline$\Phi$ & Matriz de covariância das latentes exógenas \\
\hline$\Psi$ & Matriz de covariância dos erros associados às variáveis latentes \\
\hline B & $\begin{array}{l}\text { Matriz dos coeficientes dos efeitos entre as latentes endógenas, ou dos efeitos entre as } \\
\text { variáveis Y nos modelos sem variáveis latentes }\end{array}$ \\
\hline$\Gamma$ & $\begin{array}{l}\text { Matriz dos coeficientes dos efeitos das latentes exógenas nas latentes endógenas, ou dos } \\
\text { efeitos de } \mathrm{X} \text { em } \mathrm{Y} \text { nos modelos sem variáveis latentes }\end{array}$ \\
\hline
\end{tabular}

Observe que alguns termos têm significados diferentes dependendo do contexto. Na verdade as convenções são sempre utilizadas de acordo com o sistema de equações (1.1), (1.2) e (1.3), especificadas adiante. Alguns modelos são casos particulares mais simples deste sistema, como por exemplo os modelos

\footnotetext{
* O significado de variáveis endógenas e exógenas será abordado na Seção 1.2.t.
}

** Os modelos MIMC serão vistos a partir do Capítulo 3. 
sem variáveis latentes (equação (1.4)), e nestes casos o modelo readaptado é escrito fazendo com que as convenções algumas vezes não sejam únicas.

Além das convenções desta tabela, sempre usamos em paralelo outro padrão de notação comum nos textos da área: variáveis aleatórias são representadas com letras maiúsculas, geralmente $\mathrm{X}$ e $\mathrm{Y}$. Vetores de variáveis são representados com letras minúsculas em negrito. As letras maiúsculas em negrito são reservadas para matrizes.

\subsection{2 - Os Diagramas de Caminho}

Os modelos estruturais muitas vezes envolvem relações complexas e de vários tipos entre as variáveis, as quais também podem ser de vários tipos. Isso faz com que a visualização e o entendimento de todas as relações existentes em um modelo seja bastante difícil quando dispomos apenas do sistema de equações que descrevem o modelo. Desenvolveu-se então um método gráfico para a representação dos modelos estruturais, que facilita muito a visualização do modelo que se está analisando, suas variáveis e as relações postuladas entre elas. Além disso, estes gráficos, chamados de diagramas de caminho, também servem como ferramenta para ajudar o pesquisador na definição inicial do modelo, quando ele tenta representar como um sistema de equações matemáticas o seu problema prático. Por fim alguns softwares computacionais também se valem destes gráficos como o principal método para a entrada de informações sobre as relações entre as variáveis, os tipos de variáveis existentes no modelo e seus parâmetros.

Apresentamos aqui uma breve descrição do diagrama de caminho e seus componentes, a qual acreditamos ser suficiente para que o leitor compreenda não apenas os diagramas de caminho presentes neste texto, mas em toda a literatura relacionada ao assunto, visto que estes gráficos estão disseminados de uma forma já padronizada, com muito poucas exceções.

Um círculo ou elipse representa sempre uma variável latente. O círculo é mais usado para representar os erros, sejam associados a variáveis 
latentes ou não. Em alguns textos os erros são simplesmente representados pelo seu símbolo, sem estarem envoltos por um círculo, mas neste texto sempre estarão. As elipses são usadas para representar variáveis latentes que não os erros, sejam exógenas ou endógenas*. E finalmente os retângulos são usados quando a variável é observada, fruto de algum processo de medição. A Figura 1.1 mostra cada um destes três itens.

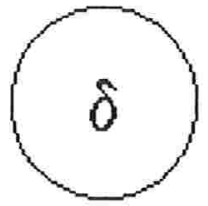

a

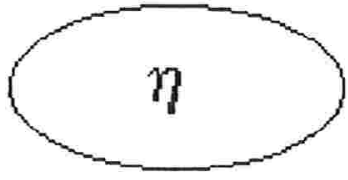

b

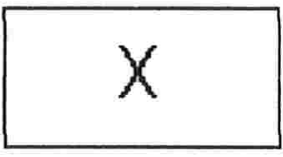

$\mathrm{C}$

Figura 1.1 - a) Círculo representando um erro. b) Elipse representando uma variável latente de interesse. c) Retângulo indicando uma variável observada

Definida a representação gráfica das variáveis, resta apenas estabelecermos as relações entre elas, o que é feito por meio de setas. As setas nos dizem não só quais variáveis afetam e são*afetadas por quais, mas também qual o tipo e o sentido da relação. Assim uma seta que sai de uma elipse e aponta para um retângulo significa: esta elipse é uma causa daquele retângulo (a elipse exerce influência no retângulo), a elipse e 0 retângulo sendo duas variáveis no modelo.

Se, no entanto, temos uma seta que aponta em ambos os sentidos, então a relação não é tida como de causa mas somente de correlação, o que significa que uma variável não causa a outra, mas ambas têm possivelmente uma causa em comum. Existem ainda as relações recíprocas onde ao mesmo tempo uma variável causa e é causada por outra. Neste caso o diagrama de caminho deve apresentar duas setas entre as duas variáveis, uma em cada sentido. Veja na Figura 1.2 os três tipos de relaçōes citadas.

\footnotetext{
"O significado de variáveis endógenas c exógenas será abordado na Seção 1.2.4.
} 
Quando temos várias variáveis que são todas correlacionadas entre si, simplificamos a notação no diagrama de caminho, como na Figura 1.2d.

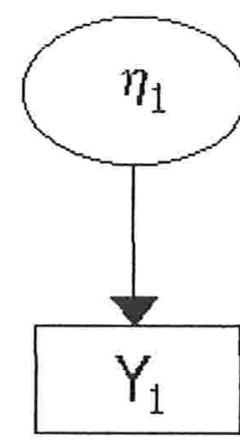

a

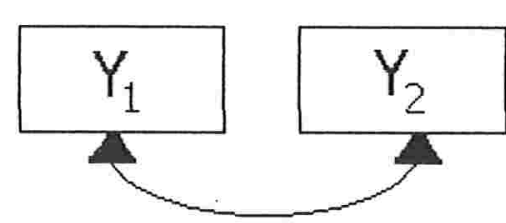

b

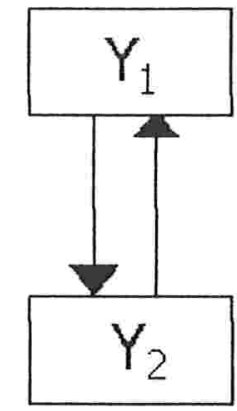

C

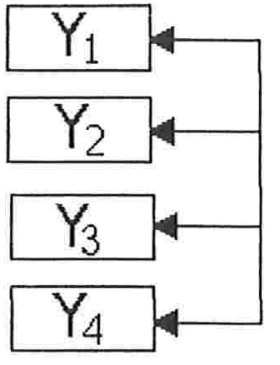

d

Figura-1.2 - a) Relação de causa, onde $\eta_{1}$ causa $Y_{1}$. b) Relação de correlação entre $Y_{1}$ e $Y_{2}$, geralmente causada por um fator comum. c) Relação de causa recíproca entre $Y_{1}$ e $Y_{2}$, onde ambas são causa e efeito. d) Várias variáveis, $Y_{1}$ a $Y_{4}$, todas correlacionadas entre si.

Apenas estes símbolos como foram definidos são suficientes para representarmos e entendermos todos os modelos contidos neste texto. Na Figura 1.3 mostramos o diagrama de caminho de um modelo completo, neste caso, o modelo suposto na introdução deste capítulo para o roubo de veículos. Note que é bem fácil entender as relações entre as variáveis e estudá-las de forma a verificar se elas fazem ou não sentido para um problema específico. De agora em diante usaremos bastante estes diagramas para tornar mais fácil a compreensão não só de determinados modelos, mas principalmente de diversos pontos importantes da teoria que queremos expor. 


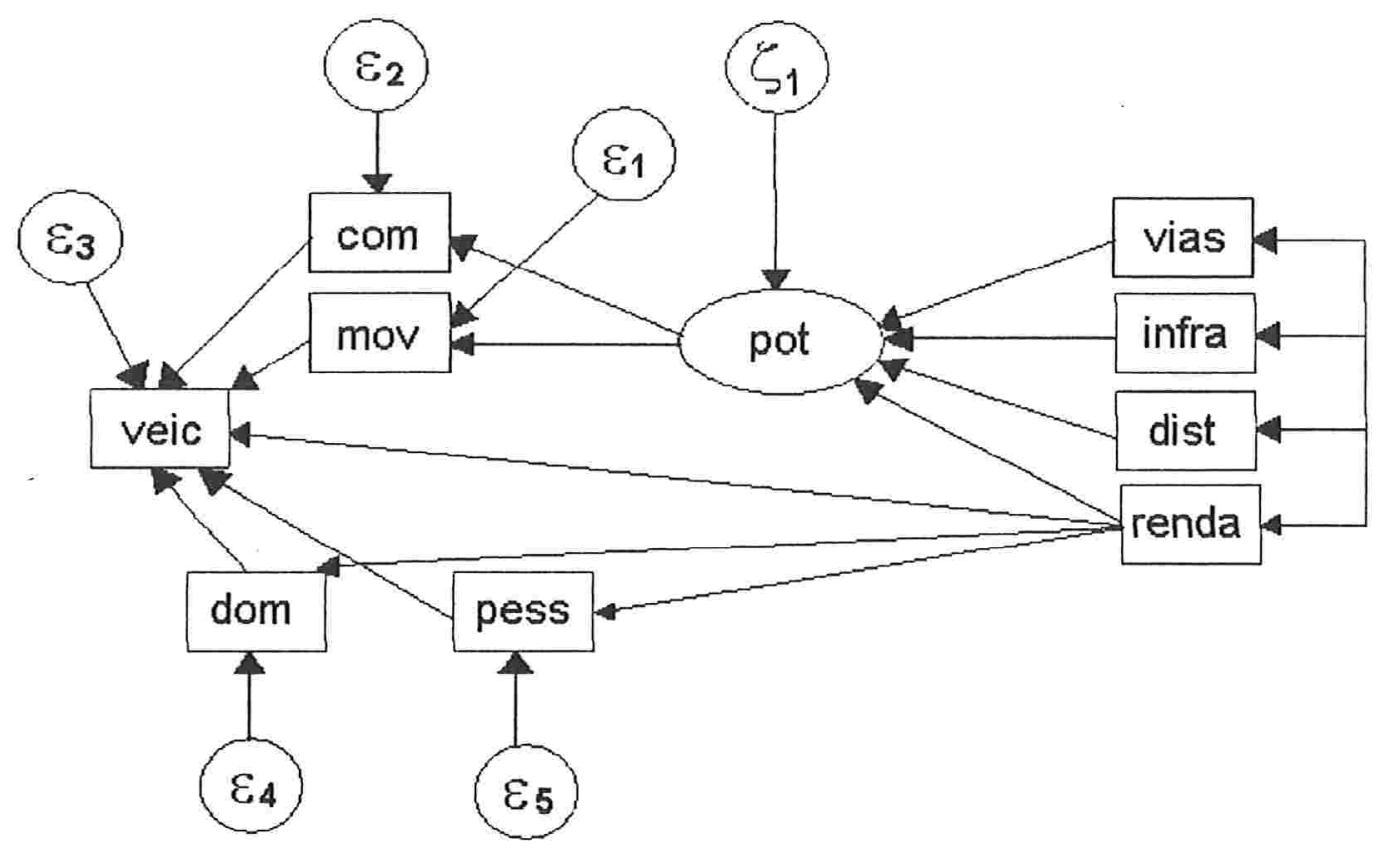

Figura 1.3 - Exemplo das relaçöes entre as variáveis do modelo para o roubo de veículos suposto no início deste capítulo. Variáveis: veic $=n^{\circ}$ de veículos roubados, com $=n^{\circ}$ de estabelecimentos comerciais, $m o v=$ movimento de pessoas, renda $=$ renda familiar, $d o m=n^{\circ}$ de domicílios, pess $=n^{0}$ de pessoas por domicílio, pot $=$ potencial comercial, vias $=n^{\circ}$ de vias de acesso ao setor censitário, infra $=$ infra-estrutura disponível, dist $=$ distância do setor ao centro da cidade.

\subsection{3 - Validade e Confiabilidade}

Um modelo estrutural sempre pode ser dividido em uma parte de mensuração (do inglês "measurement model") que compreende a relação entre as variáveis latentes e seus indicadores e outra parte chamada estrutural, onde temos as relações entre as variáveis latentes entre si. A parte de mensuração é especialmente importante para nós e assim os conceitos de validade e confiabilidade (do inglês "validity" e "reliability") também são importantes pois eles tratam de medir o quão adequado é um indicador para ser uma medida de uma variável latente.

Há uma ampla teoria sobre a mensuração disponivel na literatura. Esta teoria é especialmente importante quando estamos falando sobre modelos estruturais, pois muitas vezes envolvem variáveis latentes que precisam ser medidas por intermédio de indicadores. Necessitamos então encontrar 
indicadores, também chamados de medidas, que sejam válidos e confiáveis, conceitos que estudaremos neste tópico. Uma boa referência para o estudo aprofundado da validade e confiabilidade, inclusive fora do contexto dos modelos estruturais, é Pedhazur (1991).

\subsubsection{1 - Validade}

A validade é uma medida mais conceitual do que matemática e, embora existam procedimentos desenvolvidos para estimá-la, geralmente não são aplicáveis e a verificação da validade é feita apenas de forma conceitual.

A validade é definida como o quanto um indicador mede o que ele tem que medir. Se, por exemplo, queremos um indicador válido para a autoestima, temos que encontrar algo mensurável que seja relacionado à auto-estima, mas não necessariamente explique a auto-estima. Pedhazur (1991) enfatiza que prever não é a mesma coisa que explicar, e para uma medida ser válida ela precisa prever em algum grau o que ela mede.

Pedhazur (1991) refere-se à correlação como um exemplo de medida de validade. Mas em nosso caso, geralmente trabalharemos com variáveis latentes, e a correlação não é aplicável. Existem, no entanto, alguns métodos para se ter um valor numérico para a validade de um indicador em relação a um constructo. Bollen (1989a), Capitulo 6, explica com bastante detalhe estes métodos e propõe outros mais acessíveis. Nesta mesma referência o autor propõe uma nova definição para a validade, que seria a intensidade da relação direta entre o constructo e o indicador, que teria como estimador o próprio coeficiente padronizado entre as duas variáveis no modelo estrutural. Mais adiante será explicado resumidamente como calcular este coeficiente.

Bollen (1989a) propõe outros três estimadores para a validade, mas não nos estenderemos no assunto aqui, pois o principal objetivo é passar o conceito de validade. 


\subsubsection{2 - Confiabilidade}

Confiabilidade, que também pode ser chamada de consistência, é a parte da medida que é livre de erro aleatório. Por exemplo, se conseguíssemos fazer várias vezes a mesma pergunta a uma pessoa preservando a independência entre as respostas, então a confiabilidade seria grande se houvesse pouca variação nas respostas e pequena caso contrário. É importante observar que a confiabilidade não tem nenhuma relação com a validade, uma medida válida pode não ser consistente e vice-versa. Por exemplo, o "número médio de casas por quadra" é uma medida bastante confiável, pois pode ser medida com exatidão e pouco erro, mas provavelmente não é uma medida válida para o constructo "poluição na cidade".

O estimador da confiabilidade mais conhecido é o Alpha de Cronbach, dado por

$$
\rho_{H H}=\frac{q}{q-1}\left(1-\frac{\sum_{i=1}^{q} \operatorname{Var}\left(X_{i}\right)}{\operatorname{Var}\left(\sum_{i=1}^{q} X_{i}\right)}\right),
$$

onde q é o número de indicadores. O principal problema deste índice é que não é possível ter a confiabilidade de um indicador apenas.

Bollen (1989a) sugere uma alternativa para se estimar a confiabilidade de apenas um indicador $X$. Seja a equação

$$
X=\tau+e
$$

onde $\tau$ é a parte sem erro do indicador $\mathrm{X}$ e e é a parte aleatória. Então podemos escrever

$$
\tau=\lambda \xi+s
$$




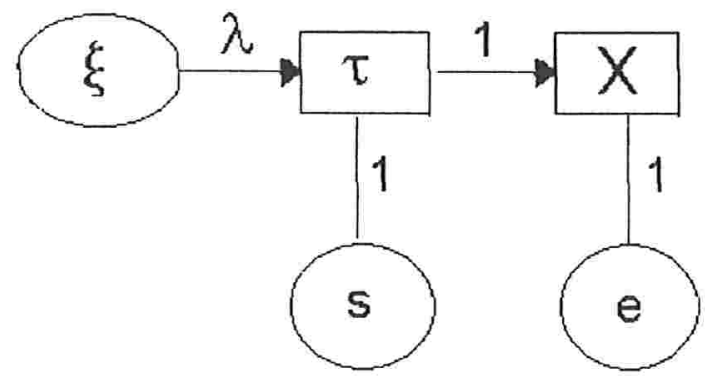

Figura 1.4 - Representação em forma de diagrama de caminho do modelo de confiabilidade proposto por Bollen

ou seja, o constructo $\xi$ causa a parte fixa de $\mathrm{X}$ representada por $\tau$, com um erro $\mathrm{S}$, que é devido a outras causas dessa parte fixa externas ao modelo. A Figura 1.4 mostra este modelo de confiabilidade em forma de diagrama de caminho. Assim a confiabilidade é definida por Bollen como

$$
\rho_{x x}=\frac{\operatorname{Var}(\tau)}{\operatorname{Var}(X)}=\frac{\operatorname{Var}(\lambda \xi+s)}{\operatorname{Var}(X)}=\frac{\lambda^{2} \operatorname{Var}(\xi)+\operatorname{Var}(s)}{\operatorname{Var}(X)} .
$$

Como não temos como estimar $\operatorname{Var}(\mathbf{S})$ podemos desprezá-la, subestimando assim a confiabilidade de $\mathrm{X}$, o que seria uma atitude conservadora.

Existem outros métodos empíricos para se estimar a confiabilidade que são muito menos utilizados, e estão expostos com detalhe em Bollen (1989a).

\subsection{4 - Relações entre as Variáveis}

Consideremos $\mathbf{x}_{(q \times 1)}$ e $\mathbf{y}_{(p \times 1)}$ vetores de variáveis observadas, $\mathbf{B}_{(\mathrm{m} \times m)}$, $\Gamma_{(m \times n)}, \Lambda_{X(q X n)}, \Lambda_{Y(p X m)}$ matrizes de parâmetros e $\eta_{(m \times 1)}, \xi_{(n \times 1)}, \varepsilon_{(p \times 1)}, \delta_{(q \times 1)}$ e $\zeta_{(m \times 1)}$, vetores de variáveis latentes. Em outras palavras, temos $q$ indicadores $(X)$ para $n$ variáveis latentes exógenas $(\xi), p$ indicadores $(\mathrm{Y})$ para $\mathrm{m}$ variáveis latentes endógenas ( $)$. Qualquer modelo estrutural pode ser representado algebricamente pelas equações de causa-efeito: 


$$
\begin{aligned}
& \eta=B \eta+\Gamma \xi+\zeta \\
& y=\Lambda_{y} \eta+\varepsilon \\
& x=\Lambda_{x} \xi+\delta
\end{aligned}
$$

e pelas relações entre as variáveis que não são relações de causa-efeito. Por exemplo, pode existir uma correlação entre $X_{1}$ e $Y_{2}$ ou entre dois erros quaisquer. Estas correlações são representadas através de matrizes que fazem parte do modelo e estão por trás do sistema de equações. Temos então a matriz de covariâncias entre as variáveis observadas, entre as variáveis latentes e entre os erros. Temos também as suposições relacionadas à distribuição das variáveis, existência ou não de autocorrelação, independência, etc., mas por hora é suficiente considerar as relações de (1.1) a (1.3). A Figura 1.5 mostra um exemplo de um modelo que envolve as três equações acima.

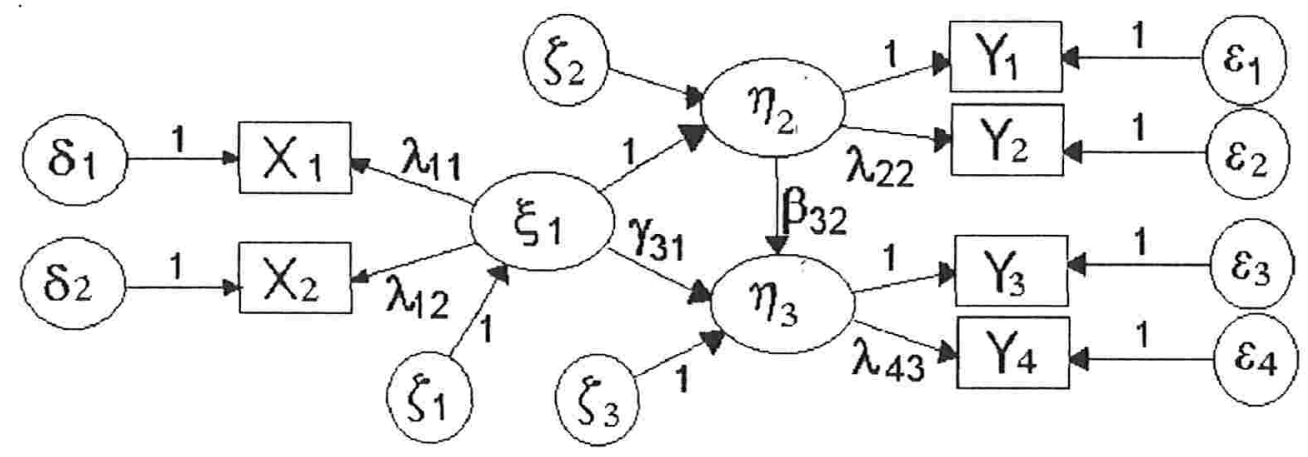

Figura 1.5 - Um exemplo de um modelo que pode ser representado pelas equações (1.1), (1.2) e (1.3). Do lado esquerdo do modelo vemos os elementos das equações de X (1.3) e do lado direito os elementos das equações de Y (1.2). No centro as relações entre as variáveis latentes forma a parte estrutural do modelo representada na equação (1.1).

O modelo de Regressão Linear Múltipla é um caso especial do sistema acima. Nele não temos variáveis latentes, isto é o mesmo que especificar $\varepsilon$ e $\delta$ como matrizes de zeros e $\Lambda_{\mathrm{x}}$ e $\Lambda_{\mathrm{y}}$ como duas matrizes identidades. Desta forma y e $\mathbf{x}$ serão medidas exatas de $\eta$ e $\xi$ respectivamente, e (1.1) torna-se: 


$$
y=B y+\Gamma x+\zeta
$$

Fazendo $\mathbf{B}=\mathbf{0}$ - isto é, as variáveis dependentes não têm relação entre si - , e x e y sendo vetores de variáveis observadas, chegamos exatamente ao modelo de Regressão Linear Multivariada. Se houver apenas um elemento no vetor $\mathbf{y}$, temos uma Regressão Linear Múltipla.

Quando consideramos em (1.4) $\mathbf{B} \neq \mathbf{0}$, temos um modelo estrutural com variáveis observadas. O fato deste modelo permitir relações de causa entre as variáveis dependentes (y) faz com que ele seja muito mais geral do que os modelos de regressão usuais.

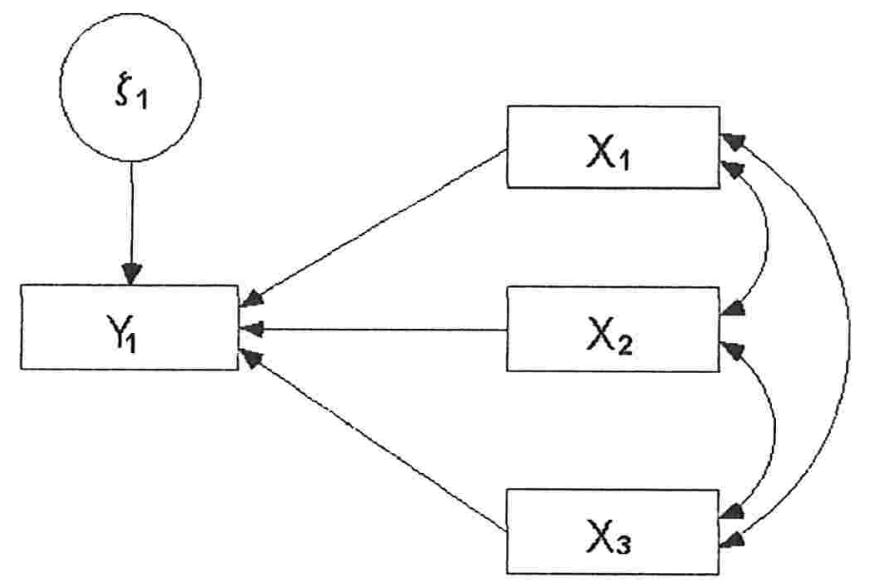

Figura 1.6a - Representação em forma de diagrama de caminho do modelo de Regressão Linear Múltipla.

Os modelos estruturais podem ser mais facilmente entendidos quando representados em forma de diagramas de caminho. A Figura 1.6a mostra um modelo de Regressão Linear Múltipla em forma de diagrama de caminho. Veja que temos apenas uma variável dependente. Podemos imaginar por exemplo que $Y_{1}$ é o valor em reais comprado por um cliente de um supermercado, e a idade $\left(X_{1}\right)$, tempo de relacionamento $\left(X_{2}\right)$ e renda pessoal mensal $\left(X_{3}\right)$ são variáveis explicativas.

A Figura 1.6b mostra um modelo de Regressão Linear Multivariada, onde temos duas variáveis dependentes, todas tendo como variáveis explicativas 
o mesmo conjunto de variáveis independentes. Observe que supomos que todas as variáveis independentes causam as duas variáveis dependentes. Omitimos as correlaçōes entre as variáveis independentes e os parâmetros referentes aos coeficientes para maior clareza do modelo. Podemos imaginar o mesmo caso anterior agora com mais uma variável dependente $Y_{2}$ que pode ser o tempo médio entre duas compras, e mais três variáveis explicativas, $\mathrm{X}_{4} \mathrm{O}$ sexo do cliente, $\mathrm{X}_{5}$ variável indicadora de estado civil solteiro e $X_{6}$ variável indicadora do estado civil casado.

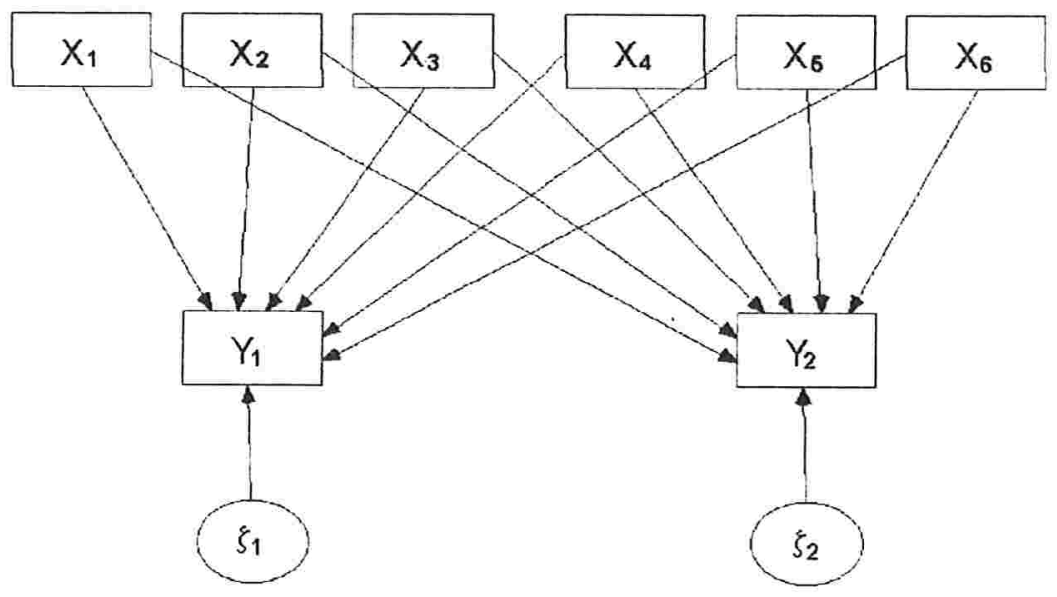

Figura 1.6b - Representação em forma de diagrama de caminho do modelo de Regressão Linear Multivariada.

\subsubsection{1 - Modelos de Equações Estruturais com Variáveis Observadas}

Os modelos de Regressão Linear Múltipla e Multivariada apresentados na subseção anterior são casos particulares de modelos estruturais com variáveis observadas. Mas para ficar mais claro, vamos agora imaginar um modelo como o da subseção anterior um pouco mais sofisticado, com novas variáveis e novas relações entre elas. Temos $X_{1}$ (idade), $X_{2}$ (tempo de relacionamento) e $X_{3}$ (renda pessoal mensal) como variáveis explicativas. $Y_{1}$ (valor comprado em mercadoria) é uma das variáveis dependentes. Mas há outras 
variáveis dependentes $-Y_{4}$ (número de parcelas do pagamento), que supomos ser explicado por $X_{3}$ (renda pessoal mensal) e por $Y_{3}$ (volume comprado em produtos não duráveis - em $\mathrm{kg}$ ), $\mathrm{Y}_{2}$ (tempo médio entre duas compras) causado por $Y_{1}$ (valor da compra) e por $Y_{3}$ (volume comprado em produtos não duráveis em kg). Ao mesmo tempo que $Y_{1}$ causa $Y_{2}, Y_{1}$ é causado por $Y_{2}$ e por $X_{1}$ (idade).

A Figura 1.7 mostra o digrama de caminho deste modelo estrutural com variáveis observadas. Veja que é possivel supor uma relação de causa entre duas variáveis dependentes (é claro que agora não faz mais sentido chamá-las de dependentes), e mais ainda, é possivel incluir até mesmo relações recíprocas, como as que existem entre $Y_{1}$ e $Y_{2}$.

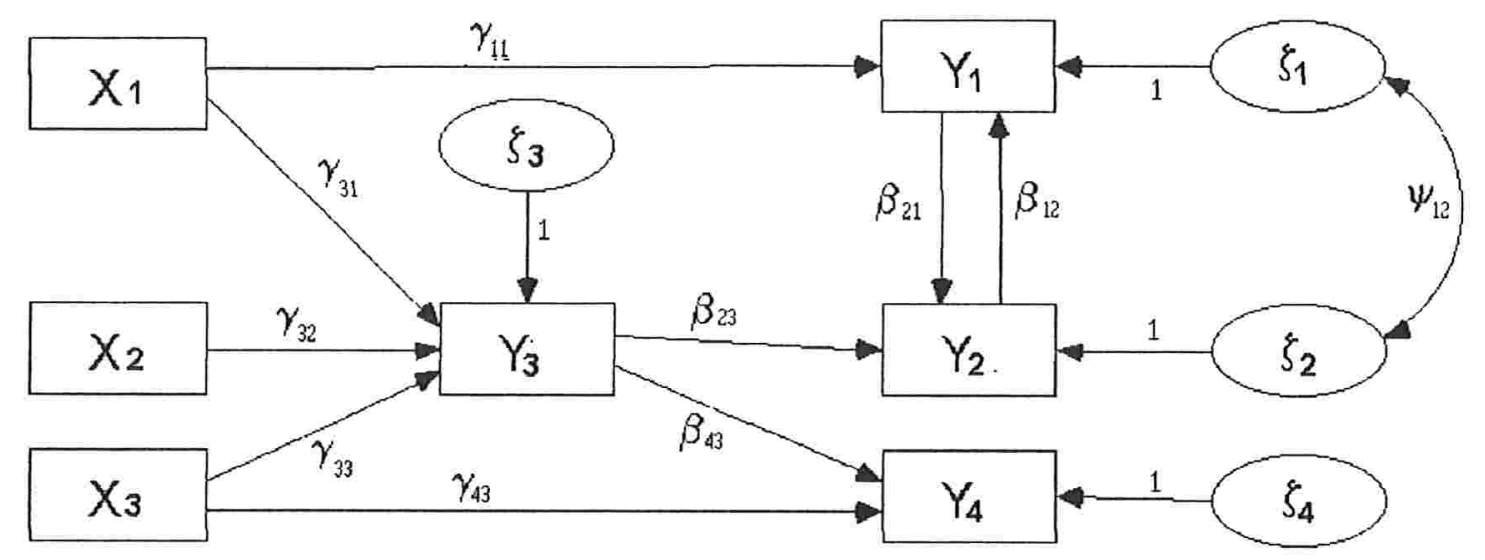

Figura. 1.7 - Modelo estrutural com variáveis observadas.

Para entender a equação (1.4) em termos matriciais, apresentamos a seguir o modelo da Figura 1.7.

$$
\begin{aligned}
& y=\quad \text { B } \quad y+\Gamma x+\zeta \\
& {\left[\begin{array}{l}
Y_{1} \\
Y_{2} \\
Y_{3} \\
Y_{4}
\end{array}\right]=\left[\begin{array}{cccc}
0 & \beta_{12} & 0 & 0 \\
\beta_{21} & 0 & \beta_{23} & 0 \\
0 & 0 & 0 & 0 \\
0 & 0 & \beta_{43} & 0
\end{array}\right]\left[\begin{array}{l}
Y_{1} \\
Y_{2} \\
Y_{3} \\
Y_{4}
\end{array}\right]+\left[\begin{array}{ccc}
\gamma_{11} & 0 & 0 \\
0 & 0 & 0 \\
\gamma_{31} & \gamma_{32} & \gamma_{33} \\
0 & 0 & \gamma_{43}
\end{array}\right]\left[\begin{array}{l}
X_{1} \\
X_{2} \\
X_{3}
\end{array}\right]+\left[\begin{array}{l}
\zeta_{1} \\
\zeta_{2} \\
\zeta_{3} \\
\zeta_{4}
\end{array}\right] .}
\end{aligned}
$$


A matriz de covariância dos erros é dada por:

$$
\Psi=\left[\begin{array}{cccc}
\Psi_{11} & \Psi_{12} & 0 & 0 \\
\Psi_{21} & \Psi_{22} & 0 & 0 \\
0 & 0 & \Psi_{33} & 0 \\
0 & 0 & 0 & \Psi_{44}
\end{array}\right]
$$

Algumas relações que passam desapercebidas na Figura 1.7 ficam evidentes com a representação matricial. Por exemplo, estamos supondo que $Y_{4}$ (número de parcelas) tem influência zero em $Y_{1}$ (valor da compra) e que nenhum $X$ tem influência direta em $Y_{2}$ (tempo médio entre duas compras), como mostram os elementos $\beta_{14}=0$ e a segunda linha de $\Gamma$ igual a zero, respectivamente.

Os parâmetros cujos valores estão fixados em zero ou qualquer outro valor são chamados de parâmetros fixos. Há ainda a possibilidade de restringirmos o valor de um parâmetro de alguma forma, por exemplo, $\gamma_{11}=\gamma_{31}$, ou $\beta_{21}=2 \beta_{23}$. Estes são chamados de parâmetros restritos. Por fim, os demais parâmetros que não têm nenhuma restrição imposta e não são fixos são chamados de parâmetros livres.

Há ainda suposições implícitas que não estão representadas nem no esquema matricial, como por exemplo $\operatorname{Cov}(\mathbf{x}, \zeta)=\mathbf{0}$ e $E[\zeta]=\mathbf{0}$. Estas duas suposições sempre estarão presentes em todos os modelos estruturais, elas são também suposições básicas nos modelos de regressão.

Em modelos estruturais costuma-se usar o termo variável exógena para toda variável cuja causa não está representada no modelo, e variável endógena para aquelas que têm suas causas determinadas dentro do modelo. Representamos convencionalmente as variáveis exógenas por $\mathbf{x}$ ou $\xi$, e as endógenas por y ou $\eta$. Seguindo a literatura, usaremos estes termos no lugar de variáveis independentes e variáveis dependentes, até porque em modelos estruturais uma mesma variável dependente em uma relação é independente em outra, criando uma inadequação desses termos. 
Um modelo do tipo da Figura 1.7 é composto pelos três tipos de efeitos comuns em modelos estruturais. O efeito direto é aquele que uma variável tem diretamente sobre a outra, representado por uma seta simples no diagrama de caminho e por um parâmetro na representação algébrica e matricial. Por exemplo, $\gamma_{11}$ é o efeito direto de $X_{1}$ em $Y_{1}$. O efeito indireto é o efeito de uma variável em outra intermediado por uma terceira variável que é chamada de variável interveniente. O efeito total é a soma dos efeitos diretos e indiretos. Assim o efeito total de $X_{3}$ em $Y_{4}$ é igual a $\gamma_{43}+\gamma_{33} \beta_{43}$, onde $\gamma_{43}$ é a parcela do efeito total devido ao efeito direto e $\gamma_{33} \beta_{43}$ é o efeito indireto de $X_{3}$ em $Y_{4}$. Para ficar mais claro, consideremos as expressões para $Y_{3} \in Y_{4}$ no modelo da Figura 1.7:

$$
\begin{aligned}
& Y_{4}=\beta_{43} Y_{3}+\gamma_{43} X_{3} \\
& Y_{3}=\gamma_{31} X_{1}+\gamma_{32} X_{2}+\gamma_{33} X_{3}
\end{aligned}
$$

substituindo $Y_{3}$ na expressão de $Y_{4}$, chegamos ao efeito total de $X_{3} e m Y_{4}$

$$
\begin{aligned}
& Y_{4}=\beta_{43}\left(\gamma_{31} X_{1}+\gamma_{32} X_{2}+\gamma_{33} X_{3}\right)+\gamma_{43} X_{3} \\
& Y_{4}=\left(\beta_{43} \gamma_{33}+\gamma_{43}\right) X_{3}+\beta_{43} \gamma_{32} X_{2}+\beta_{43} \gamma_{31} X_{1}
\end{aligned}
$$

Quando um modelo contém uma relação recíproca, do tipo da que existe entre $Y_{1}$ e $Y_{2}$ (Figura 1.7), ele é dito ser um modelo não recursivo. Não é necessário que a relação reciproca seja direta como na Figura 1.7 para que o modelo seja não recursivo basta que exista uma relação recíproca, ainda que indireta. Estes modelos são mais difíceis de serem analisados porque é como se estivéssemos lidando com uma regressão infinita: $Y_{1}$ afeta $Y_{2}$ que afeta $Y_{1}$ que afeta $Y_{2}$ que afeta.... Muitas vezes essa seqüência infinita de relações lineares fazem com que as relações no modelo não sejam bem definidas, e essa definição depende dos valores dos parâmetros envolvidos, no caso da Figura 1.7, $\beta_{12}$ e $\beta_{21}$. Se as relações são bem definidas, o modelo é dito estável, senão ele é instável. Pode-se calcular para modelos não recursivos o índice de estabilidade (para maiores detalhes veja Fox (1980) e Bentler e Freeman (1983)). 
Depois destas considerações, voltemos aos efeitos. De uma forma geral o efeito total entre as variáveis endógenas pode ser definido por:

$$
\mathbf{T}_{\mathrm{YY}}=\sum_{i=1}^{\infty} \mathrm{B}^{\mathrm{i}}
$$

onde $\mathbf{T}_{\mathrm{yy}}$ é a matriz de efeitos totais e $\mathbf{B}$ é a matriz de parâmetros das relações entre as variáveis endógenas. Quando o modelo é recursivo, Bi torna-se igual a zero a partir de certo valor de i. Se o modelo é não recursivo a somatória tem infinitos termos não nulos e pode não convergir. Neste caso $T_{y y}$ não é definido. Dado $T_{y y}, I_{y y}=T_{y y}-B$ é a matriz dos efeitos indiretos entre as variáveis endógenas.

Ressaltamos que o efeito total é sempre muito importante, uma vez que podemos ter um efeito total bem diferente do efeito direto, e neste caso considerar apenas o efeito direto nos levaria a conclusões irreais.

Agora que já sabemos como são as relações entre as variáveis em um modelo que tem apenas variáveis observadas podemos ir mais adiante e incluir as variáveis latentes.

\subsubsection{2 - Modelos de Equações Estruturais com Variáveis Latentes}

A forma geral de um modelo estrutural com variáveis latentes deve incluir as equações (1.1), (1.2) e (1.3). A equação (1.1) representa a parte estrutural do modelo, que especifica as relações que as variáveis latentes têm entre si. As equações (1.2) e (1.3) representam o que chamamos de modelo de mensuração e especificam as relações entre as variáveis observadas e as variáveis latentes. São estas relações que nos permitem medir as variáveis latentes, já que elas não são diretamente mensuráveis.

Como visto para modelos com variáveis observadas, temos também aqui implícitas as suposições de que os erros têm médias iguais a zero e não são 
correlacionados com as variáveis "regressoras" a que se referem. Assim $E[\delta]=$ $\mathrm{E}[\varepsilon]=\mathrm{E}[\zeta]=\mathrm{E}[\xi]=\mathrm{E}[\eta]=0$ e $\operatorname{Cov}[\zeta, \xi]=\operatorname{Cov}[\varepsilon, \eta]=\operatorname{Cov}[\delta, \xi]=0$.

As definições de efeito direto, indireto e total são exatamente as mesmas estudadas para os modelos estruturais com variáveis observadas, inclusive no que se refere aos modelos não recursivos.

Quando uma variável latente tem uma relação de causa com uma variável observada, dizemos que esta é um indicador da variável latente e, como as variáveis latentes não são mensuráveis elas precisam ter pelo menos um indicador para poderem ser analisadas. Em alguns casos uma variável latente pode ter outras variáveis latentes como indicadores.

Existem dois tipos de indicadores, os formativos e os reflexivos. Indicadores reflexivos são aqueles que são causados pela variável latente. Eles são chamados de reflexivos porque representam uma reflexão ou manifestação da variável latente. Este é o tipo mais comum. Eles são a base da Análise Fatorial. Os indicadores formativos são aqueles que causam a variável latente e geralmente são menos comuns nos modelos estruturais. Os créditos pela diferenciação entre indicadores formativos e reflexivos se devem a Blalock (1964) que a apresentou pela primeira vez na literatura. Na ocasião Blalock chamou os indicadores formativos e reflexivos de indicadores causa e efeito, respectivamente (do inglês causal indicators e effect indicators). $\mathrm{O}$ termo reflexivo e formativo surge somente com Bagozzi e Fornell (1982).

Como exemplo de indicador reflexivo podemos citar o número de vezes que uma criança tenta montar um quebra-cabeça até desistir, que é um efeito da variável latente "persistência". Como exemplo de indicador formativo podemos citar o número de participações em um comitê executivo que causa a variável latente "experiência". A Figura 1.8 mostra exemplos de diagramas de caminho de indicadores formativos e reflexivos. 

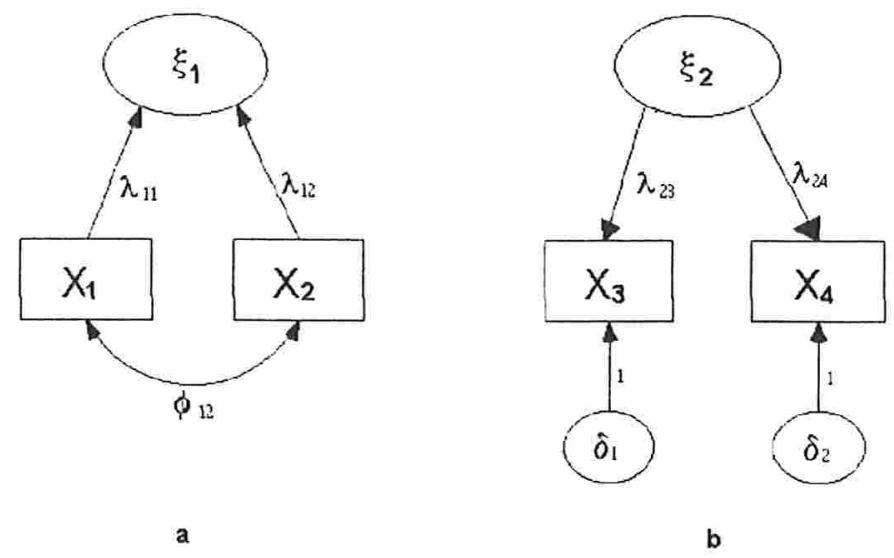

Figura $1.8-a)$ Indicadores formativos. b) Indicadores reflexivos.

Bollen (1989a) mostra no Capítulo 7, pág. 311-313, como representar um modelo estrutural com indicadores formativos com as equações (1.1), (1.2) e (1.3). Os indicadores formativos $\mathbf{x}$ são causados sem erro pelas latentes exógenas $\xi$ fazendo $\Lambda_{y}=\mathrm{I}$, onde I é a matriz identidade. Assim na equação principal $\eta$, que é causado por $\xi$, na verdade acaba sendo causado por $\mathbf{x}$, seus indicadores formativos.

$$
\begin{aligned}
& \eta=\Gamma \xi+\zeta \\
& y=\Lambda_{y} \eta+\varepsilon \\
& x=1 \xi
\end{aligned}
$$

A Figura 1.9 representa um tipo especial de modelo estrutural com variáveis latentes que chamamos de Análise Fatorial Confirmatória. Este modelo não possui variáveis latentes endógenas e pode ser representado apenas pela equação (1.3), nele a estrutura é fixada (suposta) e os dados a confirmam ou não. $\mathrm{Na}$ Análise Fatorial Exploratória o modelo é livre e os dados determinam a estrutura, isto é, supõe-se a princípio que todos os fatores têm influência em todas as variáveis observadas. 


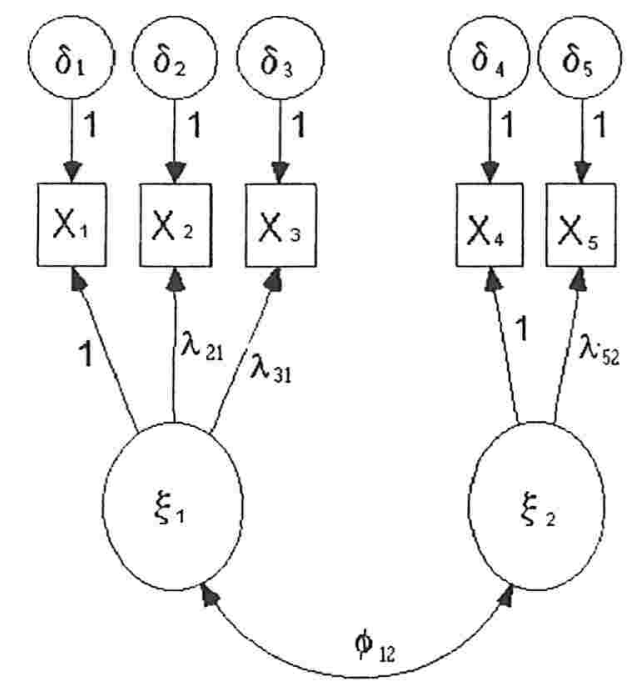

Figura 1.9 - Modelo de Análise Fatorial Confirmatória com dois fatores.

Outro aspecto que diferencia a Análise Fatorial Confirmatória da Exploratória é que na Confirmatória podemos permitir fatores e erros correlacionados entre si, o que geralmente não acontece na Exploratória.

Devido à grande importância da Análise Fatorial Confirmatória, muitos textos abordam este tema de forma bem abrangente. Para um estudo mais profundo sugerimos Bollen (1989a), Capítulo 7.

\subsection{5 - Matriz de Covariância Implicada}

Os modelos estruturais são uma técnica desenvolvida para o estudo da matriz de variâncias e covariâncias das variáveis observadas quando estão sob a suposição de uma certa estrutura de relações entre elas. É a representação de $\Sigma$ - matriz de variâncias e covariâncias populacional - através das relações entre os parâmetros do modelo que nos permite verificar o quanto nossas suposições conseguem reproduzir as relações reais entre as variáveis.

A matriz de covariância implicada $\Sigma(\theta)$ é constituída pelos elementos de $\Sigma$ reproduzidos em forma de funções dos parâmetros do modelo. Então, por 
exemplo, $\operatorname{Var}\left[X_{1}\right]$ é um elemento de $\Sigma$ e pode ser que encontremos uma relação funcional do tipo $\operatorname{Var}\left[X_{1}\right]=\lambda_{12}+\gamma_{31}$. Uma das formas de encontrar estas funçōes é através da álgebra, usando as propriedades das variâncias e covariâncias.

Neste texto sempre estaremos supondo que as variáveis aleatórias $(X$ e $Y)$ têm média igual a zero, já que $\operatorname{cov}(X, Y)=\operatorname{cov}(X+c, Y+d) e \operatorname{cov}(X+c, \xi)$ $=\operatorname{cov}(X, \xi), c$ e d constantes. Ou seja, a adição ou subtração de uma constante à variável aleatória não muda a estrutura de covariância. Isto torna muitos cálculos simplificados.

Como $\Sigma$ é matriz de variâncias e covariâncias das variáveis observadas, podemos parti-la da seguinte forma:

$$
\sum=\left[\begin{array}{ll}
\boldsymbol{\Sigma}_{\mathrm{YY}} & \boldsymbol{\Sigma}_{\mathrm{YX}} \\
\boldsymbol{\Sigma}_{\mathrm{XY}} & \boldsymbol{\Sigma}_{\mathrm{XX}}
\end{array}\right],
$$

onde $\Sigma_{Y Y}$ é a matriz de variâncias e covariâncias das variáveis observadas endógenas e $\Sigma_{\mathrm{XX}}$ das exógenas. $\Sigma_{\mathrm{YX}}$ contém as covariâncias entre as variáveis exógenas e endógenas. Podemos trabalhar um pouco algebricamente e escrever $\Sigma$ como uma função dos parâmetros que compöem (1.1), (1.2) e (1.3). Lembrando que $\mathrm{E}[\mathrm{y}]=0$, e usando (1.2) temos:

$$
\begin{aligned}
\Sigma_{Y Y}[\theta] & =E\left[y y^{\prime}\right] \\
& =E\left[\left(\Lambda_{Y} \eta+\varepsilon\right)\left(\Lambda_{Y} \eta+\varepsilon\right)^{\prime}\right] \\
& =E\left[\left(\Lambda_{Y} \eta \eta^{\prime} \Lambda_{Y}^{\prime}+\Lambda_{Y} \eta \varepsilon^{\prime}+\varepsilon \eta^{\prime} \Lambda_{Y}^{\prime}+\varepsilon \varepsilon^{\prime}\right]\right. \\
& =\Lambda_{Y} E\left[\eta \eta^{\prime}\right] \Lambda_{Y}^{\prime}+\Lambda_{Y} E\left[\eta \varepsilon^{\prime}\right]+E\left[\varepsilon \eta^{\prime}\right] \Lambda_{Y}^{\prime}+E\left[\varepsilon \varepsilon^{\prime}\right] \\
& =\Lambda_{Y} E\left[\eta \eta^{\prime}\right] \Lambda_{Y}^{\prime}+\Theta_{\varepsilon}
\end{aligned}
$$

e usando (1.1) 


$$
\begin{aligned}
\eta-B \eta & =\Gamma \xi+\zeta \\
\eta & =(I-B)^{-1}(\Gamma \xi+\zeta) \\
E\left[\eta \eta^{\prime}\right] & =E\left[(I-B)^{-1}(\Gamma \xi+\zeta)(\Gamma \xi+\zeta)^{\prime}\left[(I-B)^{-1}\right]^{\prime}\right] \\
E\left[\eta \eta^{\prime}\right] & =(I-B)^{-1} E\left[\Gamma \xi \xi^{\prime} \Gamma^{\prime}+\Gamma \xi \zeta^{\prime}+\zeta \xi^{\prime} \Gamma^{\prime}+\zeta \zeta^{\prime}\right]\left[(I-B)^{-1}\right]^{\prime} \\
E\left[\eta \eta^{\prime}\right] & =(I-B)^{-1}\left[\Gamma \Phi \Gamma^{\prime}+\Psi\right)\left[(I-B)^{-1}\right]^{\prime} .
\end{aligned}
$$

Substituindo (1.6) em (1.5)

$$
\Sigma_{Y Y}(\theta)=\Lambda_{Y}\left[(\mathbf{I}-\mathbf{B})^{-1}\left(\Gamma \Phi \Gamma^{\prime}+\Psi\right)\left[(\mathbf{I}-\mathbf{B})^{-1}\right]^{3}\right] \Lambda_{Y}^{\prime} Y+\Theta_{\varepsilon} .
$$

A matriz $\Sigma_{Y Y}(\theta)$ é a matriz de variâncias e covariâncias entre as variáveis observadas endógenas escrita como uma função das matrizes de parâmetros do modelo.

Da mesma forma podemos usar a equação (1.3) para chegar a

$$
\begin{aligned}
& \Sigma_{X X}(\theta)=\Lambda_{X} \Phi \Lambda^{\prime} X+\Theta_{\delta} \\
& \Sigma_{Y X}(\theta)=\Lambda_{Y}(I-B)^{-1} \Gamma \Phi \Lambda^{\prime} X .
\end{aligned}
$$

Com isso temos todos os elementos de $\Sigma$ representados como funções de parâmetros do modelo em $\Sigma(\theta)$.

$\mathrm{Na}$ prática geralmente não temos os valores das variâncias e covariâncias de $\Sigma$, pois são parâmetros populacionais, e por isso usamos a estimativa amostral de $\Sigma$, que denotamos por $\mathbf{S}$. Tentamos então resolver o sistema $S=\Sigma(\theta)$, onde $\theta$ é o vetor de parâmetros desconhecidos da matriz de variâncias e covariâncias implicadas, que estamos chamando de $\Sigma(\theta)$. Geralmente não existe uma solução exata para esse sistema de equações por termos mais equações (elementos diferentes em $\mathbf{S}$ ) do que parâmetros a se estimar em $\theta$, 
então o que se faz é encontrar valores para cada parâmetro tal que $\Sigma(\theta)$ seja o mais próximo possível de $\mathbf{S}$. Mais adiante veremos alguns métodos de estimação que são aplicáveis a este problema.

\subsection{6 - Identificação do Modelo}

Uma vez encontrada a matriz de covariância implicada $\Sigma(\theta)$, o próximo passo é saber se o sistema $\mathbf{S}=\Sigma(\theta)$ pode ser resolvido. No total temos $(p+q)(p+q+1) / 2$ elementos diferentes em $\mathbf{S}$ e t parâmetros a serem estimados em $\theta$. isso significa que temos para resolver um sistema de equaçöes geralmente näo lineares com $t$ incógnitas $e(p+q)(p+q+1) / 2$ equações. Para saber se este sistema tem solução, precisamos estabelecer a identificação dos parâmetros.

Dizemos que um parâmetro é identificado se ele é função apenas de parâmetros que podem ser estimados e essa função leva a uma solução única. Se todos os parâmetros de um modelo são identificados, dizemos que o modelo é identificado.

Quando um parâmetro é uma função que não leva a uma solução única, dizemos que ele é não identificado. Por exemplo, na equação $\phi_{12}+\gamma_{32}=$ $\operatorname{cov}\left(X_{1}, Y_{1}\right)$ é fácil ver que infinitos valores de $\phi_{12}$ e $\gamma_{32}$ satisfazem a igualdade (apenas $\operatorname{cov}\left(X_{1}, Y_{1}\right)$ é um valor estimável). Se isso acontece com pelo menos um parâmetro no modelo, sendo os demais parâmetros todos identificados, então o modelo é dito sub-identificado.

Por fim, pode ser que tenhamos excesso de informações para encontrar a estimativa de um parâmetro. Por exemplo, se $\phi_{12}=\operatorname{cov}\left(X_{1}, Y_{1}\right)$ e $\phi_{12}=$ $\operatorname{var}\left(\mathrm{X}_{3}\right)$ temos uma situação onde o parâmetro é superidentificado. Se um modelo tem pelo menos um parâmetro superidentificado e todos os demais parâmetros são identificados, o modelo é dito superidentificado.

Se o modelo não for identificado o sistema de equações $S=\Sigma(\theta)$ não tem solução, por isso é importante estabelecer a identificação do modelo antes de tentar estimar os parâmetros. Uma das formas de se fazê-lo é resolvendo 
o sistema algebricamente para cada parâmetro. Mas se o modelo não for bem simples pode ser muito difícil ou até impossivel escrever todas as equações do sistema e estabelecer a identificação. Por isso existem algumas regras que facilitam a verificação da identificação. Uma regra necessária mas não suficiente é que o valor de $t$ seja menor ou igual a $(p+q)(p+q+1) / 2$, onde t é o número de parâmetros no modelo. Se nosso modelo obedece a essa regra não podemos dizer que ele seja identificado, mas se ele não obedecer então já sabemos que o modelo é não identificado. Existem vários outros métodos para se tentar estabelecer a identificação, mas não existe uma forma precisa para fazer isso a não ser algebricamente. O que se consegue com os métodos existentes é dizer com certeza que um determinado modelo é não identificado. Várias destas regras são explicadas e exemplificadas em Bollen (1989a), onde também existem referências para um estudo mais profundo sobre $\mathrm{o}$ assunto.

$\mathrm{Na}$ verdade os modelos que nos interessam na prática são os modelos superidentificados, pois neste caso vamos ter um excesso de equações em relação ao número de parâmetros a se estimar, e este excesso representará os graus de liberdade do modelo. Por isso, na prática, os modelos superidentificados e os identificados são ambos chamados de modelos identificados, enquanto que os modelos sub-identificados são os únicos tidos como não identificados.

É importante também dizer que há algumas regras para a construção dos modelos que são necessárias para que haja identificação. Como as variáveis latentes não têm unidade de medida, precisamos fixar um dos coeficientes de seus indicadores ou a sua variância a um valor específico. O procedimento usual é fixar um dos coeficientes de seus indicadores com o valor 1. Isso vale também para os erros que podem ser considerados variáveis latentes. Outra necessidade é a de fixar a diagonal de B como zero, pois uma variável não pode causar a si mesma. 


\subsection{7 - Estimação dos Parâmetros}

A estimação começa com a relação $\Sigma=\Sigma(\theta)$. Como não conhecemos a matriz de covariância populacional $\Sigma$ somos levados a usar seu estimador amostral $\mathbf{S}$. A equação matricial $\mathbf{S}=\Sigma(\theta)$ é na verdade um sistema de equações geralmente não lineares que precisamos resolver. Estaremos então interessados em encontrar valores para os parâmetros que minimizem alguma função de $\Sigma(\hat{\theta})$ e S. A primeira função que nos vem a cabeça é $F(\Sigma(\hat{\theta}), \mathbf{S})=\Sigma(\hat{\theta})$ - S, que nos dá a matriz de resíduos. No entanto, segundo Browne (1984), se $\mathrm{F}(\Sigma(\hat{\theta}), \mathbf{S})$ é um escalar sempre maior que zero, sendo igual a zero somente se $\Sigma(\hat{\boldsymbol{\theta}})=\mathbf{S}$, e a função $F(\Sigma(\hat{\boldsymbol{\theta}}), \mathbf{S})$ é contínua em $\mathbf{S}$ e $\Sigma(\hat{\boldsymbol{\theta}})$, então teremos estimadores consistentes para os parâmetros. Com base nisto, apresentamos a seguir as três funções mais utilizadas para se medir a discrepância entre $\Sigma(\hat{\boldsymbol{\theta}})$ e S.

\subsubsection{1 - Máxima Verossimilhança}

Sob a suposição de multinormalidade dos vetores $\mathbf{x}$ e $\mathbf{y}$ podemos usar a função de verossimilhança da distribuição normal multivariada para encontrar os valores dos parâmetros que maximizam a probabilidade de ocorrer a amostra em questão. Maximizar a função de verossimilhança multinormal é o mesmo que minimizar

$$
F_{M L}=\log |\Sigma(\theta)|+\operatorname{tr}\left[S \Sigma(\theta)^{-1}\right]-\log |\mathbf{S}|-(p+q) .
$$

Os estimadores obtidos com $\mathrm{F}_{\mathrm{ML}}$ são assintoticamente não viciados, assintoticamente consistentes e assintoticamente eficientes, e a distribuição dos parâmetros é assintoticamente normal (Bollen (1989a)). A matriz de covariância assintótica para os estimadores de máxima verossimilhança de $\theta$ é dada por: 


$$
\left(\frac{2}{N-1}\right)\left\{E\left[\frac{\partial F_{M L}}{\partial \theta \partial \theta^{\prime}}\right]\right\}^{-1},
$$

em que $\mathrm{N}$ é o tamanho amostral.

Dividindo o valor estimado do parâmetro por seu desvio padrão, teremos uma estatística com distribuição aproximadamente normal para grandes amostras, o que nos permite fazer testes de hipóteses sobre o parâmetro ser ou não significantemente diferente de zero.

Por fim, um aspecto muito importante é que $(\mathrm{N}-1) \mathrm{F}_{\mathrm{ML}}$ tem distribuição assintótica $\chi^{2} \operatorname{com}(p+q)(p+q+1) / 2-t$ graus de liberdade sob a suposição do modelo estar correto, o que nos permite testar a validade do modelo.

\subsubsection{2 - Mínimos Quadrados Não Ponderados}

Consiste em minimizar a função

$$
F_{U L S}=1 / 2\left\{\operatorname{tr}\left[(S-\Sigma(\theta))^{2}\right]\right\}
$$

que na verdade é minimizar uma função da soma dos quadrados de cada elemento na matriz de resíduos, análogo ao que se faz na estimação de parâmetros em um modelo de regressão.

Os estimadores obtidos por FuLs são consistentes, e não requerem nenhuma suposição a respeito da forma da distribuição das variáveis. Mas eles não são os mais eficientes e nem são invariantes quanto à escala das variáveis. Browne (1982) sugere alguns métodos para se calcular a significância dos parâmetros quando se usa Futs. 


\subsubsection{3 - Mínimos Quadrados Generalizados}

A função que se deve minimizar é

$$
F_{G L S}=1 / 2 \operatorname{tr}\left(\left\{[S-\Sigma(\theta)] W^{-1}\right\}^{2}\right)
$$

onde W é uma matriz de pesos e essa ponderação imposta sobre a matriz de resíduos é o único fator que diferencia $F_{G L S}$ de $F_{U L S}$. $A$ escolha de $\mathbf{W}=\mathbf{S}$ leva a estimadores consistentes, assintoticamente multinormais e eficientes.

Se escolhermos $\mathbf{W}=\mathbf{I}$, teremos que $F_{G L S}$ será igual a $F_{U L S}$ e se escolhermos $\mathbf{W}=\Sigma(\hat{\boldsymbol{\theta}})$, onde $\Sigma(\hat{\boldsymbol{\theta}})$ é obtido pelo $\mathrm{F}_{\mathrm{ML}}$, então teremos que $\mathrm{F}_{\mathrm{GLS}}$ será igual a $\mathrm{F}_{\mathrm{ML}}$.

Os estimadores obtidos através de $F_{G L S}$ são invariantes quanto à escala das variáveis e $(\mathrm{N}-1) \mathrm{F}_{\mathrm{GLS}}$ tem distribuição $\chi_{(p+q)(p+q+1) / 2-t}^{2}$. Essas propriedades valem apenas para algumas escolhas de $\mathbf{W}$, entre elas $\mathbf{W}=\mathbf{S}$.

Existem outras funções usadas para estimação, como mínimos quadrados ordinários, mínimos quadrados em 2 estágios e em 3 estágios, que podem ser encontradas em Jonhston (1984), Wonnacott e Wonnacott (1979) e Fox (1984).

\subsection{8 - Avaliação do Modelo}

Quando terminamos o processo de estimação dos parâmetros precisamos verificar de alguma forma se conseguimos com os parâmetros estimados reproduzir bem a matriz $\mathbf{S}$. Na verdade, o que devemos fazer é algum tipo de comparação entre $\mathbf{S}$ e a matriz de covariância implicada $\Sigma(\hat{\theta})$ que se obteve por intermédio do ajuste dos parâmetros. Se a diferença entre as duas for grande, nosso modelo não está explicando bem as relações entre as variáveis presentes nos dados, se for pequena, nosso modelo tem boa aderência aos dados. 
Existem muitos índices para verificar a bondade de ajuste dos modelos estruturais, mas citaremos aqui apenas os principais. Vários outros podem ser vistos em Bollen (1989a), Byrne (2001) e Arbuckle (1999).

\subsubsection{1 - Teste Qui-Quadrado}

O teste qui-quadrado é um teste simultâneo de que todos os resíduos em $\Sigma-\Sigma(\hat{\theta})$ sejam iguais a zero, para modelos superidentificados.

Sob $\mathrm{H}_{0}, \Sigma=\Sigma(\hat{\theta}),(\mathrm{N}-1) \mathrm{F}_{\mathrm{ML}}$ tem distribuição $\chi_{(p+q)(p+q+1) / 2-\imath}^{2} . \mathrm{Na}$ verdade esse é um teste de razão de verossimilhanças, pois, considerando Lo como a função de verossimilhança maximizada sobre o espaço paramétrico restrito à hipótese nula, e $L_{1}$ a mesma função maximizada sobre todo o espaço paramétrico sem restrição, temos:

$$
\log \left(L_{0}\right)=-1 / 2(N-1)\left\{\log |\Sigma(\hat{\theta})|+\operatorname{tr}\left[\Sigma(\hat{\theta})^{-1} S\right]\right\}
$$

Sob a hipótese nula de que as suposiçöes e restrições do modelo estão corretamente representando as relações existentes nos dados, o estimador de $\Sigma$ é $\Sigma(\hat{\theta})$. O máximo da função de log-verossimilhança sob todo o espaço paramétrico é atingido quando estimamos $\Sigma$ com S. Assim:

$$
\log \left(L_{1}\right)=-1 / 2(N-1)\left\{\log |S|+\operatorname{tr}\left(\mathbf{S}^{-1} \mathbf{S}\right)\right\}
$$

Sabemos que - $2 \log \left(L_{0} / L_{1}\right)$ tem distribuição assintótica quiquadrado, então:

$$
\begin{aligned}
-2 \log \left(L_{0} / L_{1}\right) & =-2 \log \left(L_{0}\right)+2 \log \left(L_{1}\right) \\
& =(N-1)\left\{\log |\Sigma(\hat{\theta})|+\operatorname{tr}\left[\Sigma(\hat{\boldsymbol{\theta}})^{-1} \mathbf{S}\right]\right\}-(N-1)\{\log |\mathbf{S}|+(p+q)\} \\
& =(N-1)\left\{\log |\Sigma(\hat{\boldsymbol{\theta}})|+\operatorname{tr}\left[\Sigma(\hat{\boldsymbol{\theta}})^{-1} \mathbf{S}\right]-\log |\mathbf{S}|-(p+q)\right\} \\
& =(N-1) F_{M L_{1}}
\end{aligned}
$$


onde $\mathrm{F}_{\mathrm{ML}}$ é aplicada no ponto $\Sigma(\hat{\theta})$.

Como sob $H_{0}, \Sigma(\hat{\theta})=\Sigma$, a rejeição da hipótese nula implica na inadequação do modelo, isto é, se o modelo estiver correto esperamos obter um p-valor alto.

Observamos que ( $N$ - 1) $F_{M L}$ só tem sentido se o modelo for superidentificado. Se no modelo todos os parâmetros são identificados, então haverá uma solução exata para a equação $\Sigma(\theta)=\mathbf{S}$ e a estatística qui-quadrado terá grau de liberdade igual a zero. Se o modelo é sub-identificado haverá muitas soluções exatas, o que faz com que o modelo não tenha utilidade. Assim, os modelos estruturais de interesse serão sempre superidentificados, também porque sempre devemos nos preocupar em representar os dados com o mínimo possível de parâmetros livres para que o modelo não seja complicado e inútil.

O teste é válido se a amostra é suficientemente grande, as variáveis não têm excessiva curtose ou assimetria e a análise é feita com a matriz de covariância. A distribuição de (N - 1) $\mathrm{F}_{\mathrm{GLS}}$ também é qui-quadrado se as variáveis não têm curtose ou assimetria excessiva. Se a distribuição é multinormal a curtose deve ser 3 e a assimetria deve ser 0 . Se os valores destas estatísticas forem muito diferentes disso devemos tomar cuidado com a validade do teste. Mardia (1970, $1974,1985)$ propôs um teste para verificar a curtose e assimetria multivariadas.

$\mathrm{O}$ teste qui-quadrado tende a ter um poder excessivo para grandes amostras, o que causa rejeições excessivas de modelos. Por isso o teste quiquadrado não costuma ser tido como decisivo na medida da qualidade do ajuste, e outros indices de verificação da adequação de ajuste são também muito usados.

\subsubsection{2 - Residuos}

Se um modelo é bem ajustado, esperamos que os resíduos sejam pequenos. Então, olhando a matriz de resíduos $\mathbf{S}-\Sigma(\hat{\theta})$ teremos uma idéia de quais elementos não estão sendo bem ajustados pelo modelo. Como a escala das 
variáveis influencia no tamanho dos resíduos é melhor usar o resíduo padronizado (Hu e Bentler (1995), Jöreskog e Sörbom (1989)) que sempre tem valores entre 0 e 1 e um bom ajuste supõe resíduos menores que 0,05 (Byrne (2001)). O resíduo padronizado é calculado com base na diferença entre a matriz de correlação amostral e a matriz de correlação estimada. Como temos a matriz de variâncias e covariâncias estimadas sob o modelo e a matriz de variâncias e covariâncias amostrais, torna-se fácil obter as referidas matrizes de correlações.

Também relacionada ao resíduo, a raiz do quadrado médio dos resíduos é bastante usada, bem como sua média e mediana (Bollen (1989a)).

\subsubsection{3 - Índices de Ajuste Incremental}

Existem muitos índices de ajustes que comparam de alguma forma o modelo ajustado com um suposto modelo onde as restrições são máximas e por isso o ajuste é muito ruim. Esse suposto modelo é chamado de "Independence Model" ou "Baseline Model", e não precisa ser um modelo padrão, podendo variar de acordo com a conveniência de cada caso. Geralmente ele supõe haver uma variável latente para cada indicador, erros não correlacionados, bem como as variáveis latentes, e os parâmetros ligando os indicadores às variáveis latentes são todos iguais a 1 . Ou seja, é um modelo de estrutura amarrada que força os indicadores a serem independentes, bem como os constructos. O seu ajuste será muito ruim se os dados realmente contemplam uma estrutura de relações como no modelo que estamos testando.

Um destes índices que tem por base o "Baseline Model" é o NFI (Normal Fit Index - Bentler e Bonett (1980)) dado por: $\mathrm{NFI}=\frac{\mathrm{F}_{\mathrm{b}}-\mathrm{F}_{\mathrm{m}}}{\mathrm{F}_{\mathrm{b}}}=\frac{\chi_{b}^{2}-\chi_{M}^{2}}{\chi_{b}^{2}}$, onde $F_{b}$ é a $F_{M L}$ calculada para o modelo "baseline" e $F_{m}$ é a $F_{M L}$ para o modelo que estamos testando. A fórmula com a estatística qui-quadrado segue multiplicando-se o numerador e o denominador por $(\mathrm{N}-1)$, o que mostra que na verdade o tamanho amostral é cortado deste índice e não o afeta. É desejável que 
este valor seja alto, maior que 0,9 pelo menos. Uma modificação do NFI que faz com que o tamanho amostral não seja eliminado da expressão é

$$
C F I=1-\frac{\max \left((N-1) F_{m}-d f, 0\right)}{\max \left((N-1) F_{b}-d f_{b}, 0\right)}
$$

proposto por Bentler (1990), onde df e $\mathrm{df}_{\mathrm{b}}$ são respectivamente os graus de liberdade para o modelo testado e para o modelo "baseline". O CFI leva em conta o tamanho da amostra e por isso é hoje tido como mais adequado do que o $\mathrm{NFI}$. Hu e Bentler (1999) sugerem que o CFI seja maior que 0,95 para se ter um bom ajuste.

Outros indices como o IFI (Incremental Fit Index - Bollen 1989b) levam em conta a parcimônia do modelo, pois quanto maior o número de parâmetros, menor o número de graus de liberdade e menor o IFI, que é dado por:

$$
I F I=\frac{F_{b}-F_{m}}{F_{b}-\left[d_{m} /(N-1)\right]}=\frac{\chi_{b}^{2}-\chi_{m}^{2}}{\chi_{b}^{2}-d f_{m}}
$$

que deve estar em torno de 0,95 para um bom ajuste, segundo Bollen.

\subsubsection{4 - Parâmetro de Não Centralidade}

Quando o modelo que supomos para os dados não é o correto, ou seja, $\Sigma \neq \Sigma(\theta)$, a função ( $N-1) F_{M L}$ tem uma distribuição $\chi^{2}$ não central com parâmetro de não centralidade $d$, que pode ser estimado por $(N-1) F_{M L}-d f$. Quanto maior for este parâmetro, pior o ajuste. Por isso ele pode ser considerado uma medida de quão ruim foi o ajuste do modelo. É possível e útil calcular um intervalo de confiança para o parâmetro de não centralidade (Steiger (1990)), e um bom modelo seria aquele cujo intervalo incluísse o valor zero. Para um estudo mais detalhado sobre o parâmetro de não centralidade da distribuição $\chi^{2}$ 
recomendamos MacCallum et al. (1996), Bollen (1989a), Hu e Bentler (1995) e Satorra e Sarris (1985).

\subsubsection{5 - RMSEA (Root Mean Square Error of Approximation)}

Esse índice foi proposto por Steiger e Lind (1980), mas só nos últimos tempos é que o RMSEA tem sido reconhecido como um dos critérios mais informativos para ajuste de modelos estruturais. $O$ índice é dado por

$$
\text { RMSEA }=\sqrt{\frac{d}{(N-1) d f}},
$$

onde d é parâmetro de não centralidade, apresentado na subseção anterior e df é o $n^{\circ}$ de graus de liberdade do modelo (Arbuckle (1999)). Segundo Browne e Cudeck (1993), valores de RMSEA menores que 0,08 indicam um ajuste razoável e valores inferiores a 0,05 indicam bom ajuste.

Existem vários outros indicadores que podem ser usados para avaliar o ajuste do modelo. Byrne (2001) e Arbuckle (1999) descrevem uma boa parte destes índices que estão disponíveis no software AMOS. Bollen (1989a) e Hu e Bentler (1995) dão uma visão mais completa e teórica de vários índices de ajuste.

\subsection{9 - Reespecificação do Modelo}

Uma vez que ajustamos um modelo estrutural aos dados e não conseguimos um bom ajuste, podemos tentar melhorar o modelo tornando livre um ou mais parâmetros fixos. Pode ser que supomos não existir uma correlação entre erros que na realidade existe, ou supomos igual a zero um coeficiente que é importante.

O procedimento correto após se estimar o modelo uma vez e fazer alguma mudança, é coletar os dados novamente e só então estimar o novo 
modelo. O problema de se mexer no modelo e o re-estimar várias vezes é o mesmo das comparações múltiplas em uma análise de variância: quanto mais procuramos, mais fácil será encontrar algo que seja significante simplesmente devido ao acaso.

$\mathrm{Na}$ prática, porém, a re-coleta de dados é complicada e a reespecificação e re-estimação do modelo com os mesmos dados é o procedimento mais comum.

Após construir um modelo podemos usar os índices estudados anteriormente para verificar se o modelo melhorou, mas como não sabemos a distribuição destes índices, também não vamos saber se a melhora foi significante ou não. Por isso, quando queremos comparar modelos é importante que tenhamos medidas das quais conhecemos a distribuição.

Nos casos que estudaremos, a comparação entre modelos é válida apenas entre modelos hierárquicos. Um modelo é hierárquico em relação a outro quando ele é exatamente igual ao outro, a não ser por ter um número diferente de restrições. Geralmente quando queremos melhorar um ajuste, apenas liberamos ou criamos algumas restrições, assim o novo modelo é hierárquico em relação ao antigo.

\subsubsection{1 - Teste da Razão de Verossimilhanças}

O teste da razão de verossimilhanças consiste em simplesmente calcular o valor de (N-1) $F_{M L}$ para os dois modelos. Como (N-1) $F_{M L}$ tem uma distribuição $\chi^{2}$, a diferença desta estatística para os dois modelos tem distribuição $\chi^{2}$ com número de graus de liberdade igual a diferença nos graus de liberdades dos dois modelos. Uma desvantagem deste teste é que é preciso ajustar os dois modelos para calculá-lo. 


\subsubsection{2 - Teste do Multiplicador de Lagrange ou Índice de Modificação}

Este índice pode ser usado apenas nos casos em que queremos reespecificar o modelo atual, tornando livre um ou mais parâmetros fixos. Para cada parâmetro fixo é calculado um valor para o Índice de Modificação ou Multiplicador de Lagrange.

O teste se baseia na derivada parcial da função de verossimilhança do modelo atual em relação aos parâmetros do modelo que estão restritos. Se a derivada for tomada em relação a um parâmetro livre ela será igual a zero porque essa condição já foi imposta para minimizar a função de verossimilhança. Mas a derivada em relação aos parâmetros restritos geralmente não será igual a zero e quanto maior ela for, maior será o ganho em termos de ajuste com a liberação do respectivo parâmetro restrito.

O Índice de Modificação tem distribuição assintótica qui-quadrado com o número de graus de liberdade igual à diferença entre os graus de liberdades do modelo atual e o menos restrito. Ele é muito usado para se saber com antecedência quais parâmetros fixos incrementarão mais o ajuste do modelo se liberados. Uma grande vantagem deste índice é que ele pode ser calculado para todos os parâmetros fixos sem que precisemos ajustar novos modelos. Bollen (1989a), pág. 293, dá uma descrição mais detalhada do Índice de Modificação.

Juntamente com o Índice de Modificação, pode-se calcular o valor esperado da mudança nos parâmetros se o parâmetro fixo em questão é tornado livre (Sarris, Satorra e Sörbom (1987)).

\subsubsection{3 - Valores dos Parâmetros e Resíduos}

Outros pontos interessantes em termos de reespecificação do modelo consistem na matriz dos resíduos e nos valores estimados dos 
parâmetros. Tanto resíduos grandes demais quanto valores inconsistentes para os parâmetros podem nos dar indicações de que parâmetros devemos liberar ou restringir.

É importante dizer que toda modificação no modelo deve ser acompanhada de uma aceitação teórica, isto é, devemos apenas fazer mudanças se estas realmente fazem sentido, dentro do contexto teórico do problema e não simplesmente fazer modificações porque elas melhoram o modelo.

O objetivo deste capítulo foi apresentar a teoria de modelos estruturais de uma forma introdutória e resumida, a fim de servir como uma base para os capítulos seguintes, nos quais falaremos de aspectos relacionados a indicadores formativos. No entanto há muito mais a ser dito sobre modelos estruturais e indicamos Bollen (1989a) como uma excelente referência para uma abordagem mais profunda e também como uma boa fonte de referências no assunto. Byrne (2001) é uma referência mais atual onde pode-se encontrar não só uma explicação introdutória da teoria de modelos estruturais, mas também aplicações destes modelos com a utilização de software, e referências atuais. 


\section{Capítulo 2 - Relações Causais}

Todo modelo estrutural é baseado em relações de causa entre as variáveis. Quando fazemos um diagrama de caminho e ligamos uma variável a outras com uma seta simples estamos supondo que ali existe uma relação de causa, isto é, algumas variáveis causam outras e säo causadas por terceiras.

No nosso texto as relações de causa são especialmente importantes porque o que diferencia os indicadores formativos dos reflexivos, como já vimos anteriormente, é a direção da relação causal entre eles e a respectiva variável latente. Além da direção, a causa contém outros componentes como associação e isolamento, que estudaremos com um pouco de detalhe neste capítulo.

\section{1 - Definição}

A definição de causa pode ser bastante complexa e abstrata se pesquisarmos na literatura. Há livros inteiros que discorrem sobre o assunto. Não é nosso objetivo aqui nos aprofundarmos nessa discussão, no entanto o leitor mais interessado pode consultar Pearl (2000). Quando falamos de causalidade em modelos estruturais é mais produtivo defini-la de uma forma simples e bastante aceita na área: se tivermos duas variáveis, $X$ e $Y$, isoladas de qualquer influência externa, e se a cada mudança em $X, Y$ também sofre uma mudança, então dizemos que $X$ causa $Y$. Veja que esta definição contém três elementos básicos necessários para a constatação da existência da causa. O primeiro, isolamento, se faz claro com o termo "isoladas de qualquer influência externa", e implica que nada a não ser $X$ seja responsável pela mudança ocorrida em $Y$. $O$ segundo elemento, a associação, expressa em "a cada mudança de $X, Y$ também sofre uma mudança", implica em que haja uma relação entre os valores de $X$ e $Y$. O último elemento, a direção da causa, evidente no termo " $X$ causa $Y$ ", significa que a causa é determinada por $\mathrm{X}$ em $\mathrm{Y}$, e não o contrário. A seguir estudaremos cada um destes três elementos separadamente. 


\section{2 - Isolamento}

Embora a definição teórica seja simples e fácil de ser entendida, na prática a relação de causa é praticamente impossível de ser provada porque nunca conseguimos ter um isolamento total entre o modelo e as influências externas.

Nos modelos causais o isolamento é um problema potencial, difícil de ser tratado, mas é de suma importância para a validade dos relacionamentos estabelecidos. Se um modelo implica que $X$ causa $Y$ então não pode haver nenhuma outra variável entre as duas. Brief et al. (1995) mostra uma situação em que o escore com relação à satisfação com o trabalho não é causado somente pelo constructo satisfação com o trabalho. O constructo satisfação com o trabalho está na cabeça das pessoas, formado com o tempo e não é diretamente mensurado. $\mathrm{O}$ escore é o seu indicador. Se forem dados às pessoas pequenos presentes ou elogios, isso pode influenciar o valor do escore dado pela pessoa, o qual não retratará fielmente o constructo. Os presentes e elogios são exemplos de variáveis que quebram o isolamento. Edward e Bagozzi (2000) chamam esta situação de "história" porque variáveis externas acabam fazendo parte do sistema, entrando neste temporalmente entre o constructo e seu indicador.

O fato de não conseguirmos isolar o modelo de influências externas faz com que seja necessário representá-las e controlá-las de alguma forma. Assim o erro que sempre está presente nos modelos estruturais representa entre outras coisas, o efeito desconhecido e suposto pequeno de variáveis que estão fora do sistema, mas que agem nele. Os termos de erro estão sempre ligados às variáveis endógenas, são influências supostas aleatórias de fora do modelo, e a princípio, os erros são supostos não correlacionados uns aos outros. Para que também exista um isolamento entre as variáveis exógenas e o meio exterior, estes termos de erro são supostos não correlacionados com as variáveis exógenas do modelo. Estas suposições de erros não correlacionados entre si e não correlacionados 
também com as variáveis exógenas estarão sempre subentendidas neste texto, a menos que se diga explicitamente o contrário.

\section{3 - Associação}

A associação bivariada é uma condição necessária, sob condições de isolamento, para que se possa estabelecer a relação de causa entre duas variáveis - Bollen (1989a), Finkel (1995), Menardi (1991), Edward e Bagozzi (2000). Bollen (1989a) diz que em um modelo estrutural pode haver teoricamente uma relação de causa sem que haja a associação. Em muitos casos um indicador é causado por mais de uma variável latente e às vezes nem conseguimos saber quais as principais causas de uma variável .

Se $X_{1}$ causa $Y$ de forma positiva, mas $X_{2}$, também no modelo, causa $Y$ de forma negativa, então a associação bivariada entre $X_{1}$ e $Y$ pode não existir, mesmo havendo a relação de causa. Podemos criar um exemplo simples e hipotético desta situação com as variáveis: estabilidade do casamento $(\mathrm{Y})$, tempo de casamento $\left(X_{1}\right)$ e freqüência de discussões $\left(X_{2}\right)$. Pode ser que o tempo de casamento tenha influência positiva na estabilidade do mesmo, enquanto que a freqüência de discussões teria influência negativa (veja Figura 2.1). Se $\gamma_{1}$ e $\gamma_{2}$ são ambos significantes, com sinais contrários e dimensões semelhantes, a inclusão de $X_{1}$ e $X_{2}$ pode fazer com que seus efeitos se anulem, e, embora exista a relação de causa, não observaremos a associação.

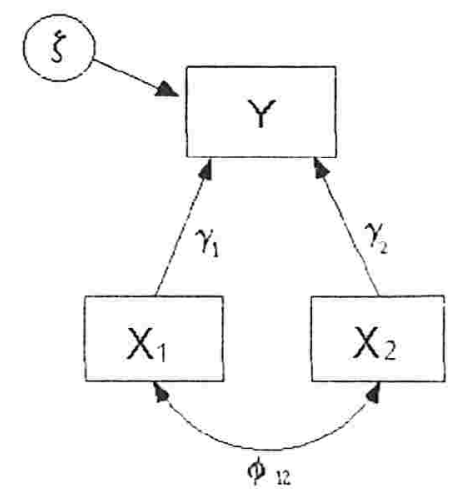

Figura 2.1 - As duas variáveis preditoras $X_{1}$ e $X_{2}$ causam $Y$. Se suas influências forem inversas, pode acontecer de uma anular a outra e não observarmos associação entre $X_{1}$ e $Y$ ou entre $X_{2}$ e $Y$. 
É importante deixar claro que sempre deve haver a associação parcial (correlação parcial) para que haja a relação causal. Outro ponto importante é que muitas vezes a verificação prática da associação pode ser dificultada por causa de fatores como o erro amostral e a multicolinearidade.

A existência da associação bivariada também não estabelece necessariamente uma relação de causa. Pode ser que uma terceira variável seja a causa de ambas as variáveis correlacionadas e é esta causa comum que faz com que exista a associação. Este fato de que a associação não implica em causa é bem conhecido dos usuários de regressão.

Quando existe uma associação entre duas variáveis mas não existe a causa, esta associação é chamada de espúria. Esta é uma situação bem fácil de exemplificar. O número de entradas de pessoas com ferimentos graves em um hospital de uma cidade pode estar relacionado com o número de campanhas de prevenção a acidentes de trânsito. Isso não quer dizer necessariamente que as campanhas são responsáveis pelos acidentes graves, mas provavelmente o número de acidentes de trânsito é o causador comum das campanhas e das entradas, explicando a associação entre as duas.

Simon (1957) é um trabalho cujo interesse básico pode ser resumido na tentativa de inferir um efeito de causa a partir da constatação da existência da associação bivariada. Simon estudou a associação e sua implicação em causa trabalhando com duas variáveis em um primeiro momento e depois com mais variáveis. Um resumo de suas conclusões mais relevantes pode ser encontrado em Asher (1983), Capítulo 2. Segundo Simon, para que possamos dizer que a correlação é uma prova da causa no contexto de apenas duas variáveis, temos que fazer duas suposições: (1) a de que podemos especificar a direção da causa e (2) a de que não existe uma terceira variável que possa ser causa simultânea das duas variáveis em questão. Estudaremos a primeira suposição adiante, mas o problema principal é a segunda suposição pois sem o isolamento completo das duas variáveis existe uma infinidade de possíveis variáveis externas que podem estar influenciando o sistema. 
Para o caso de três variáveis onde o modelo especifica $X_{1}$ causando $X_{2}$ e $X_{3}$ causando ambos $X_{1}$ e $X_{2}$, Simon concluiu que certas correlações parciais devem ir para zero para que haja uma relação de causa (veja um resumo em Asher (1983)).

A confusão ou má interpretação da associação como causa é um problema bastante pertinente na prática da modelagem. Antes de se supor que uma associação observada implica em uma relação de causa deve-se ponderar quais são as reais conseqüências disso. É freqüente interpretar modelos de regressão e modelos estruturais dizendo "se $\mathrm{X}$ variar em a unidades, vamos ter uma mudança em $Y$ de $b$ unidades". Esta variação em uma variável que causa outra variação em outra variável é matemática e é válida para a equação que se está interpretando, mas pode não ser verdade quando a variação é aplicada à situação real que o modelo descreve, porque os coeficientes do modelo representam uma associação, não uma relação de causa.

$\mathrm{Na}$ tentativa de explicar uma variável com outra ou mesmo de somente medir a associação entre variáveis, muitas medidas de associação têm sido desenvolvidas e usadas para todos os tipos de dados. Liebetrau (1983) faz um apanhado geral citando uma grande variedade destas medidas, das quais destacamos o coeficiente de correlação de Pearson, de Spearman e o de Kendall para dados contínuos e ordinais, o coeficiente qui-quadrado de Pearson, o coeficiente de contingência e medidas baseadas na razão de chances para dados nominais, além de várias outras existentes.

\section{4 - Direção da Causa}

Um outro componente das relações de causa é a direção, que também é chamada de prioridade causal - Bollen (1989a). Será que $X$ causa $Y$ ou o contrário? Se $X$ causa $Y$ dizemos que $X$ tem prioridade causal sobre $Y$. Quando fazemos um diagrama de caminho fica evidente qual foi a direção especificada para a causa, mas a direção também está presente nos modelos quando escrito de forma algébrica. Isto significa que a direção da causa deve ser corretamente 
especificada, de outra forma o sistema de equações algébricas será diferente do real, podendo implicar em um modelo totalmente diferente do que deveria ser.

É comum ao construir um diagrama de caminho para um grupo de variáveis, termos dúvidas em relação à direção da causa. A título de exemplo, podemos pensar que a percepção de propaganda seria um constructo que causa o constructo intenção de compra. Mas pode-se argumentar também que a intenção de compra é causada por outros fatores e que quanto maior ela for, mais a pessoa prestará atenção na propaganda, assim maior a percepção de propaganda, ou seja, a direção da relação causal seria invertida. Nestes casos pode ser muito difícil chegar a uma solução comprovadamente correta.

No exemplo anterior pode-se ainda dizer que a relação de causa realmente existe nos dois sentidos: a percepção de propaganda causaria a intenção de comprar que por sua vez teria um efeito de aumentar a percepção de propaganda e assim continuadamente. Essa relação de causa recíproca pode ser incorporada nos modelos estruturais, o que o tornará não recursivo. Bollen (1989a) cita a percepção subjetiva de renda e a percepção subjetiva de prestígio ocupacional como variáveis com possível relação recíproca de causa. Arbuckle (1999) cita um estudo de Felson e Bohrnstedt (1979), onde a percepção de desempenho acadêmico teria uma relação recíproca com a percepção de boa aparência.

Enfim, a direção especificada para a causa tem papel essencial nos modelos estruturais e assim não pode ser tratada com pouca atenção. A experiência e conhecimento de um profissional no assunto de que trata o modelo são muito importantes para a validação das suposições do modelo, mas nem sempre são suficientes.

Uma das formas mais simples de se saber se $X$ causa $Y$ ou se $Y$ causa $X$ é tentar observar qual deles acontece primeiro, este vai ser a causa e 0 outro o efeito. É suposto sempre haver um período de tempo entre a variável causadora e a causada, sendo que a causadora acontece sempre antes. Mas este procedimento pode não ser possivel, principalmente quando $X$ ou $Y$ é uma variável latente, ou quando o intervalo de tempo entre o acontecimento de $X$ e $Y$ é 
muito pequeno. Outra forma de se encontrar a direção da relação causal é por meio de experimentos. Podemos, por exemplo, induzir uma mudança em $\mathrm{Y}$. Se $\mathrm{X}$ também mudar, então temos uma boa evidência de que $X$ não é a causa de $Y$. Bollen (1989a) pág. 66, menciona ainda os experimentos mentais para o caso em que uma das variáveis é latente e a outra é observada, ou as duas são latentes. Este experimento consiste em se imaginar uma mudança na variável latente e então decidir se uma mudança no indicador seria aceitável. É claro que pode ser feito o inverso, imagina-se uma mudança no indicador e determina-se se uma mudança na variável latente seria admissível.

Concluímos este capítulo enfatizando que as relações causais e seus três componentes - isolamento, associação e direção - são de primária importância para os modelos estruturais e para a definição de indicadores formativos, sendo que a direção da causa é o que diferencia indicadores formativos dos indicadores reflexivos em primeira instância, mas o tipo de indicador gera conseqüências diferenciadas com relação a cada um dos três componentes. Indicadores formativos geralmente são variáveis exógenas, isto é, suas causas estão fora do modelo. Para contornar esta falta de isolamento do modelo com variáveis externas geralmente supomos que os indicadores formativos são correlacionados entre si. O fato de os indicadores formativos não necessariamente terem uma causa em comum como os reflexivos, faz com que não esperemos padrões de associação entre eles e a variável latente por eles formada. Este assunto é relacionado ao que chamamos de consistência interna, que se espera presente entre os indicadores reflexivos, mas não formativos, e que estudaremos um pouco mais a fundo no Capítulo 4. 


\title{
Capítulo 3 - Breve Relato das Principais Referências sobre Indicadores Formativos
}

\author{
O modelo de Análise Fatorial Exploratória \\ $x=L f+\delta$
}

supõe que a variável observada é causada pela variável latente. Foi assim que Spearman (1904) iniciou a teoria da Análise Fatorial, imaginando que as notas de estudantes de História Clássica, Francês e Inglês pudessem ser resumidas em uma única variável que na verdade seria a responsável pela causa das anteriores. A partir de então a teoria da Análise Fatorial Exploratória se desenvolveu bastante, sendo muito utilizada principalmente nos campos da Psicometria, Econometria, Sociologia e Biometria, mas sempre considerando que a variável latente era a causadora da variável observada. Dessa forma até os dias atuais, a imensa maioria dos modelos que incluem variáveis latentes em sua estrutura, considera os indicadores como sendo reflexivos - Bollen e Ting (2000) - algumas vezes em ocasiões onde indicadores formativos seriam mais apropriados. Bollen (1984), pág. 380 , diz que indicadores formativos são pouco utilizados e são comumente assumidos como sendo indicadores reflexivos. Ele continua exemplificando essa situação citando o uso da raça e educação como indicadores reflexivos da exposição à discriminação e status sócio-econômico respectivamente, quando deveriam ser considerados indicadores formativos.

$\mathrm{O}$ fato de encontrarmos muito mais modelos que usam indicadores reflexivos do que os que usam indicadores formativos não deixa de refletir a realidade dos modelos aplicados em psicologia, onde parece que os indicadores reflexivos são mesmo dominantes - Bollen e Ting (2000). Constructos ligados a personalidade, atitude, emoções geralmente causam variáveis observadas Fornell e Bookstein (1982). Por outro lado é comum encontrar em marketing e sociologia constructos que requerem o uso de indicadores formativos, embora não sejam muitos os modelos que os usam - Diamantopoulos e Winklhofer (2001). 
São possíveis exemplos status sócio-econômico, qualidade de vida, intenção de compra, discriminação social, potencial de compra, propensão a criminalidade, etc.

Com isso, a literatura disponível sobre indicadores formativos é de certa forma bem reduzida, sendo que alguns textos se destacam como principais no assunto. Por meio deles conseguimos ter uma visão relativamente completa e detalhada do que existe hoje sobre esse tipo de indicador. Adicionalmente, essa literatura principal nos fornece referências necessárias para os demais textos que abordam o tema de forma mais secundária, bem como referências para a teoria necessária para entender os indicadores formativos no contexto dos modelos estruturais.

Assim sendo achamos interessante citar esses textos acompanhados de uma breve descrição do seu conteúdo antes de passar aos dois capítulos seguintes que discorrerão com mais detalhes a respeito dos indicadores formativos. Aproveitamos para incluí-los em ordem cronológica, de forma que transpareça um pouco da história dos indicadores formativos.

Diamantopoulos (1999) cita Bridgman (1927) como sendo o primeiro artigo que inclui uma visão de indicadores formativos em seu texto, sem no entanto fazer uma diferenciação formal entre indicadores formativos e reflexivos. Depois disso parece que a literatura mais antiga em indicadores formativos é Blalock (1964), pág. 162-169, que chama estes indicadores de indicadores causais (causal indicators), e, pela primeira vez chama a atenção para o uso indevido de indicadores reflexivos quando o correto seria indicadores formativos. Um pouco antes de Blalock, Curtis e Jackson (1962) abordaram o tema de indicadores múltiplos e a associação entre eles, mas não chegaram a mencionar os indicadores formativos de uma forma direta. No seu artigo os autores argumentam a não necessidade de associação positiva entre dois indicadores ainda que ambos sejam positivamente relacionados à variável latente. Para dar um exemplo dessa situação, Curtis e Jackson citaram a satisfação conjugal e a duração do casamento como indicadores positivamente relacionados ao constructo estabilidade do casamento, mas que poderiam até estar negativamente 
associados entre si. Apesar do exemplo convincente, esta afirmação ia de certa forma contra a idéia dominante entre os usuários de modelos estruturais da época, que esperavam sempre encontrar correlações positivas entre indicadores positivamente relacionados a um constructo, princípio chamado de consistência interna e muito utilizado até os dias atuais. Bollen (1984) mais de 20 anos depois retoma o artigo de Curtis e Jackson e mostra de uma forma clara e teórica que a consistência interna é válida apenas para indicadores reflexivos, sendo que quando usamos indicadores formativos não devemos esperar qualquer tipo de relação necessária entre os mesmos.

Após Blalock (1964), as publicações mais significantes em relação a indicadores formativos foram as que dizem respeito aos modelos MIMIC, já no final da década de 60 e começo de 70. Os modelos chamados MIMIC (Multiple Indicators and Multiple Causes) são modelos que possuem variáveis latentes com indicadores reflexivos e formativos ao mesmo tempo. Se nem todas as variáveis latentes têm esta estrutura, então não consideraremos o modelo como sendo do tipo MIMIC. Na época em questão os MIMICs mais comuns são modelos com apenas uma variável latente e seus indicadores formativos e reflexivos, como o da Figura 3.1.

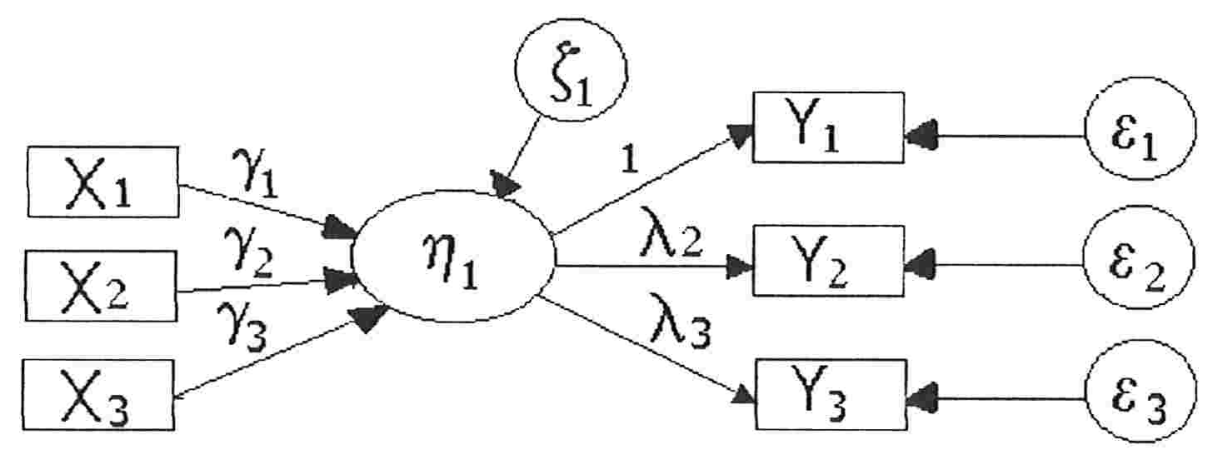

Figura 3.1 - Modelo do tipo MIMIC mais comum, com apenas uma variável latente.

Os modelos MIMIC podem ser escritos na forma das equações (1.1), (1.2) e (1.3) com pequenas modificações. Em particular, o modelo da Figura 3.1 pode ser representado pelo sistema de equações: 


$$
\begin{aligned}
& \eta_{1}=\Gamma x+\zeta_{1} \\
& y=\Lambda_{y} \eta_{1}+\varepsilon \\
& x=\xi
\end{aligned}
$$

Como um exemplo deste tipo de modelo, poderiamos considerar o constructo propensão a crimes em uma determinada área urbana. Ele pode ter como indicadores formativos variáveis mensuráveis como taxa de alfabetização, renda média pessoal e número de distritos policiais na área. Como indicadores reflexivos poderiamos citar variáveis que nos ajudam a medir a própria criminalidade, isto é, causadas por ela, como número de homicídios, número de roubo de veículos, quantidade de entorpecente apreendida, etc. .

Hauser e Goldberger (1971) é um artigo um pouco extenso que tenta entre outras coisas resolver o problema de estimação para os modelos MIMIC com uma única variável latente. De uma forma bem clara os autores mostram como usam o modelo na forma reduzida para chegar a um sistema de equações do qual dependem as estimativas dos parâmetros, e ao principal problema a ser resolvido: os coeficientes dos indicadores reflexivos têm múltiplos estimadores, que são razões de correlações entre variáveis no modelo. Bollen e Davis (1994a) chamam esta multiplicidade de estimadores de restrição de proporcionalidade, que explicaremos melhor no Capítulo 5. Até então se resolvia o problema estimando os parâmetros empiricamente usando a média destas razões, mas Hauser e Goldberger chegam a um novo processo de estimação que eles chamam de eficiente, no qual usam Mínimos Quadrados Generalizados para estimar os parâmetros do modelo.

Mas foi com Jöreskog e Goldberger (1975) que se chegou definitivamente a um método de estimação por máxima verossimilhança para os modelos do tipo MIMIC com apenas uma variável latente. Os autores desenvolvem matematicamente o método de estimação, recorrendo às vezes a resultados julgados como conhecidos do leitor, o que pode dificultar um pouco o entendimento do texto. Eles também comparam em termos de eficiência o 
estimador de máxima verossimilhança com outros dois estimadores também desenvolvidos no artigo.

Com o artigo de Jöreskog e Goldberger parece que as questões sobre os modelos do tipo MIMIC foram todas solucionadas e não encontramos artigo posterior sobre o assunto. A partir da segunda metade dos anos 70 até os dias de hoje não tivemos muitas manifestações de textos sobre indicadores formativos, mas tivemos um bom avanço teórico e metodológico em alguns poucos textos importantes.

Bollen (1984) explica detalhadamente e de forma simples porque o princípio da consistência interna não é aplicável a indicadores formativos e alerta para o possível desprezo de indicadores formativos que não obedecem a esse princípio. Isto é, como um dos principais métodos para se selecionar indicadores era a consistência interna, os pesquisadores eram levados a descartarem indicadores que não seguissem esse princípio. A consistência interna (veja Capítulo 4) diz que indicadores de um mesmo constructo devem ser correlacionados entre si, visto que eles têm uma causa em comum. Bollen usa Curtis e Jackson (1962) para mostrar que isto nem sempre é verdade quando se têm indicadores formativos.

Uma boa referência para o estudo de indicadores formativos no contexto de modelos estruturais é Bollen (1989a), que exemplifica de uma forma bem completa e clara em vários pontos do livro, ocasiões em que estes indicadores são mais apropriados. Nesse livro, que se tornou uma das principais referências em modelos estruturais, o autor mostra também alguns problemas pertinentes aos indicadores formativos, como a determinação de sua confiabilidade e a identificação do modelo. No Capítulo 7, pág. 311-313, Bollen indica como acomodar indicadores formativos nos sistemas gerais de equações dos modelos estruturais, que mostramos no Capítulo 1.

Bollen e Lennox (1991) traçam vários paralelos entre indicadores formativos e reflexivos, delineando as principais diferenças entre os dois casos. 0 conteúdo deste artigo é apresentado no Capítulo 4, onde juntamente com outras fontes, tentamos esclarecer os principais pontos que fazem com que os 
indicadores formativos sejam diferentes e devam ser tratados de forma diferente dos indicadores reflexivos.

MacCallum e Browne (1993) tratam do problema de identificação de modelos com indicadores formativos, da possível existência de modelos equivalentes e do problema de se obter elementos nulos na matriz de covariância implicada sob certas suposições de não correlação entre os indicadores formativos. Eles chegam a algumas regras de identificação, sem no entanto fornecer provas, e dão algumas sugestões de como eliminar o problema de identificação em modelos com indicadores formativos.

Um dos artigos mais importantes sobre identificação, estimação e testes de modelos com indicadores formativos é Bollen e Davis (1994a). É um texto apresentado em uma convenção em Miami, em 1993, o que faz com que as citações utilizem este ano como referência. No nosso caso estaremos nos referindo a 1994, que é o ano da última versão que conseguimos do próprio autor, já que o artigo nunca foi realmente publicado. Apesar disso ele contém boa parte da teoria sobre indicadores formativos que não encontramos em nenhum outro texto e é bastante citado na literatura. Os autores começam definindo um conjunto de regras para a identificação de modelos com indicadores formativos, descrevem a restrição de proporcionalidade existente em certos modelos e como usá-la para verificar a adequação da estrutura do modelo e terminam com uma seção bem interessante sobre estimação e teste de modelos com indicadores formativos subidentificados. São dados vários exemplos de modelos não identificados que, segundo os autores, podem servir de guia para uma grande parte dos possíveis problemas relacionados à identificação e estimação de modelos com indicadores formativos. Embora não provem as regras de identificação, eles se referem a um outro artigo deles mesmo (Bollen e Davis (1994b)), também não publicado, para uma prova detalhada.

O conteúdo deste artigo é discutido com bastante ênfase no Capítulo 5 , pois julgamos que sendo o artigo não publicado e na falta de outras referências sobre o assunto, seria de grande importância que disponibilizássemos aqui suas idéias. 
Diamantopoulos e Winklhofer (1999) fazem um apanhado geral sobre indicadores formativos em modelos estruturais. De uma forma não teórica, os autores introduzem o assunto e sugerem o uso de indicadores formativos para a construção de escalas em muitos casos onde estes indicadores seriam mais adequados.

Edward e Bagozzi (2000) começam revendo as definições de constructo e indicador, relações causais, isolamento, associação e direção da causa. Depois partem para seu propósito principal, que é gerar um guia para a especificação da direção da causa e da estrutura do modelo através da prédefinição de blocos estruturais. Dessa forma, uma vez definido o problema, o pesquisador o estudaria minuciosamente, inclusive com base na teoria já existente sobre $o$ assunto e então teria condições de classificar seu modelo em uma das estruturas existentes e detalhadas no texto de Edward e Bagozzi. Ao fazer isso, já estariam definidas a estrutura do modelo ou de parte dele e a direção da causa entre os indicadores e o constructo. Uma visão mais profunda sobre o conteúdo deste artigo é encontrada no Capítulo 6.

Bollen e Ting (2000) propöem um método de diferenciação entre indicadores formativos e reflexivos baseado em testes de tétrades, que serão vistos com detalhes no Capitulo 6. Resumidamente, a existência de certas estruturas de indicadores reflexivos implicam na existência de certos tétrades nulos, que podem ser testados. Se os testes nos dão evidências de que estes tétrades não são nulos, então sob certas suposições esta evidência seria também de que os indicadores não são reflexivos, mas formativos.

As referências citadas neste capítulo cobrem a maior parte da teoria existente sobre indicadores formativos em modelos estruturais, e são, sem dúvida as mais importantes. Existem muitas outras que abordam os indicadores formativos, mas de forma mais superficial, na maioria das vezes simplesmente com a inclusão destes indicadores em modelos estruturais, nos quais o assunto principal não são os indicadores formativos. Não citaremos estes artigos aqui, porém as referências acima levarão a praticamente todos eles. 


\section{Capítulo 4 - Indicadores Formativos e Reflexivos: uma Comparação}

Neste capítulo estamos empenhados em fazer uma comparação entre indicadores formativos e reflexivos, de modo que possamos entender a diferença entre os dois do ponto de vista mais teórico.

Esta comparação se faz necessária porque o primeiro impulso que temos ao construir um modelo estrutural é o de usar indicadores reflexivos. Isto não acontece sem explicação já que modelos estruturais muitas vezes se valem do uso de variáveis latentes que nasceram com a Análise Fatorial Exploratória.

A teoria sobre a Análise Fatorial Exploratória se desenvolveu muito, tanto em relação a métodos de estimação como no campo de programas computacionais, o que fez com que a técnica fosse muito aplicada e aceita nos mais diversos campos do conhecimento.

A Análise Fatorial Confirmatória e depois os modelos estruturais tomaram emprestada grande parte dos métodos e definições usados na Análise Fatorial Exploratória, e principalmente o conceito de fator é exatamente o mesmo.

Tudo isso teve uma grande contribuição para que nos dias atuais as variáveis latentes sejam vistas como causadoras de certas variáveis observadas. $O$ pesquisador às vezes sequer tenta checar a direção do mecanismo de causa, e ao invés disso usa a "direção padrão" que vai da variável latente para a variável observada, a qual ele já está acostumado devido ao uso da Análise Fatorial Exploratória.

Felizmente parece que na grande maioria dos casos essa direção convencional é realmente a direção correta, mas temos dado exemplos que fogem a esta regra, além de vários outros existentes na literatura citada, o que julgamos ser suficiente para que, ao postular um modelo, estejamos atentos a este ponto particular. 


\section{1 - Definição de Variável Latente}

A diferença entre usar indicadores formativos ou reflexivos começa talvez com a própria definição da variável latente. Quando uma variável latente tem apenas indicadores reflexivos então ela é, no exato sentido da palavra, uma variável não observável que é causa de outras variáveis observadas e que é causada por variáveis não observadas. Estas variáveis são, se assim podemos dizer, algo que imaginamos existir e que explica relações que podemos observar.

A situação é diferente no caso de variáveis com somente indicadores formativos. As variáveis não são realmente não observáveis, elas podem ser tidas como uma combinação linear de seus indicadores - MacCallum e Browne (1993). Aqui existem duas situações distintas a se considerar. Quando a variável latente é formada exatamente pelos seus indicadores, ou seja, não contém um termo de erro, caímos na definição de Análise de Componentes Principais, onde cada componente é uma combinação linear das variáveis observadas. Uma vez encontrados os componentes, eles podem ser calculados e deixam de ser não observados. O segundo caso a considerar é quando a variável latente é formada pelos seus indicadores, com um termo de erro também incidindo sobre ela. Ainda neste caso, a variável latente torna-se observável após a definição dos seus indicadores uma vez que ela é uma função dos mesmos, embora uma função inexata, com erro. Veja que a maioria das variáveis observadas que são usadas como indicadores reflexivos são supostas não desprovidas de erro, isto é, existe o erro de mensuração, o qual não impede que a variável seja considerada observada. É importante notar a diferença, é como se uma vez tendo observado a realização dos indicadores, o constructo passa a ser uma variável observada também. MacCallun e Browne (1993) sugerem até mesmo que se dê um nome especial a estas variáveis, para distinguí-las das tradicionais variáveis latentes que causam indicadores reflexivos. No seu artigo eles chamam as variáveis latentes com indicadores formativos de "variáveis compostas" (do inglês "composite variables" - veja nota na Seção 4.6), e vão mais longe, dizem que os indicadores 
formativos na verdade são variáveis exógenas mensuráveis e por isso são inapropriadamente chamadas de indicadores.

Neste sentido as variáveis compostas seriam semelhantes às que Rindskopf (1984) rotulou de "variáveis fantasmas" (do inglês "phantom variables"). A única diferença entre as variáveis compostas e as variáveis fantasmas de Rindskopf é que estas não têm significado, são simplesmente usadas para possibilitar a inclusão de alguma restrição no modelo, enquanto que as compostas carregam um significado como qualquer variável latente com indicadores reflexivos.

Resumindo, quando usamos indicadores reflexivos a variável latente é conceitualmente bem mais abstrata do que quando usamos indicadores formativos.

\section{2 - O Princípio da Consistência Interna}

Em Bollen e Lennox (1991) vemos que uma das correntes mais aceitas entre os pesquisadores é a da consistência interna, que diz que os indicadores relacionados a um mesmo constructo devem ser correlacionados entre si, isto é, ao escolher indicadores para um constructo, deve-se dar preferência aos que forem correlacionados. Este fato já é presenciado na Análise Fatorial Exploratória onde um fator acaba sendo o constructo responsável por um conjunto de variáveis correlacionadas entre si, e no fundo o que esta técnica faz é procurar na matriz de correlação grupos de variáveis correlacionadas. Na Análise Fatorial Confirmatória também é comum olhar a matriz de covariância e deixar como indicadores de um constructo apenas grupos de indicadores correlacionados. A idéia é que se a correlação entre indicadores é pequena, então eles devem estar medindo conceitos diferentes - Nunnally (1978) -, ou seja, são indicadores de constructos diferentes.

É fácil mostrar que se dois indicadores são positivamente relacionados a uma variável latente, entäo eles devem ser positivamente 
correlacionados. Suponha o modelo seguinte com apenas um constructo, representado esquematicamente na Figura 4.1:

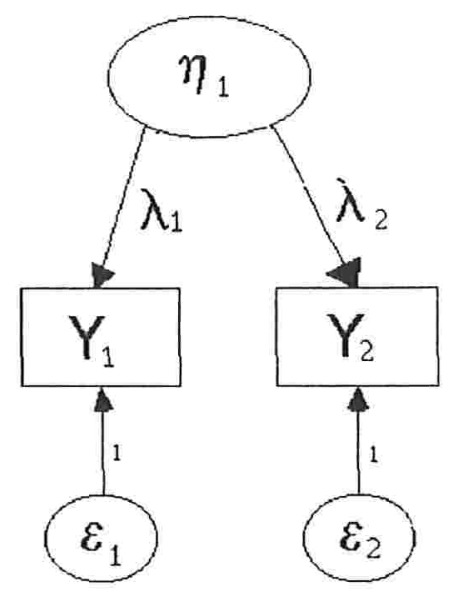

Figura 4.1 - Modelo com dois indicadores positivamente relacionados a um constructo. $\lambda_{1}$ e $\lambda_{2}$ são positivos e significantes, o que implica que Corr $\left(\mathrm{Y}_{1}, \mathrm{Y}_{2}\right)$ também é positiva.

$$
\begin{aligned}
& Y_{1}=\lambda_{1} \eta_{1}+\varepsilon_{1} \\
& Y_{2}=\lambda_{2} \eta_{1}+\varepsilon_{2}
\end{aligned}
$$

$$
\begin{aligned}
\operatorname{Cov}\left(Y_{1}, Y_{2}\right) & =\operatorname{Cov}\left(\lambda_{1} \eta_{1}+\varepsilon_{1}, \lambda_{2} \eta_{1}+\varepsilon_{2}\right) \\
& =\operatorname{Cov}\left(\lambda_{1} \eta_{1}, \lambda_{2} \eta_{1}\right) \\
& =\lambda_{1} \lambda_{2} \operatorname{Var}\left(\eta_{1}\right) .
\end{aligned}
$$

Como $\operatorname{Var}\left(\eta_{1}\right)$ é positiva bem como $\lambda_{1}$ e $\lambda_{2}$, concluímos que $\operatorname{Cov}\left(Y_{1}, Y_{2}\right)$ também é positiva. Aqui estamos assumindo que $\operatorname{Cov}\left(\varepsilon_{i}, \eta_{1}\right)=0, i=1,2$.

Segundo este resultado, indicadores com alta correlação entre si seriam os melhores para se estudar a variável latente. Veja que se um indicador tem correlação negativa com um outro, então podemos inverter suas escalas (ou 
em muitos casos mudar a forma como é feita a questão*) de forma que eles sejam positivamente correlacionados, ou seja, quando falamos em correlação entre indicadores não importa se é positiva ou negativa. Com isto em mente, se temos parâmetros significantes que ligam indicadores a um constructo, vimos que aqueles serão correlacionados entre si, ou seja, a correlação alta entre indicadores é um fator importante para que seus coeficientes sejam significantes. Daí a importância da consistência interna na escolha de indicadores de um mesmo constructo.

No entanto note que a demonstração anterior foi feita considerando apenas indicadores reflexivos, e assim o que fizemos foi mostrar que a consistência interna é válida para indicadores reflexivos.

Quando trabalhamos com indicadores formativos esta relação entre efeito positivo e correlação é comprovadamente não necessariamente verdadeira, visto que neste caso não temos como calcular $\operatorname{Cov}\left(\mathrm{Y}_{1}, \mathrm{Y}_{2}\right)$ como função de parâmetros do modelo. Assim, cuidado especial deve ser tomado ao se escolher indicadores que causam um constructo porque eles não necessariamente precisam ser correlacionados. Bollen e Lennox (1991) alertam que procurar indicadores correlacionados quando eles são formativos pode fazer com que deixemos de fora algum indicador importante para o modelo.

Observe que os indicadores formativos causam a variável latente e não sabemos nada da relação entre eles, assim ela pode ser ou não alta - Bollen (1984). Os indicadores reflexivos são causados por uma fonte que estamos considerando no modelo, e indicadores reflexivos de uma mesma variável latente têm uma causa em comum, o que faz com que sejam correlacionados quando não consideramos a variável latente que os forma**.

\footnotetext{
* Suponha, por exemplo, que temos o constructo Relacionamento Familiar e dois de seus indicadores são "satisfação com a forma com que vocé é tratado pelos seus pais" e "freqüència de desentendimentos entre você e seus pais". E de se supor uma correlação negativa entre estes indicadores, mas se mudarmos a questão para "insatisfação com a forma com que você é tratado pelos seus pais", então a correlação torna-se positiva. Neste caso podemos também inverter a escala de satisfação.

** Se temos $\mathrm{X}_{1}$ e $\mathrm{X}_{2}$, ambos indicadores reflexivos de uma mesma variável latente $\xi$, então a correlação entre $\mathrm{X}_{1} \mathrm{e} \mathrm{X}_{2}$, dado $\xi$ deve ser nula. No entanto $\xi$ é não observável e a correlação entre $\mathrm{X}_{1}$ e $\mathrm{X}_{2}$ desconsiderando $\xi$ será alta por terem $\xi$ como causa comum. Isto é uma explicação em outras palavras do porque da busca por correlaçào alta entre indicadores reflexivos da mesma variável latente.
} 


\section{3 - A Multicolinearidade}

Intimamente relacionado com o que acabamos de dizer sobre a consistência interna está o aspecto da multicolinearidade.

Quando os indicadores reflexivos de uma mesma variável latente são correlacionados, isto não deve ser problema porque a variável latente é a responsável por esta correlação. Veja que não há problema de multicolinearidade, se a correlação entre dois indicadores é alta, também serão altos seus coeficientes, e isto deve acontecer mesmo quando se têm muitos indicadores altamente correlacionados. É comum se fazer uma analogia com modelos de regressão onde temos uma multicolinearidade que é problemática quando temos vários preditores bastante correlacionados. No caso da regressão, pode ser que a exclusão de preditores correlacionados seja a solução, visto que um deles pode ser suficiente para levar em conta o efeito dos outros na variável resposta. A diferença é que na regressão os preditores são variáveis independentes enquanto que em modelos estruturais os indicadores reflexivos são variáveis dependentes.

Uma forma fácil de entender isso é pensar que sendo os indicadores reflexivos dependentes de uma variável latente, então a sobreposição entre eles causada pela alta correlação é explicada pela causa comum que é a variável latente. Assim esta sobreposição é boa porque é uma indicação que temos de que as variáveis têm a mesma causa e estamos corretos em considerá-los como indicadores reflexivos de uma variável latente.

Por outro lado, a multicolinearidade encontrada em modelos de regressão pode representar um problema em modelos estruturais quando estamos falando de indicadores formativos. Bollen e Lennox (1991) recomendam que "deve existir uma alta correlação entre indicadores reflexivos, mas nenhuma recomendação é possivel para indicadores formativos" porque a correlação entre eles depende de fatores externos ao modelo neste caso. Eles comentam ainda que a multicolinearidade pode vir a ser um problema para indicadores formativos a partir do momento em que fica difícil distinguir o impacto de cada indicador na variável latente por causa da variância comum que eles dividem. 


\section{4 - Confiabilidade e Validade}

Como vimos no Capítulo 1, a validade de um indicador pode ser representada pelo coeficiente que o relaciona à variável latente. Este é um dos métodos para se verificar a validade, criado por Bollen e descrito com detalhes em Bollen (1989a), Capítulo 6. Se considerarmos este método, não teremos problemas com o cálculo da validade, seja o indicador formativo ou reflexivo. Isto é verdade mesmo considerando os outros meios para se obter a validade, descrito em Bollen (1989a), Capítulo 6.

Já com relação à confiabilidade (ou consistência) não podemos dizer o mesmo. Aplicar a definição de consistência do indicador X (veja Capítulo 1 , Seção 1.2.3.2)

$$
\rho_{x x}=\frac{\operatorname{Var}(\tau)}{\operatorname{Var}(X)}
$$

como é feito para indicadores reflexivos não tem mais sentido porque o modelo

$$
X=\tau+e
$$

não é mais válido. Usar o Coeficiente Alfa de Cronbach (veja Capítulo 1, Seção 1.2.3.2) também não resolve o problema porque este coeficiente calcula a confiabilidade de um conjunto de dois ou mais indicadores, e note que só faz sentido se temos um conjunto de indicadores com uma causa em comum. O uso do coeficiente alfa está muito ligado ao princípio da consistência interna. Sempre estaremos interessados em calcular a confiabilidade para itens semelhantes, fortemente ligados entre si, e este é o caso apenas dos indicadores reflexivos que têm uma causa em comum.

Se temos variáveis observadas que não guardam nenhuma relação necessária entre si, como é o caso dos indicadores formativos, não faz sentido colocá-los em um grupo para verificar sua consistência como um grupo, porque 
eles não formam um grupo, cada indicador formativo pode ter sua causa específica diferente da dos demais indicadores. Tentar encontrar a confiabilidade de indicadores formativos individualmente parece que seria uma forma mais sensata de aplicar a definição de confiabilidade a esse tipo de variável, mas não existe um meio amplamente aceito e simples para fazer isso.

\section{5 - Representação Amostral da Variável Latente}

Os indicadores reflexivos geralmente carregam um alto grau de colinearidade entre si, por serem formados pela mesma variável latente, fato que faz com que a exclusão de um indicador reflexivo não seja de grande prejuízo para que tenhamos informações sobre a variável latente, principalmente se eles têm a mesma confiabilidade - Bollen e Lennox (1991). Quando usamos indicadores formativos, cada um é único, como se estivesse representando um pedaço da variável latente, assim nenhum indicador formativo pode ser substituído por outro, não importa sua consistência - Bollen e Lennox (1991).

Dessa forma, outro aspecto em que os indicadores reflexivos e formativos diferem é com relação à representatividade das variáveis latentes na amostra. Ao se usar indicadores formativos, a exclusão de um deles pode significar a exclusão de informações não contidas em qualquer outra variável observada, e portanto, que o constructo não está sendo representado na amostra. Já com indicadores reflexivos temos um cenário diferente. Mesmo se um deles não puder ser coletado na amostra, a multicolinearidade natural entre eles fará com que não se perca muita informação, isto é, os outros indicadores reflexivos amostrados certamente conterão grande parte da informação contida no indicador reflexivo não amostrado, e o constructo provavelmente estará bem representado na amostra. 


\section{6 - Escala e Índice}

Segundo Bollen e Lennox (1991) uma forma comum de se obter valores estimados de uma variável latente é construindo composições* da soma não ponderada de seus indicadores. É comum também o uso destas composições em posterior regressão, como variáveis preditoras. Quando os indicadores são reflexivos, estas composições são chamadas por Diamantopoulos e Winklhofer (1999) de escalas, já quando os indicadores são formativos, são chamadas índices.

Suponha que temos quatro indicadores reflexivos, $Y_{1}, Y_{2}, Y_{3}$ e $Y_{4}$ do fator $\eta_{1}$. A soma $Y_{1}+Y_{2}+Y_{3}+Y_{4}$ seria uma possivel composição, segundo a literatura, freqüentemente utilizada. No caso dos indicadores reflexivos, temos:

$$
\begin{aligned}
Y_{1}+Y_{2}+Y_{3}+Y_{4} & =\left(\lambda_{1}+\lambda_{2}+\lambda_{3}+\lambda_{4}\right) \eta_{1}+\left(\varepsilon_{1}+\varepsilon_{2}+\varepsilon_{3}+\varepsilon_{4}\right) \\
& =\lambda \eta_{1}+\varepsilon,
\end{aligned}
$$

ou seja, a composição não é igual à variável latente a não ser que $\lambda$ seja igual a 1 e não tenhamos os termos de erros.

Bollen e Lennox (1991) mostram ainda que a correlação entre a variável latente e a composição anterior não é igual a 1, a não ser no improvável caso onde a variância do erro seja igual a zero, resultado que vale igualmente para indicadores formativos.

O uso da soma de indicadores reflexivos para a construção de escalas não é visto por alguns pesquisadores como sendo um método adequado, por não representar com fidelidade a variável latente, como acabamos de ver. Em Bollen (1989a), página 305, encontra-se outro método que leva mais em conta a teoria e por isso é mais consistente e aceito. Suponha o modelo

\footnotetext{
"O que estamos aqui chamando de composição é uma tradução do termo inglês "composite variables". Bollen e Lennox (1991) citam as "composite variables" como sendo uma combinação linear de indicadores de uma variável latente com o objetivo de criar escores para esta variável e possibilitar assim seu posterior uso, inclusive em outras análises, como Regressão ou Análise de Variância. MacCallum e Browne (1993) também usam o mesmo termo "composite variables" para definir a variável latente que tem apenas indicadores formativos. Eles argumentam que estas variáveis não são latentes no senso comum e seriam melhores definidas com un nome especílico. Neste caso traduzimos o termo como "variáveis compostas".
} 


$$
x=\Lambda_{x} \xi+\delta
$$

com $\Phi$ sendo a matriz de variâncias e covariâncias das variáveis latentes $\xi$, e $\Sigma$ a mesma matriz para os indicadores. Então

$$
\operatorname{Cov}(\mathbf{x}, \xi)=\operatorname{Cov}\left(\Lambda_{\mathbf{x}} \xi+\delta, \xi\right)=\Lambda_{\mathbf{x}} \Phi
$$

Se considerarmos o vetor $\mathbf{y}=[\xi \mid \mathbf{x}]$, composto pelas variáveis latentes e seus indicadores centralizados como tendo distribuição multinormal, então a esperança condicional de $\xi$ dado $\mathbf{x}$ é dada por

$$
E[\xi \mid x]=\Phi \Lambda^{\prime}{ }_{x} \Sigma^{-1} x
$$

cuja prova pode ser vista no resultado 4.6 de Johnson e Wichern (1992). Substituindo as quantidades pelos seus estimadores chegamos à seguinte expressão para o cálculo do escore estimado da variável latente

$$
\hat{\xi}=\hat{\phi} \hat{\Lambda} \hat{\Sigma}^{-1} \mathbf{x} .
$$

É importante ter em mente que tanto usando um composto da soma dos indicadores, como a expressão anterior, o máximo que conseguimos é estimar $\xi$, e esta estimativa terá um certo erro. Por isso é preciso um cuidado especial no uso destes escores em análises posteriores como a regressão, que supõe que as variáveis preditoras não contêm erro.

Ao usar indicadores formativos, temos uma situação diferente, onde a expressão desenvolvida não é justificável para se estimar $\xi$. No entanto, a própria equação do modelo, considerando apenas um constructo

$$
\xi=\lambda_{1} X_{1}+\lambda_{2} X_{2}+\lambda_{3} X_{3}+\ldots,{ }_{, \ldots} \lambda_{k} X_{k}+\zeta
$$


já nos fornece um meio de estimar $\xi$ através da soma ponderada dos indicadores, com pesos iguais a seus coeficientes. Mas veja que os índices calculados desta forma ainda contêm um erro, sendo portanto válido o aviso dado no parágrafo anterior quanto ao seu posterior uso.

De qualquer forma vemos que a construção de índices ou escalas requer seus próprios métodos, de acordo com os indicadores serem formativos ou reflexivos. 


\title{
Capítulo 5 - Indicadores Formativos e Principais Aspectos Teóricos
}

\begin{abstract}
Nosso objetivo neste capítulo é apresentar a teoria existente sobre indicadores formativos. Embora o conteúdo teórico que envolve este tipo de variável não seja extenso, acreditamos que ele possa ajudar o pesquisador quando este se deparar com a necessidade do uso de tais indicadores.

Como a literatura especializada poucas vezes menciona o trabalho com indicadores formativos, a maioria dos usuários de modelos estruturais provavelmente ficará indecisa sobre o que fazer ao encontrar este tipo de variável como parte de um modelo. Bollen e Davis (1994a) dizem que muitos pesquisadores nem mesmo consideram os indicadores formativos por não os conhecerem. Ainda segundo Bollen e Davis, mesmo quem conhece não sabe ao certo como incorporá-los ao modelo, e às vezes o fazem de forma errada.

Assim, queremos neste capítulo mostrar ao leitor o que são os indicadores formativos a fim de facilitar sua compreensão e uso.
\end{abstract}

\section{1 - Identificação}

A identificação de modelos estruturais com indicadores formativos é com certeza o principal fator que leva ao receio quanto ao uso destes modelos.

Devemos lembrar, no entanto, que mesmo os modelos que possuem apenas indicadores reflexivos não têm uma regra de identificação clara, sendo que em modelos estruturais mais complexos é muito difícil se provar a identificação, e muitas vezes temos que recorrer a processos computacionais para isso, embora esses ainda não sejam infalíveis.

Com relação a modelos com indicadores formativos, embora não exista uma regra válida para todos os casos, a identificação na maioria dos casos pode ser checada através de condições necessárias ou suficientes. Se o modelo não obedece a uma condição necessária, então já sabemos que ele não é 
identificado. Se um modelo obedece a uma condição suficiente, então já pode ser tido como identificado. Estas duas proposições são a base de toda utilidade que as regras de identificação têm.

Antes de falar sobre a identificação dos modelos com indicadores formativos, é muito importante que estejamos familiarizados com a identificação dos modelos com apenas indicadores reflexivos. Não abordaremos esse tópico aqui por acharmos que o mesmo foge ao assunto geral deste texto além de ser bastante extenso. Embora tenhamos passado por alguns comentários breves no Capítulo 1, recomendamos que o leitor leia Bollen (1989a), Capítulo 7, que traz um texto bem completo sobre $\mathrm{o}$ assunto, bem como boas referências. $\mathrm{O}$ autor também discorre sobre várias regras para identificação de modelos estruturais com variáveis observadas apenas (Capítulo 4).

\section{2 - Regras para Identificação de Modelos com Indicadores Formativos}

Passaremos nesta seção pelas regras de identificação de modelos com indicadores formativos encontradas atualmente na literatura relacionada ao assunto, sendo que usaremos principalmente os resultados de Bollen e Davis (1994a), que se mostrou o texto mais completo sobre este assunto. Como o artigo não foi publicado, achamos interessante abordar mais detalhadamente alguns tópicos do mesmo, já que não são encontrados em outra referência. Com isto este texto também se torna uma fonte alternativa para o acesso a algumas conclusões de Bollen e Davis (1994a).

\subsection{1 - Regra da Escala}

Esta é uma regra que vale também para os modelos estruturais com indicadores reflexivos. É a regra mais básica para qualquer modelo estrutural, segundo a qual toda variável latente deve ter uma escala ou unidade, caso contrário ela não passa de um conceito abstrato e é impossível analisá-la. Esta 
escala deve ser dada ao constructo pelo pesquisador, através da imposição de alguma restrição.

Para resolver este problema é comum fixar o coeficiente de um dos indicadores ao valor 1 , fazendo com que a variável latente fique com a mesma unidade do indicador. Outras formas de se dar escala a uma variável latente são fixar sua variância ou fixar o caminho que a leva a outra variável latente. Estas formas são todas válidas e a escolha de uma delas leva em conta que efeitos são mais importantes de se estimar.

Esta regra é necessária, mas não suficiente, de forma que devemos verificá-la sempre, em todos os modelos estruturais.

\subsection{2 - Regra t}

Esta também é uma regra básica, mesmo para modelos sem indicadores formativos.

Segundo a regra $\mathrm{t}$ devemos ter um número menor ou igual de parâmetros a serem estimados do que o número de elementos diferentes na matriz de variâncias e covariâncias das variáveis observadas. Se tivermos, por exemplo, 5 variáveis observadas, devemos ter no máximo 15 parâmetros a se estimar. Se t é o número de parâmetros livres e p é o número de variáveis observadas, então podemos generalizar a regra dizendo que t deve ser menor ou igual a $p(p+1) / 2$.

O problema aqui é que estimar os parâmetros de um modelo estrutural é o mesmo que tentar resolver o sistema $S=\Sigma(\theta)$, que tem $p(p+1) / 2$ equações e t incógnitas (veja Capítulo 1). Se tivermos mais incógnitas (parâmetros a se estimar) do que equações vamos nos deparar com um sistema indefinido, com infinitas soluções, ou seja, o modelo não pode ser identificado.

Esta também é uma condição necessária, mas não suficiente para a identificação, visto que mesmo obedecendo a esta condição o modelo pode não ser identificado. 


\subsection{3 - Regra dos Dois Caminhos Emitidos}

A regra dos dois caminhos emitidos é uma regra específica para modelos com indicadores formativos que também é necessária, mas não suficiente para a identificação. A primeira menção desta regra na literatura devese a MacCallum e Browne (1993), ocasião em que eles mostram que em um dado modelo estrutural com indicadores formativos há uma falta de identificação nos caminhos que ligam uma variável latente explanatória com indicadores reflexivos às variáveis latentes com indicadores formativos, e nas variâncias dos resíduos deste modelo. Depois MacCallum e Browne generalizaram a regra, dizendo que a mesma vale de uma forma geral e não apenas para seu modelo específico, o que tem como base, segundo eles, vários estudos com modelos diferentes que foram analisados computacionalmente e algebricamente.

A fim de tentar entender melhor o problema de identificação dos modelos com variáveis latentes com indicadores formativos emitindo apenas um caminho nos apoiamos no conceito de variável fantasma, encontrado em Rindskopf (1984). Neste artigo, as variáveis fantasmas são inseridas no modelo apenas para que consigamos impor alguma restrição em seus parâmetros. Por exemplo, a Figura 5.1 mostra o efeito indireto de $\xi_{1}$ em $\eta_{1}$ tendo $\eta_{2}$ como intermediador.

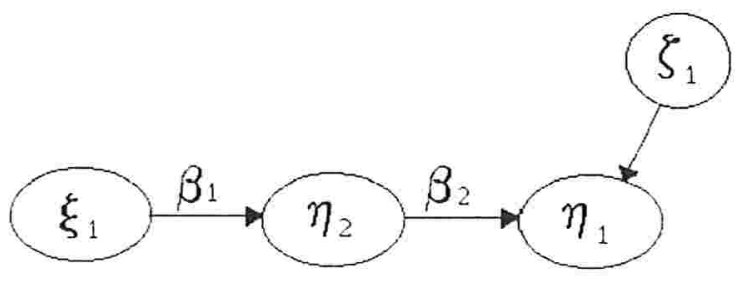

Figura 5.1 - Diagrama de caminho que mostra um modelo onde a variável fantasma $\eta_{2}$ é usada para possibilitar a restrição de que o efeito de $\xi_{1}$ em $\eta_{1}$ seja positivo. Para isso deve haver a restrição $\beta_{1}=\beta_{2}$, sem a qual o modelo não é identificado. 
Se quisermos impor a restrição de que o efeito de $\xi_{1}$ em $\eta_{1}$ seja maior do que zero, uma possivel alternativa é fixar $\beta_{1}=\beta_{2}$ e o efeito será $\beta_{1} \beta_{2}=\beta_{1}{ }^{2}$ $>0$. Na Figura 5.1 omitimos propositalmente os indicadores reflexivos de $\eta_{1}$ e $\xi_{1}$, mostrando apenas a parte estrutural de um modelo fictício, em que $\eta_{2}$ não tem indicadores no contexto de Rindskopf (1984) - esta variável latente só é incorporada ao modelo para possibilitar a restrição de que o efeito seja positivo. A não ser por isso, $\eta_{2}$ não tem função no modelo, com ou sem $\eta_{2}$ o modelo é matematicamente o mesmo. Se $\beta_{1}$ não é restrito a ser igual a $\beta_{2}$ o modelo se torna não identificado. Continuando a considerar a parte estrutural do modelo representado na Figura 5.1, temos

$$
\begin{aligned}
& \eta_{1}=\beta_{2} \eta_{2}+\zeta_{1} \\
& \eta_{2}=\beta_{1} \xi_{1} .
\end{aligned}
$$

Substituindo (5.2) em (5.1), temos

$$
\eta_{1}=\beta_{2} \beta_{1} \xi_{1}+\zeta_{1}
$$

Veja que o produto $\beta_{1} \beta_{2}$ é na verdade um único parâmetro, digamos, $\beta_{3}$, coeficiente de $\xi_{1}$. Para um dado valor de $\beta_{3}$ existem infinitos valores para $\beta_{1}$ e $\beta_{2}$ que satisfazem $\beta_{1} \beta_{2}=\beta_{3}$, ou seja, o modelo não é identificado. Na verdade o problema pode ser visto como o de resolver o sistema de uma equação e duas incógnitas $\beta_{1} \beta_{2}=K$, onde $K=$ constante. $O$ problema claramente não tem solução única.

Se incluirmos um termo de resíduo em $\eta_{2}$, tal que a equação (5.2) fique

$$
\eta_{2}=\beta_{1} \xi_{1}+\zeta_{2}
$$

e, substituindo (5.3) em (5.1) temos 


$$
\begin{aligned}
\eta_{1} & =\beta_{2}\left(\beta_{1} \xi_{1}+\zeta_{2}\right)+\zeta_{1} \\
& =\beta_{2} \beta_{1} \xi_{1}+\beta_{2} \zeta_{2}+\zeta_{1} .
\end{aligned}
$$

$O$ resíduo pode ser representado como $Z=\beta_{2} \zeta_{2}+\zeta_{1}$ e sua variância $\operatorname{Var}(Z)=\beta_{2}^{2} \Psi_{2}+\Psi_{1}$, onde $\Psi_{1}$ e $\Psi_{2}$ são as variâncias de $\zeta_{1}$ e $\zeta_{2}$ respectivamente. Note que se $\Psi_{2}$ for substituído por $\Psi_{2}+$ d e $\Psi_{1}$ por $\Psi_{1}-\beta_{2}^{2}$ d, a variância de $Z$ continuará a mesma, para qualquer valor de d, restrito apenas ao fato de que $\Psi_{2}$ deve ser positivo. A constante d constitui uma indeterminação pois pode assumir infinitos valores, assim concluímos que a variância dos resíduos é não identificada*.

Resumindo, a variável fantasma de Rindskopf causa uma não identificação do modelo mesmo que um termo de residuo seja adicionado a ela, caso não tenhamos a restrição $\beta_{1}=\beta_{2}$.

Ainda nesse contexto, a adição de indicadores formativos a $\eta_{2}$ não altera o problema de identificação. Supondo dois indicadores formativos, a equação (5.3) ficaria:

$$
\eta_{2}=\beta_{1} \xi_{1}+\lambda_{1} x_{1}+\lambda_{2} x_{2}+\zeta_{2}
$$

e, substituindo (5.4) em (5.1):

$$
\eta_{1}=\beta_{2} \beta_{1} \xi_{1}+\beta_{2} \lambda_{1} x_{1}+\beta_{2} \lambda_{2} x_{2}+\beta_{2} \zeta_{2}+\zeta_{1}
$$

O problema de identificação da variância do resíduo permanece exatamente o mesmo pois o resíduo continua podendo ser representado por $Z=$ $\beta_{2}{ }^{2} \zeta_{2}+\zeta_{1}$. Veja que este problema não tem relação com o valor de $\beta_{2}$. Por outro lado, temos o sistema de três equações e quatro incógnitas:

\footnotetext{
"Podemos utilizar o mesmo raciocínio para o produto $\beta_{1} \beta_{2}$. Se substituirmos $\beta_{1}$ por $\beta_{1} C$ e $\beta_{2}$ por $\beta_{2} C$. o coeficiente de $\xi_{1}$ fica o mesmo para qualquer valor de $C$. assim o produto $\beta_{1} \beta_{2}$ se caracteriza como uma fonte de não identificação do modelo.
} 


$$
\begin{aligned}
& \beta_{2} \beta_{1}=k_{1} \\
& \beta_{2} \lambda_{1}=k_{2} \\
& \beta_{2} \lambda_{2}=k_{3}
\end{aligned}
$$

que não tem solução única, configurando-se assim em outra fonte de não identificação. Mostramos aqui, em uma situação simples que a inclusão de indicadores formativos em um modelo estrutural não altera o problema de identificação da parte estrutural do sistema. Consideramos agora, como um último passo, a inclusão de um novo caminho emitido por $\eta_{2}$, que tem apenas um indicador formativo $\left(\xi_{1}, \eta_{1}\right.$ e $\eta_{3}$ são supostas variáveis latentes com indicadores reflexivos). Conforme a Figura 5.2 o novo sistema de equações é:

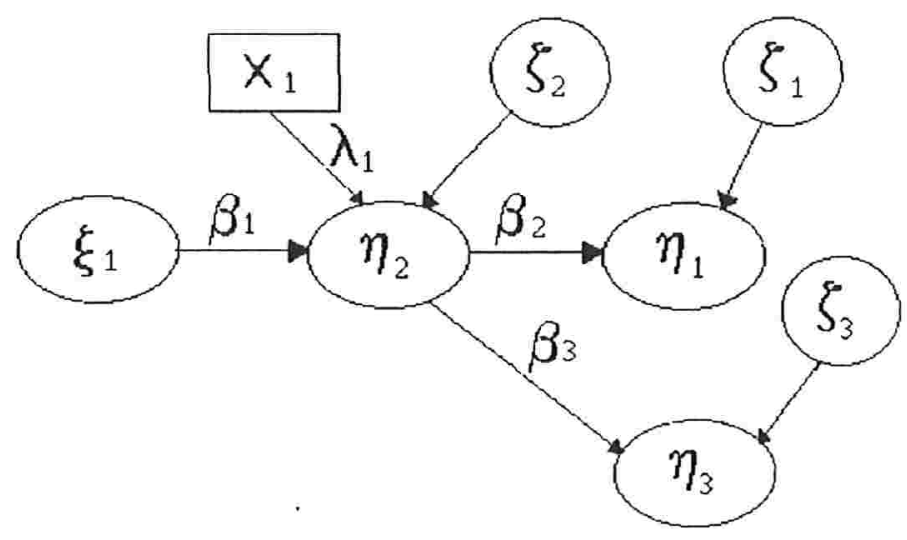

Figura 5.2 - Diagrama de caminho de um modelo com dois caminhos partindo de uma variável latente com indicador formativo.

$$
\begin{aligned}
& \eta_{1}=\beta_{2} \eta_{2}+\zeta_{1} \\
& \eta_{3}=\beta_{3} \eta_{2}+\zeta_{3} \\
& \eta_{2}=\beta_{1} \xi_{1}+\lambda_{1} x_{1}+\zeta_{2} .
\end{aligned}
$$

Substituindo (5.7) em (5.6) e (5.5), temos: 


$$
\begin{aligned}
& \eta_{1}=\beta_{2} \beta_{1} \xi_{1}+\beta_{2} \lambda_{1} x_{1}+\left(\beta_{2} \zeta_{2}+\zeta_{1}\right) \\
& \eta_{3}=\beta_{3} \beta_{1} \xi_{1}+\beta_{3} \lambda_{1} x_{1}+\left(\beta_{3} \zeta_{2}+\zeta_{3}\right) .
\end{aligned}
$$

Agora temos quatro parâmetros $\left(\beta_{1}, \beta_{2}, \beta_{3}\right.$ e $\left.\lambda_{1}\right)$ para representar quatro efeitos (os efeitos de $\xi_{1}$ e $X_{1}$ em $\eta_{1}$ e $\eta_{3}$ ), e assim o problema de identificação citado anteriormente já não existe. Embora possa parecer o contrário, as variâncias dos resíduos também são identificadas. Os resíduos de $\eta_{1}$ e $\eta_{3}$ são representados por $\zeta_{1}$ e $\zeta_{3}$ no diagrama de caminho na Figura 5.2, os quais são não correlacionados. Nas expressões (5.8) e (5.9) somos tentados a dizer que os resíduos de $\eta_{1}$ e $\eta_{3}$ são $\beta_{2} \zeta_{2}+\zeta_{1}$ e $\beta_{3} \zeta_{2}+\zeta_{3}$ respectivamente, mas estes dois resíduos são correlacionados por causa da presença de $\zeta_{2}$ em ambos, o que impede que calculemos a variância dos resíduos da forma como fizemos anteriormente. MacCallum e Browne (1993) ainda completam dizendo que se especificarmos uma correlação entre $\zeta_{1}$ e $\zeta_{2}$, teremos um modelo não identificado.

Quisemos mostrar com os exemplos anteriores como um modelo que tem uma variável latente com indicadores formativos e emite apenas um caminho não é identificado, e como a emissão de um segundo caminho ajuda nesta identificação. $O$ exercício que fizemos serve para que tenhamos uma visão da não identificação causada pela emissão de apenas um caminho, mas não serve como uma prova. MacCallum e Browne (1993) também generalizam esta regra e dizem que é válida sem entretanto apresentarem uma prova formal. Bollen e Davis (1994a) referem-se a Bollen e Davis (1994b) para uma prova deste resultado, mas não conseguimos encontrar esta referência por se tratar de um artigo não publicado. Entendemos então que a literatura especializada em indicadores formativos e modelos estruturais carece até o momento de uma prova formal desta regra.

MacCallum e Browne (1993) mostram um modelo com duas variáveis latentes com apenas indicadores formativos e que emitem um caminho cada, e enfatizam que matematicamente o modelo fica o mesmo, bem como os resultados de ajuste, se retirarmos estas variáveis latentes do modelo e ligarmos os 
indicadores formativos destas variáveis latentes diretamente às variáveis afetadas por aquelas que foram retiradas do modelo. Embora não tenhamos problemas em fazer isso do ponto de vista matemático, do ponto de vista conceitual o procedimento é muito problemático porque pode mudar muito o significado do modelo.

Essa indeterminação que leva à possibilidade de exclusão de alguns caminhos do modelo é causada pela multiplicidade de caminhos ligando duas variáveis latentes com indicadores reflexivos (no exemplo da Figura 5.1 temos dois caminhos, $\beta_{1}$ e $\beta_{2}$, para ligar apenas duas variáveis com indicadores reflexivos, $\xi_{1}$ e $\eta_{1}$ ). O fato de a variável latente com indicadores reflexivos emitir mais de um caminho não resolve o problema de identificação se ambos os caminhos levam ao mesmo conjunto de indicadores reflexivos. O mesmo raciocínio, segundo MacCallum e Browne (1993), vale para a identificação da variância dos erros. Neste caso, uma solução pode ser excluir o termo de erro ao invés de se excluir a variável latente com indicadores formativos.

Vale lembrar que uma forma de identificar estes modelos é a inclusão de indicadores reflexivos nas variáveis latentes com apenas indicadores formativos. Esta provavelmente é a forma que menos penaliza o modelo em termos conceituais, porém pode ser difícil, uma vez definido o modelo e coletados os dados, encontrar novos indicadores. A reespecificação de indicadores formativos como reflexivos deve ser feita com muito critério, não levando em conta apenas o fato da identificação, mas se o indicador tem realmente natureza reflexiva.

\subsection{4 - Regra MIMIC}

Modelos do tipo MIMIC, como já vimos no Capítulo 3, são modelos em que as variáveis latentes têm indicadores formativos e reflexivos. Se nem todas as variáveis latentes têm indicadores formativos e reflexivos ao mesmo tempo, então uma parte da estrutura do modelo não é do tipo MIMIC. Esta regra diz respeito apenas aos modelos que possuem todas as variáveis latentes com 
indicadores formativos e reflexivos, ou, poderiamos dizer, inteiramente do tipo MIMIC. É comum encontrar na literatura modelos completos com apenas uma variável latente e seus indicadores. Bollen (1989a), pág. 331 mostra uma regra de identificação para estes modelos quando eles têm apenas uma variável latente. Para serem identificados é necessário que a variável latente tenha pelo menos dois indicadores reflexivos e um indicador formativo.

Bollen e Davis (1994a) expandem esta regra para modelos MIMIC de forma a adaptá-la para modelos com indicadores formativos com $m$ variáveis latentes, onde cada variável latente tem influência apenas em indicadores reflexivos ou em outra variável latente. Novamente Bollen e Davis remetem o leitor para Bollen e Davis (1994b) para uma prova desta regra de identificação. O artigo não foi publicado por isso não conseguimos ter acesso ao mesmo, porém citaremos a regra, que é suficiente para identificação. Ela é composta de 4 partes:

1 - Cada variável latente deve afetar pelo menos dois indicadores reflexivos. Mas se temos $m$ variáveis latentes não é necessário que haja $2 m$ indicadores reflexivos, na verdade a quantidade mínima seria $m+1$, sendo que neste caso cada variável latente teria um indicador reflexivo que é afetado só por ela, e existiria um indicador reflexivo afetado por todas as variáveis latentes;

2 - É necessário haver pelo menos $m$ indicadores formativos e a matriz $\Gamma$ dos coeficientes dos indicadores formativos nas variáveis latentes deve ser de posto-linha completo. O fato dela ter posto completo obriga que cada variável latente tenha pelo menos um indicador formativo;

3 - Todos os termos de erro dos indicadores reflexivos devem ser não correlacionados uns com os outros e com os erros da variável latente. Ou seja, a matriz $\Theta$ deve ser diagonal. Esta é uma condição que freqüentemente pode ser relaxada e o modelo continua identificado;

4 - O modelo que relaciona os indicadores formativos às variáveis latentes e as variáveis latentes entre si tem uma estrutura identificada. Para verificar essa condição basta considerar as variáveis latentes como se fossem observadas e usar métodos para identificação de modelos estruturais com 
variáveis observadas. Um bom apanhado destes métodos pode ser encontrado em Bollen (1989a), pág. 93-104.

Se todas estas condições são satisfeitas, então o modelo é identificado.

\subsection{5 - Exemplo}

Às vezes é difícil usar este conjunto de regras para estabelecer a identificação de um modelo como um todo devido ao seu tamanho e complexidade. Neste caso, sempre que possível pode-se usar a estratégia de identificar o modelo por partes, como sugere Bollen (1989a), pág. 328 - 332.

Primeiro se verifica a identificação dos indicadores e fatores de primeira ordem (fatores que não causam outros fatores, mas apenas indicadores), deixando de lado a parte estrutural. O modelo é tratado como em uma Análise Fatorial Confirmatória, onde temos apenas indicadores reflexivos. Depois, usando os fatores de primeira ordem como variáveis observadas e deixando de fora os indicadores, verifica-se a identificação da parte estrutural. Bollen (1989a), pág. 328 - 332, cita este método como tendo apenas estes dois passos, mas Bollen e Davis (1994a) comentam que é possível usar tantos passos quantos forem necessários, generalizando a regra de dois passos.

Esta técnica é compreendida de uma forma bem mais fácil através de ilustrações. A fim de que se possa tirar maior proveito deste texto, reproduziremos aqui um exemplo retirado de Bollen e Davis (1994a), com alguns comentários adicionais que julgamos importantes, mas recomendamos que sejam consultados outros exemplos em Bollen (1989a), pág. 328 - 332, ou Bollen e Davis (1994a) para uma abrangência de modelos diferentes.

Suponha o modelo representado pelo diagrama de caminho da Figura 5.3, cujo sistema de equações é: 


$$
\begin{aligned}
& {\left[\begin{array}{l}
\eta_{1} \\
\eta_{2} \\
\eta_{3}
\end{array}\right]=\left[\begin{array}{ccc}
0 & 0 & 0 \\
1 & 0 & 0 \\
\beta_{31} & 0 & 0
\end{array}\right]\left[\begin{array}{l}
\eta_{1} \\
\eta_{2} \\
\eta_{3}
\end{array}\right]+\left[\begin{array}{cc}
\gamma_{11} & \gamma_{12} \\
0 & 0 \\
0 & 0
\end{array}\right]\left[\begin{array}{l}
X_{1} \\
X_{2}
\end{array}\right]+\left[\begin{array}{l}
\zeta_{1} \\
\zeta_{2} \\
\zeta_{3}
\end{array}\right]} \\
& {\left[\begin{array}{l}
Y_{1} \\
Y_{2} \\
Y_{3} \\
Y_{4}
\end{array}\right]=\left[\begin{array}{ccc}
0 & 1 & 0 \\
0 & \lambda_{22} & 0 \\
0 & 0 & 1 \\
0 & 0 & \lambda_{43}
\end{array}\right]\left[\begin{array}{l}
\eta_{1} \\
\eta_{2} \\
\eta_{3}
\end{array}\right]+\left[\begin{array}{l}
\varepsilon_{1} \\
\varepsilon_{2} \\
\varepsilon_{3} \\
\varepsilon_{4}
\end{array}\right],}
\end{aligned}
$$

e com as matrizes implícitas de variâncias e covariâncias dos erros $\varepsilon$, das latentes $\eta$ e dos erros $\zeta$ dadas respectivamente por:

$$
\Theta_{\varepsilon}=\left[\begin{array}{cccc}
\theta_{11} & 0 & 0 & 0 \\
0 & \theta_{22} & 0 & 0 \\
0 & 0 & \theta_{33} & 0 \\
0 & 0 & 0 & \theta_{44}
\end{array}\right] ; \quad \Psi=\left[\begin{array}{ccc}
\psi_{11} & 0 & 0 \\
0 & \psi_{22} & 0 \\
0 & 0 & \psi_{33}
\end{array}\right] \text { e } \Phi=\left[\begin{array}{ccc}
\phi_{11} & 0 & 0 \\
0 & \phi_{22} & 0 \\
0 & 0 & \phi_{33}
\end{array}\right] \text {. }
$$

Observe que o modelo em questão passa pela regra dos dois ou mais caminhos e pela regra-t pois temos $6(6+1) / 2=21$ elementos na matriz de covariâncias dos X's e Y's, e apenas 15 parâmetros para se estimar, como se pode ver no sistema de matrizes.

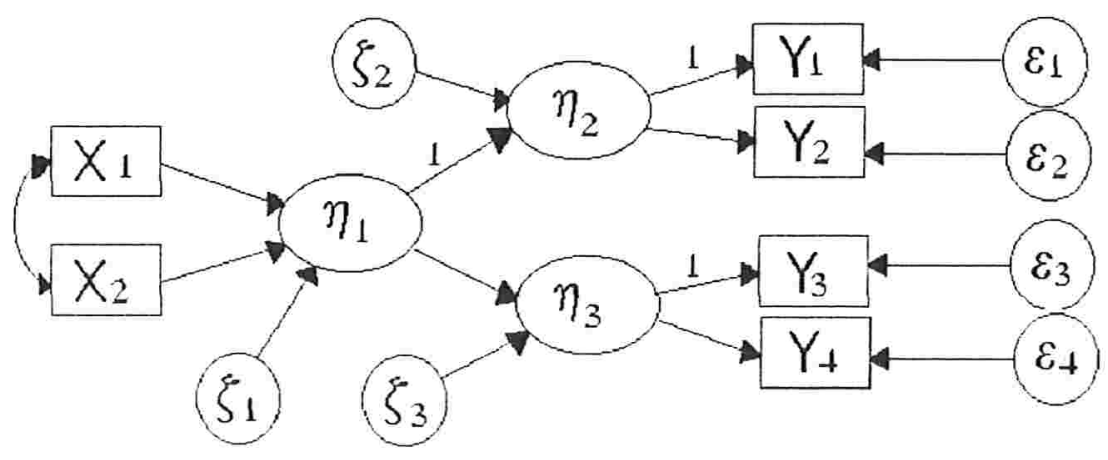

Figura 5.3-Modelo estrutural com indicadores formativos e reflexivos. A verificação da identificação se dá por partes. Primeiro a estrutura fatorial que envolve $\eta_{2}, \eta_{3}$ e os indicadores formativos, depois o restante do modelo. 
Toda variável latente também tem uma escala, conseguida através dos coeficientes fixados em 1. Estas três regras são necessárias e se o modelo tivesse falhado em alguma delas não precisaríamos ir adiante, o modelo seria não identificado.

O modelo não pode ser testado com a regra MIMIC porque sua estrutura não é a de um modelo MIMIC, onde todas as variáveis latentes têm indicadores formativos e reflexivos. Usaremos então a estratégia de identificar 0 modelo por partes. O primeiro passo é verificar se a parte de mensuração é identificada, ou seja, se as relações entre indicadores e fatores de primeira ordem estão identificadas. Para isso construímos um modelo de Análise Fatorial Confirmatória com a parte de mensuração do modelo. Os indicadores formativos devem ser representados como no caso de variáveis latentes exatamente determinadas por indicadores reflexivos e a variável latente que tinha apenas indicadores formativos $\left(\eta_{1}\right)$ não aparece nesta primeira parte do teste de identificação (veja Figura 5.4).

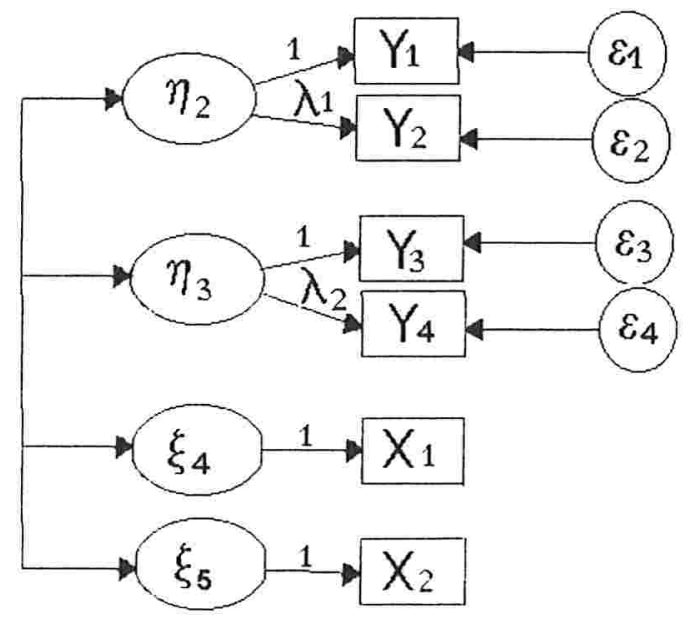

Figura 5.4 - Parte de mensuraçăo do modelo da Figura 5.3, transformada em um modelo de Análise Fatorial Confirmatória. Os indicadores formativos são formados por variáveis latentes que os determinam com exatidão, sem erros.

As novas variáveis $\xi_{4}$ e $\xi_{5}$ são criadas somente para representar os indicadores formativos. Agora estes indicadores passam a ser considerados 
reflexivos, e temos um modelo de Análise Fatorial Confirmatória, construído apenas para o estudo da identificação da parte estrutural, que é o primeiro passo para a identificação por partes.

O modelo da Figura 5.4 é identificado, pois ele pode ser representado pelo sistema de equações

$$
\begin{aligned}
& Y_{1}=\eta_{2}+\varepsilon_{1} \\
& Y_{2}=\lambda_{1} \eta_{2}+\varepsilon_{2} \\
& Y_{3}=\eta_{3}+\varepsilon_{3} \\
& Y_{4}=\lambda_{2} \eta_{3}+\varepsilon_{4} \\
& X_{1}=\xi_{4} \\
& X_{4}=\xi_{5}
\end{aligned}
$$

As variáveis observadas têm matriz de variâncias e covariâncias

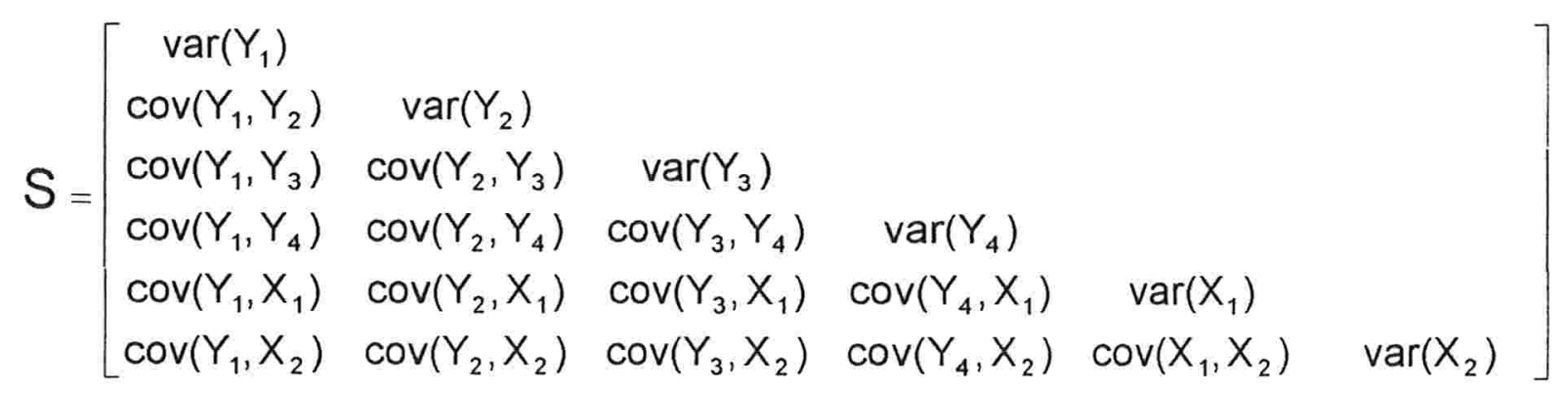

e a matriz das variâncias e covariâncias implicadas escrita em termos dos parâmetros do modelo

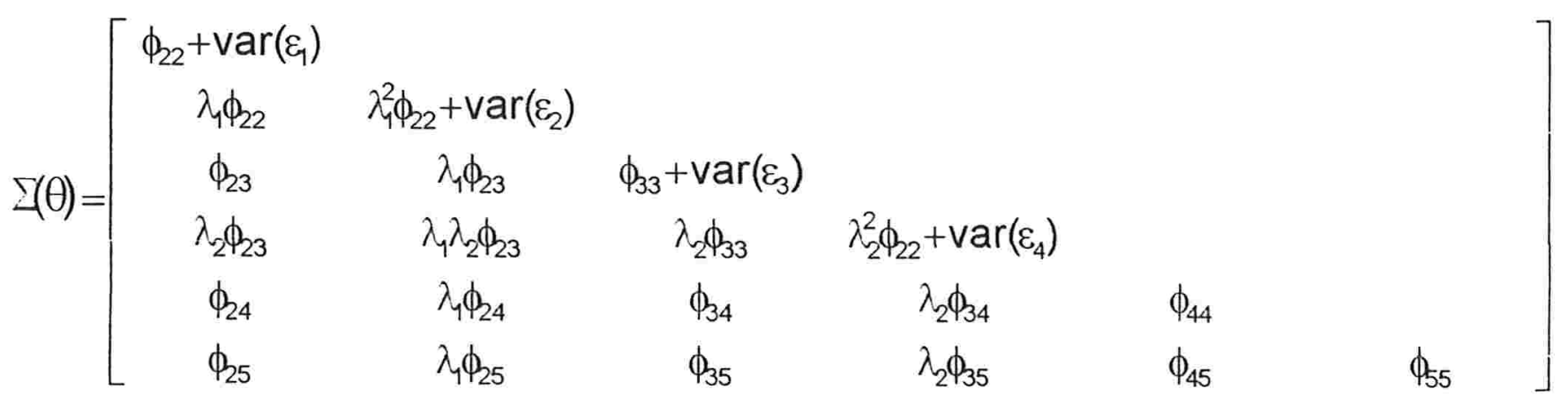


Considerando o sistema $\mathbf{S}=\Sigma(\theta)$ formado pelas duas matrizes acima, temos 21 equações e 16 parâmetros $\left(\phi_{22}, \phi_{23}, \phi_{24}, \phi_{25}, \phi_{33}, \phi_{34}, \phi_{35}, \phi_{44}, \phi_{45}\right.$, $\phi_{55}, \operatorname{var}\left(\varepsilon_{1}\right), \operatorname{var}\left(\varepsilon_{2}\right), \operatorname{var}\left(\varepsilon_{3}\right), \operatorname{var}\left(\varepsilon_{4}\right), \lambda_{1}$ e $\left.\lambda_{2}\right)$, ou seja, o modelo obedece a regra t. Os parâmetros $\phi_{23}, \phi_{24}, \phi_{25}, \phi_{34}, \phi_{35}, \phi_{44}, \phi_{45}, \phi_{55}$, são identificados pois eles aparecem sozinhos em $\Sigma(\theta)$ e assim já podem ser escritos como uma função direta dos elementos de $\mathbf{S}$. Por exemplo, $\phi_{24}=\operatorname{cov}\left(\mathrm{X}_{1}, \mathrm{Y}_{1}\right)$. Ainda, é fácil ver que

$$
\begin{aligned}
& \lambda_{1}=\frac{\operatorname{cov}\left(Y_{2}, Y_{3}\right)}{\operatorname{cov}\left(Y_{1}, Y_{3}\right)} ; \quad \lambda_{2}=\frac{\operatorname{cov}\left(Y_{1}, Y_{4}\right)}{\operatorname{cov}\left(Y_{1}, Y_{3}\right)} ; \quad \phi_{22}=\frac{\operatorname{cov}\left(Y_{1}, Y_{2}\right)}{\lambda_{1}} \\
& \operatorname{var}\left(\varepsilon_{1}\right)=\operatorname{var}\left(Y_{1}\right)-\phi_{22}
\end{aligned}
$$

e assim podemos mostrar facilmente que todos os 16 parâmetros podem ser escritos como funções simples dos elementos de $\mathbf{S}$, portanto o modelo é identificado. Na verdade, o que fizemos acima foi mostrar que existe pelo menos uma forma de resolver o sistema de equações para cada parâmetro. Como existem mais equações do que parâmetros, certamente temos mais informações do que precisamos e assim parâmetros podem ter mais de uma forma implicada, e o modelo é superidentificado. Como já foi comentado no Capítulo 1, estes são os modelos úteis pois podem ser testados.

Continuando com a regra da identificação por partes, vimos que o primeiro passo consistiu na identificação da parte de mensuração do modelo. $O$ modelo da Figura 5.3 passou nessa primeira etapa. O segundo passo consiste em se verificar a identificação da parte estrutural do modelo considerando agora as variáveis latentes do modelo de Análise Fatorial Confirmatória (passo 1) como variáveis observadas. No nosso exemplo o segundo passo consiste em se verificar a identificação do modelo na Figura 5.5, que é o modelo da Figura 5.3 com $\eta_{2}$ e $\eta_{3}$ consideradas indicadores, pois sua identificação já foi testada no passo 1 . Observe que agora podemos aplicar a regra MIMIC. 


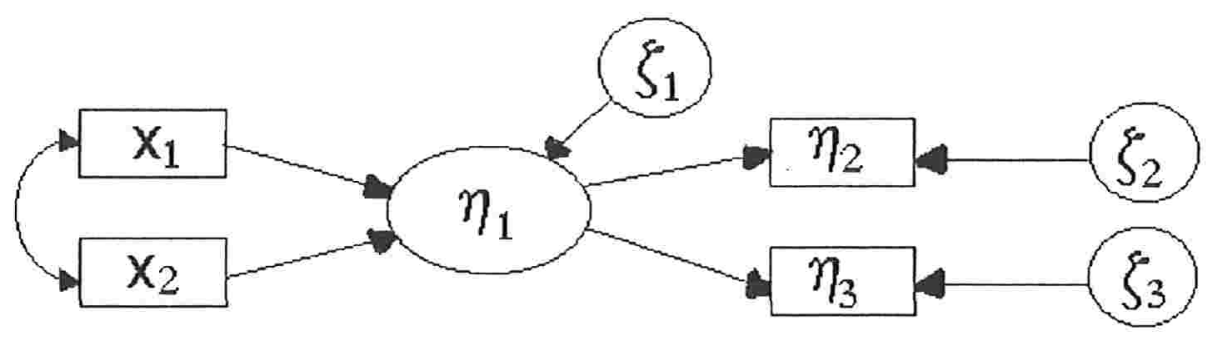

Figura 5.5 - Parte estrutural do modelo da Figura 5.3, onde as variáveis latentes $\eta_{2}$ e $\eta_{3}$ säo consideradas indicadores. O modelo torna-se exatamente um MIMIC com uma única variável latente.

A regra MIMIC número 1 é obedecida visto que temos dois indicadores reflexivos. A regra número 2 também porque temos mais do que um indicador formativo e a matriz $\Gamma$ tem posto 1 , ela só tem uma linha. Os erros são não correlacionados. Como aqui só temos uma variável latente, a condição número 4 é automaticamente satisfeita, assegurando então que o modelo da Figura 5.5 é identificado e portanto o modelo da Figura 5.3, que é nosso modelo inicial, também é identificado.

Até agora comentamos as regras de identificação propriamente ditas para modelos com indicadores formativos. Bastante relacionado a este tema estão dois outros assuntos tratados em Bollen e Davis (1994a), os quais passaremos a discutir.

O primeiro deles, o estudo de modelos não identificados, através dos chamados "modelos em forma parcialmente reduzida" trata de como podemos obter informações de modelos não identificados através de uma regra para identificá-los.

O outro tópico que discutiremos diz respeito a certas restrições que estão automaticamente presentes em modelos com variáveis latentes com mais de um indicador formativo. Estas restriçōes à primeira vista passam desapercebidas, mas existem e podemos testá-las, obtendo com isso informação importante sobre a especificação do modelo. 


\section{3 - Modelos com Indicadores Formativos não Identificados}

A regra dos dois ou mais caminhos citada na seção anterior para a identificação de modelos estruturais com indicadores formativos apareceu pela primeira vez no artigo de MacCallum e Browne (1993), ocasião em que eles notaram que, nos casos em que havia apenas um caminho, não havia diferenças matemáticas no modelo se fossem retiradas as variáveis latentes com indicadores formativos, e fosse especificada uma relação de causa direta entre os indicadores formativos e as variáveis influenciadas pelos constructos excluídos. No artigo, MacCallum e Browne constatam a não identificação do modelo e seguem recomendando a retirada de variáveis latentes com indicadores formativos que emitem apenas um caminho, a fim de que o modelo passe a ser identificado. Bollen e Davis (1994a) retomam este problema do número de caminhos emitidos e tentam estudar os modelos não identificados, chegando a alguns resultados importantes que resumiremos a seguir.

Primeiramente eles denominam os modelos que se tornam identificados por causa da exclusão de variáveis latentes com indicadores formativos que emitem apenas um caminho de "Modelo em Forma Parcialmente Reduzida - FPR". Como o FPR é freqüentemente identificado, é possível estimar seus parâmetros e fazer testes tanto de ajuste do modelo como um todo, como da significância de seus parâmetros. Muitos modelos, como o da Figura 5.6, têm um FPR (Figura 5.7) que difere pouco do modelo original. E isto torna o FPR bastante útil para inferências a respeito do modelo original.

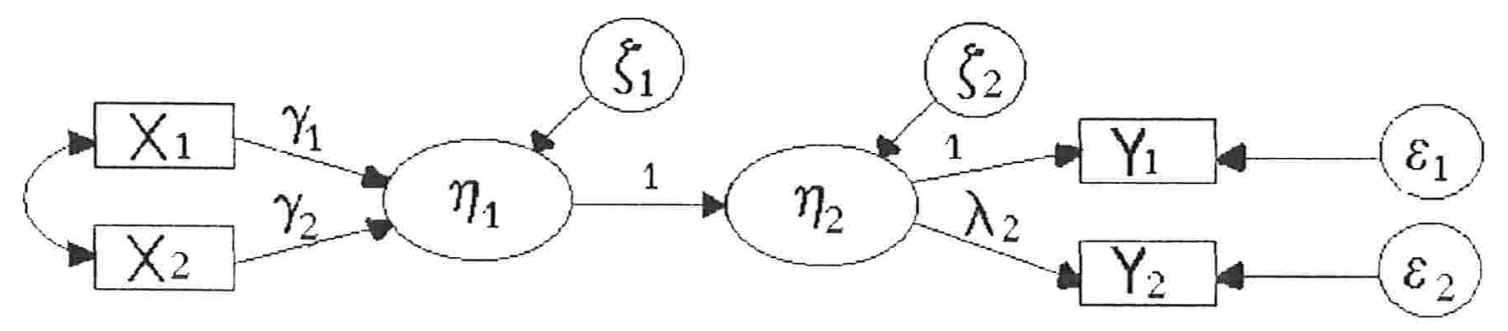

Figura 5.6 - Modelo estrutural com indicadores formativos näo identificado: a variável latente $\eta_{1}$ emite apenas um caminho. 
Tomemos como referência o modelo representado na Figura 5.6, cujo sistema de equações é:

$$
\begin{aligned}
& \eta_{1}=\gamma_{1} x_{1}+\gamma_{2} x_{2}+\zeta_{1} \\
& \eta_{2}=\eta_{1}+\zeta_{2} \\
& Y_{1}=\eta_{2}+\varepsilon_{1} \quad Y_{2}=\lambda_{2} \eta_{2}+\varepsilon_{2}
\end{aligned}
$$

e as covariâncias implicadas:

$$
\begin{aligned}
& \operatorname{Cov}\left(X_{1}, Y_{1}\right)=\operatorname{Cov}\left(X_{1}, \eta_{2}+\varepsilon_{1}\right)=\operatorname{Cov}\left(X_{1}, \eta_{1}+\zeta_{2}+\varepsilon_{1}\right)= \\
& =\operatorname{Cov}\left(X_{1}, \gamma_{1} X_{1}+\gamma_{2} X_{2}+\zeta_{1}+\zeta_{2}+\varepsilon_{1}\right) \\
& =\gamma_{1} \operatorname{Var}\left(X_{1}\right)+\gamma_{2} \operatorname{Cov}\left(X_{1}, X_{2}\right) \\
& \operatorname{Cov}\left(X_{1}, Y_{2}\right)=\lambda_{2}\left(\gamma_{1} \operatorname{Var}\left(X_{1}\right)+\gamma_{2} \operatorname{Cov}\left(X_{1}, X_{2}\right)\right) \\
& \operatorname{Cov}\left(X_{2}, Y_{1}\right)=\gamma_{1} \operatorname{Cov}\left(X_{2}, X_{1}\right)+\gamma_{2} \operatorname{Var}\left(X_{2}\right) \\
& \operatorname{Cov}\left(X_{2}, Y_{2}\right)=\lambda_{2}\left(\gamma_{1} \operatorname{Cov}\left(X_{2}, X_{1}\right)+\gamma_{2} \operatorname{Var}\left(X_{2}\right)\right. \\
& \operatorname{Cov}\left(Y_{1}, Y_{2}\right)=\operatorname{Cov}\left(\eta_{2}+\varepsilon_{1}, \lambda_{2} \eta_{2}+\varepsilon_{2}\right)= \\
& =\operatorname{Cov}\left[\gamma_{1} X_{1}+\gamma_{2} X_{2}+\zeta_{1}+\zeta_{2}+\varepsilon_{1}, \lambda_{2}\left(\gamma_{1} X_{1}+\gamma_{2} X_{2}+\zeta_{1}+\zeta_{2}\right)+\varepsilon_{2}\right] \\
& =\lambda_{2} \gamma_{1}^{2} \operatorname{Var}\left(X_{1}\right)+\lambda_{2} \gamma_{1} \gamma_{2} \operatorname{Cov}\left(X_{1}, X_{2}\right)+\lambda_{2} \gamma_{1} \gamma_{2} \operatorname{Cov}\left(X_{1}, X_{2}\right)+ \\
& +\lambda_{2} \gamma_{2}^{2} \operatorname{Var}\left(X_{2}\right)+\lambda_{2} \operatorname{Var}\left(\zeta_{1}\right)+\lambda_{2} \operatorname{Var}\left(\zeta_{2}\right) \\
& \operatorname{Var}\left(Y_{1}\right)=\operatorname{Var}\left(\eta_{2}+\varepsilon_{1}\right)=\operatorname{Var}\left(\gamma_{1} X_{1}+\gamma_{2} X_{2}+\zeta_{1}+\zeta_{2}+\varepsilon_{1}\right)= \\
& =\gamma_{1}^{2} \operatorname{Var}\left(X_{1}\right)+\gamma_{2}^{2} \operatorname{Var}\left(X_{2}\right)+\operatorname{Var}\left(\zeta_{1}\right)+\operatorname{Var}\left(\zeta_{2}\right)+\operatorname{Var}\left(\varepsilon_{1}\right)+ \\
& +2 \gamma_{1} \gamma_{2} \operatorname{Cov}\left(X_{1}, X_{2}\right) \\
& \operatorname{Var}\left(Y_{2}\right)=\operatorname{Var}\left[\lambda_{2}\left(\gamma_{1} X_{1}+\gamma_{2} X_{2}+\zeta_{1}+\zeta_{2}\right)+\varepsilon_{2}\right]= \\
& =\lambda_{2}^{2} \gamma_{1}^{2} \operatorname{Var}\left(X_{1}\right)+\lambda_{2}^{2} \gamma_{2}^{2} \operatorname{Var}\left(X_{2}\right)+\lambda_{2}^{2} \operatorname{Var}\left(\zeta_{1}\right)+ \\
& +\lambda_{2}^{2} \operatorname{Var}\left(\zeta_{2}\right)+\operatorname{Var}\left(\varepsilon_{2}\right)+2 \lambda_{2}^{2} \gamma_{1} \gamma_{2} \operatorname{Cov}\left(X_{1}, X_{2}\right) .
\end{aligned}
$$

Além das variâncias e covariâncias acima ainda temos as variâncias e covariâncias entre os indicadores formativos, que não têm relação com 
nenhum parâmetro da matriz de variâncias e covariâncias implicadas, e assim são estimadas diretamente. São elas:

$$
\begin{aligned}
& \operatorname{Cov}\left(X_{1}, X_{2}\right)=\operatorname{Cov}\left(X_{1}, X_{2}\right) \\
& \operatorname{Var}\left(X_{1}\right)=\operatorname{Var}\left(X_{1}\right) \\
& \operatorname{Var}\left(X_{2}\right)=\operatorname{Var}\left(X_{2}\right) .
\end{aligned}
$$

Veja que não temos falta de identificação nos parâmetros $\lambda_{2}, \gamma_{1}$ e $\gamma_{2}$. $\mathrm{Na}$ verdade eles estão superidentificados. Com as equações (5.13), (5.14) e (5.15), podemos estimar $\lambda_{2}, \gamma_{1}$ e $\gamma_{2}$ e ainda temos outras equações das quais eles fazem parte, como a (5.16).

Por outro lado os parâmetros $\Psi_{11}, \Psi_{22}, \theta_{11}$ e $\theta_{22}$, que representam $\operatorname{Var}\left(\zeta_{1}\right), \operatorname{Var}\left(\zeta_{2}\right), \operatorname{Var}\left(\varepsilon_{1}\right)$ e $\operatorname{Var}\left(\varepsilon_{2}\right)$, respectivamente, só estão presentes nas equaçōes (5.17), (5.18) e (5.19). Como há apenas três equações para se estimar quatro parâmetros, temos um problema de identificação. Então o que faz com que o modelo seja não identificado são as variâncias dos erros e não os seus coeficientes, portanto, quando utilizamos o FPR continuaremos a ter os mesmos coeficientes e podemos, através do FPR, fazer inferências sobre eles para o modelo original. A título de facilitar a visualização e compreensão apresentamos 0 FPR da Figura 5.6 na Figura 5.7.

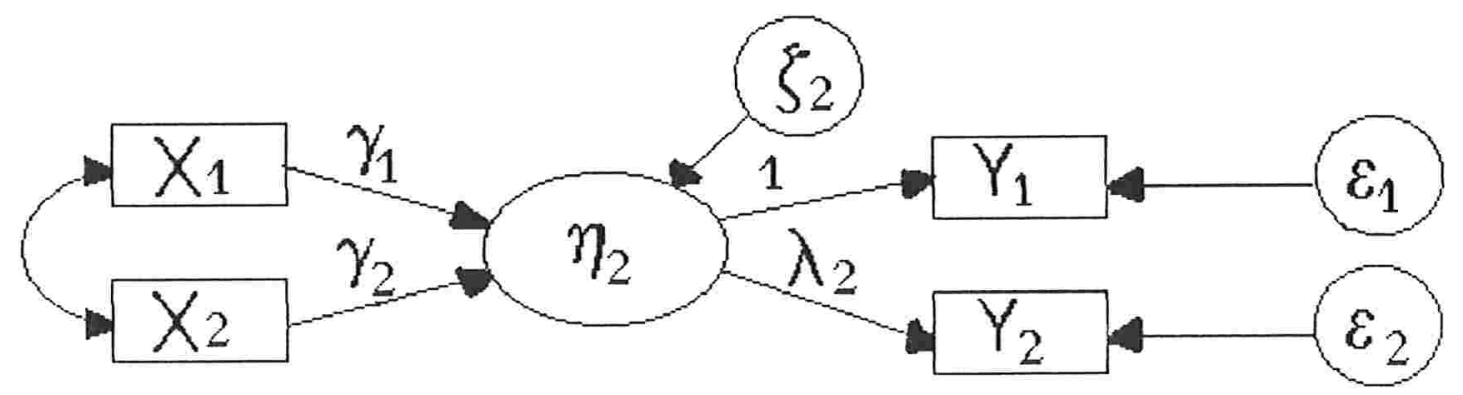

Figura 5.7 - Modelo da Figura 5.6 representado na sua forma parcialmente reduzida (FPR). 
O fato da inferência no FPR tanto sobre o ajuste do modelo completo como sobre a significância dos parâmetros de forma isolada serem válidas para o modelo original acontece porque "o modelo original e o FPR são matematicamente iguais", como explicam Bollen e Davis (1994a). Observe que no FPR apenas não teremos informações sobre $\Psi_{11}$ e $\Psi_{22}$ do modelo original. Na verdade, neste caso usar o FPR é como usar a equação (5.17) para identificar $\Psi_{11}+\Psi_{22}$, e, substituindo seus valores em (5.18) e (5.19), estimar $\theta_{11}$ e $\theta_{22}$.

O exemplo que acabamos de mostrar é uma situação muito interessante para o uso do FPR porque a eliminação de apenas uma variável latente não causou muitas mudanças no modelo, sendo que o FPR ainda ficou bem parecido com o modelo original. No entanto, há casos, como o modelo apresentado em MacCallum e Browne (1993), em que o FPR é muito diferente do modelo original e neste caso pode haver a perda de coeficientes no modelo original, que eram importantes para o pesquisador. Então o analista pode se ver de frente com o problema de não ter no FPR informações que ele gostaria ou precisaria ter. Esta se constitui em uma limitação do uso do FPR para o estudo de modelos com indicadores formativos não identificados.

Vimos o uso do FPR apenas para modelos onde variáveis latentes com indicadores formativos contêm somente um caminho. Mas, mesmo havendo a emissão de dois ou mais caminhos, o modelo pode ainda ser não identificado. Geralmente isso acontece se as variáveis latentes influenciadas pelo constructo com indicadores formativos possuem relação causal entre si. Neste caso ainda pode existir o FPR e para se chegar a ele exclui-se a variável latente com indicadores formativos, traçando caminhos diretamente dos indicadores formativos até todos os constructos influenciados pela variável latente excluída. Deve-se excluir também qualquer relação causal que exista entre as variáveis latentes remanescentes, e no lugar colocar erros correlacionados. A Figura 5.8 apresenta um exemplo deste método. O primeiro modelo é não identificado e o segundo é o seu FPR. 


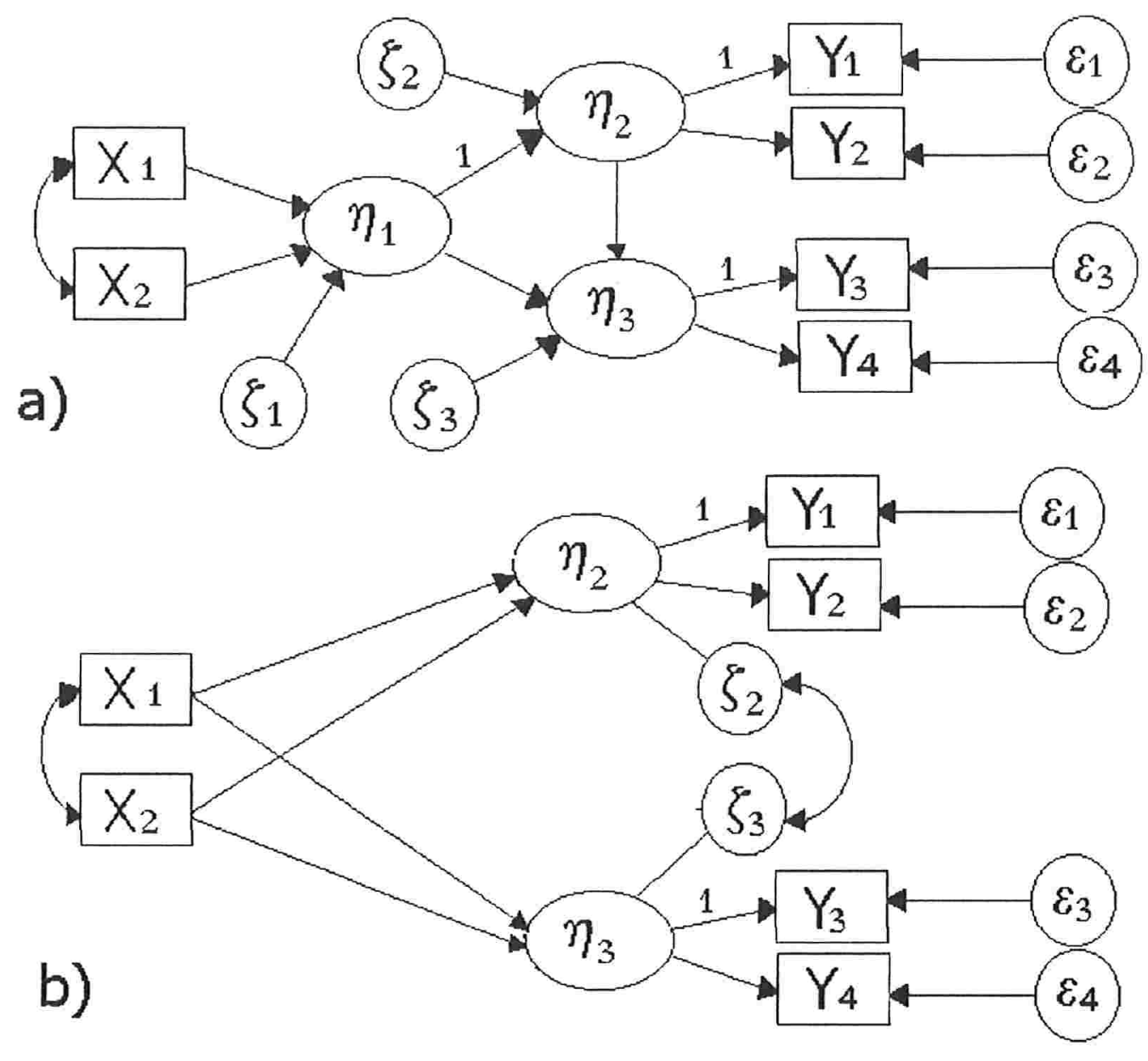

Figura 5.8 - a) Um modelo estrutural com indicadores formativos não identificado e b) Sua Forma Parcialmente Reduzida.

Uma forma alternativa de identificar o modelo da Figura 5.8a e outros similares seria excluir o termos de erros de $\eta_{1}$ e correlacionar $\zeta_{2} \operatorname{com} \zeta_{3}$. Bollen e Davis (1994a) chamam este modelo de "Zero Error Variance Model", que traduzimos como Modelo com Erro de Variância igual a Zero - MVZ. Isto decorre do fato de que $\eta_{1}$ passa a não ter erro, ou também poderíamos dizer, tem erro com média e variância iguais a zero. Esta forma pode possibilitar a comparação de mais parâmetros com o modelo inicial não identificado do que o FPR. A Figura 5.9 apresenta o diagrama de caminho para o MVZ da Figura 5.8a. 


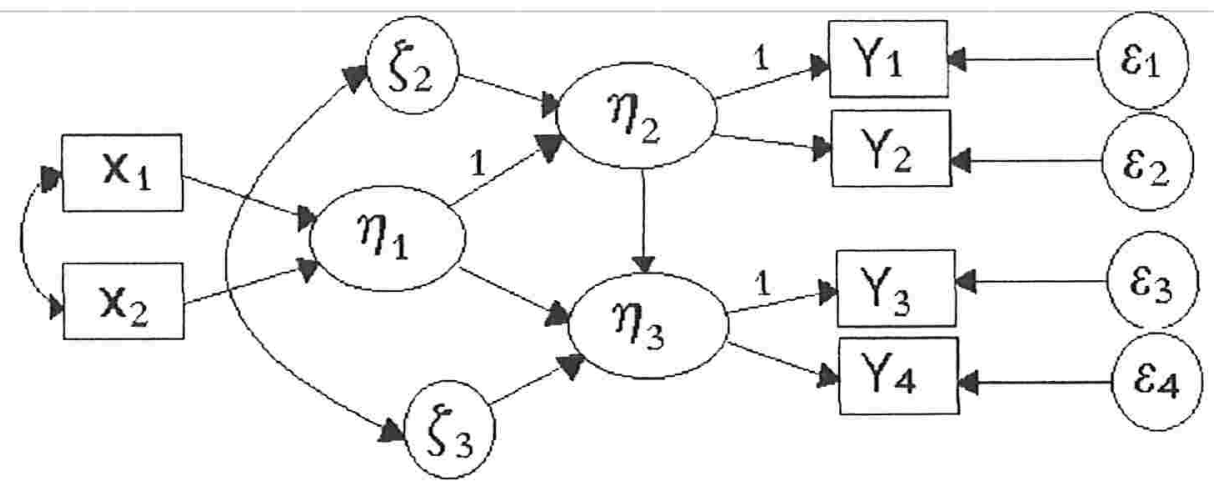

Figura 5.9 - Diagrama de caminho para o MVZ da Figura 5.8a.

\section{4 - A Restrição de Proporcionalidade}

A restrição de proporcionalidade está presente em um modelo sempre que temos uma variável latente que serve como intermediadora para todo o efeito de duas ou mais variáveis exógenas em duas ou mais variáveis endógenas. Este é o caso comum dos modelos do tipo MIMIC. Para facilitar a compreensão, considere o MIMIC da Figura 5.10, cujo sistema de equações, já em forma reduzida, é:

$$
\begin{aligned}
& Y_{1}=\gamma_{1} X_{1}+\gamma_{2} X_{2}+\zeta_{1}+\varepsilon_{1} \\
& Y_{2}=\lambda_{2} \gamma_{1} X_{1}+\lambda_{2} \gamma_{2} X_{2}+\lambda_{2} \zeta_{1}+\varepsilon_{2} \\
& Y_{3}=\lambda_{3} \gamma_{1} X_{1}+\lambda_{3} \gamma_{2} X_{2}+\lambda_{3} \zeta_{1}+\varepsilon_{3} .
\end{aligned}
$$

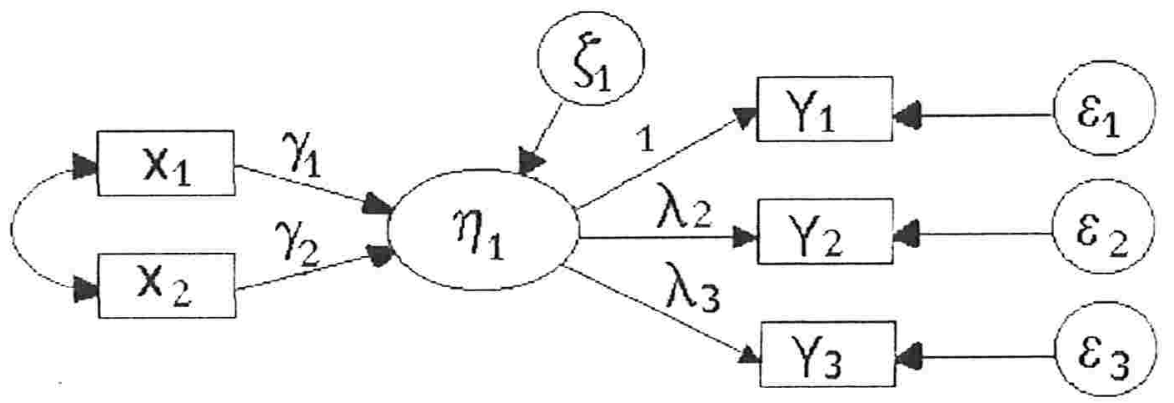

Figura 5.10 - Exemplo de modelo MIMIC que implica em restrição de proporcionalidade. 
Observe que podemos expressar o parâmetro $\lambda_{2}$ como uma razão entre os coeficientes de $X$ na equação de $Y_{2}$ e os coeficientes de $X$ na equação de $Y_{1}$. O mesmo vale para o parâmetro $\lambda_{3}$. No caso de $\lambda_{2}$ temos:

$$
\lambda_{2}=\frac{\lambda_{2} \gamma_{1}}{\gamma_{1}}=\frac{\lambda_{2} \gamma_{2}}{\gamma_{2}}
$$

Hauser e Goldberger (1971) expressam a mesma restrição de uma forma um pouco diferente, usando correlações. Esta relação de proporcionalidade que existe entre os coeficientes de $X_{1}$ e $X_{2}$ é obrigatória se o modelo está corretamente especificado. $O$ fato de existir esta relação entre os coeficientes de $X_{1}$ e $X_{2}$ faz com que exista também uma superidentificação do parâmetro $\lambda_{2}$. No exemplo é como se ele pudesse ser estimado por duas proporções diferentes (veja Hauser e Goldberger (1971)). Quando o modelo é estimado, a equação (5.20) não será exatamente verdadeira, isto é, a razão entre os coeficientes estimados de $X$ nas duas equações não será igual, mas se o modelo é correto o erro que se encontra deve ser devido somente a flutuações amostrais.

A restrição de proporcionalidade pode ser uma ferramenta útil para se estudar a existência da variável latente com indicadores formativos como intermediadora dos efeitos dos indicadores formativos.

Quando o modelo é identificado, o ajuste do mesmo pelos atuais softwares já leva em conta a restrição de proporcionalidade. Se o ajuste do modelo é bom, nada temos a fazer pois o nosso modelo já é considerado correto. Se, porém, o modelo falhou nos testes de ajuste, então existe algo errado com o mesmo e pode ser que a restrição de proporcionalidade não seja válida (está sendo imposta mas não deveria). Uma forma para se testar essa hipótese é ajustar o respectivo FPR, que não contém a restrição de proporcionalidade. Como um modelo é hierárquico ao outro, pode-se inferir a significância da restrição de proporcionalidade pela diferença no valor da estatística qui-quadrado entre os dois modelos. 
Ressaltamos que o MVZ ainda mantém a restrição de proporcionalidade, por isso mesmo nos modelos não identificados ainda é possivel testar essa restrição ajustando o FPR e o MVZ e verificando a significância da diferença entre seus valores do qui-quadrado.

Bollen e Davis (1994a) dizem que se um teste concluir que a retirada da restrição de proporcionalidade é significante, isso pode ter dois motivos: (1) a variável latente com indicadores formativos não é uma intermediadora dos efeitos dos indicadores formativos como foi postulado inicialmente ou (2) existe pelo menos um indicador formativo que afeta alguma variável que não é afetada pela variável latente com indicadores formativos. Neste caso o pesquisador deve verificar a teoria sobre a qual se baseou para construir o modelo, ou exploratoriamente ele pode também recorrer aos índices de modificação (veja Capítulo 1, Seção 1.2.9.2).

A diferenciação entre indicadores formativos e reflexivos é um tema que poderia ser tratado dentro da teoria dos indicadores formativos, ou seja, neste capítulo. No entanto a sua importância nos fez optar pela inclusão de um novo capítulo para tratar deste assunto. Assim, veremos a seguir as ferramentas existentes para nos ajudar a decidir se nossos indicadores são formativos ou reflexivos. 


\section{Capítulo 6 - Especificação da Direção da Causa}

No Capítulo 2 discutimos um pouco sobre as relações causais entre variáveis, e um dos tópicos abordados foi a direção da causa. Falamos rapidamente então sobre algumas regras básicas para se tentar inferir a direção da causa como, por exemplo, a verificação da precedência temporal entre as variáveis, ou a realização de experimentos. Estas técnicas, bem como todo o texto que incluímos no Capitulo 2, diz respeito a variáveis de uma forma geral, no contexto de modelagem, e não foi direcionado de alguma forma a indicadores de modelos estruturais.

Neste capítulo queremos ser mais específicos, isto é, falar sobre a direção causal especificamente relacionada a indicadores em modelos estruturais. Já mencionamos algumas vezes o quanto é importante que indicadores formativos e reflexivos sejam corretamente especificados como tais nos modelos estruturais, e agora vamos discorrer sobre métodos para se especificar a direção da causa. Infelizmente este não é um dos assuntos mais tratados na literatura, e quando falamos de especificação correta da direção de indicadores apenas duas referências aparecem como indispensáveis, além de várias outras que são gerais e levam ao exposto no Capítulo 2, que não vamos repetir aqui. As duas referências, coincidentemente publicadas no mesmo ano, são Bollen e Ting (2000) e Edward e Bagozzi (2000). A primeira usa a teoria já antiga dos tétrades em modelos de Análise Fatorial para desenvolver um teste que, sob algumas suposições, pode pelo menos nos ajudar a concluir algo sobre a direção da causa entre indicadores e constructos. A segunda referência, menos teórica, chega a algumas "máscaras" básicas nas quais todos os casos de modelos estruturais se encaixariam, e uma vez determinada a "máscara", o tipo de indicador é automaticamente revelado.

A seguir falaremos sobre estes dois métodos, o que ocasionará a divisão deste capítulo em duas seções, cada uma referente a um artigo. Começamos com Bollen e Ting (2000). 


\section{1 - O Uso de Tétrades para a Especificação da Direção Causal}

A palavra "tétrade", que traduzimos por nossa conta do inglês "tetrad", diz respeito a certas diferenças entre produtos de covariâncias nos modelos de Análise Fatorial e nos modelos estruturais, que devem ser nulas se a estrutura do modelo está corretamente especificada.

Geralmente o tétrade é representado pela letra grega $\tau$ (tau) seguida de quatro números cuja ordem indica quais covariâncias estamos usando. Assim, de acordo com o padrão seguido por Bollen e Ting (1993), que também adotamos aqui, $\tau_{\mathrm{abcd}}$ é um tétrade cuja equação em termos de covariâncias é $\sigma_{\mathrm{ab}} \sigma_{\mathrm{cd}}-\sigma_{\mathrm{ac}} \sigma_{\mathrm{bd}}$, onde $\sigma_{a b}=\operatorname{Cov}\left(X_{a}, X_{b}\right), X_{a}$ e $X_{b}$ sendo dois indicadores.

Os tétrades são conhecidos há bastante tempo. Spearman (1927) demonstrou que um único fator que tem quatro ou mais indicadores reflexivos implica na existência de alguns tétrades que devem ser iguais a zero, exceto por variações amostrais. Esta condição que caracteriza alguns tétrades em modelos com variáveis latentes com quatro ou mais indicadores fez com que estes tétrades fossem muito mencionados na literatura como "vanishing tetrads", termo em inglês que vamos traduzir por "tétrades nulos" neste texto. Assim, podemos dizer que os modelos estruturais geralmente implicam na existência de certos tétrades nulos.

Ao ajustar um modelo que representa bem os dados, devemos esperar, portanto, que alguns tétrades, calculados como função dos parâmetros do modelo tenham valor aproximadamente igual a zero, qualquer diferença se devendo a flutuações amostrais. Isso faz com que tenhamos uma forma alternativa de testar o modelo que consiste em se testar se os tétrades nulos são realmente iguais a zero. Com base nisso foi desenvolvida a "Análise de Tétrades Exploratória" por Glymour et al. (1987), e posteriormente a "Análise de Tétrades Confirmatória", por Bollen e Ting (1993). Existem meios para se testar se os tétrades nulos são iguais a zero de forma individual ou simultânea, mesmo para dados não normais, ou para correlações ao invés de covariâncias - Bollen (1990).

Mostraremos agora como um modelo que contém uma variável latente com quatro ou mais indicadores reflexivos implica na existência dos 
tétrades nulos. Para isso, suponha o modelo apresentado na Figura $6.1 \mathrm{a}$, cujo sistema de equações é:

$$
\begin{aligned}
& X_{1}=\lambda_{1} \xi_{1}+\delta_{1} \\
& X_{2}=\lambda_{2} \xi_{1}+\delta_{2} \\
& X_{3}=\lambda_{3} \xi_{1}+\delta_{3} \\
& X_{4}=\lambda_{4} \xi_{1}+\delta_{4}
\end{aligned}
$$

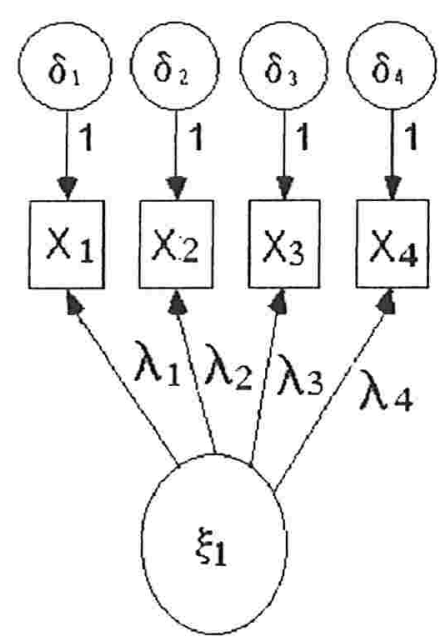

a)

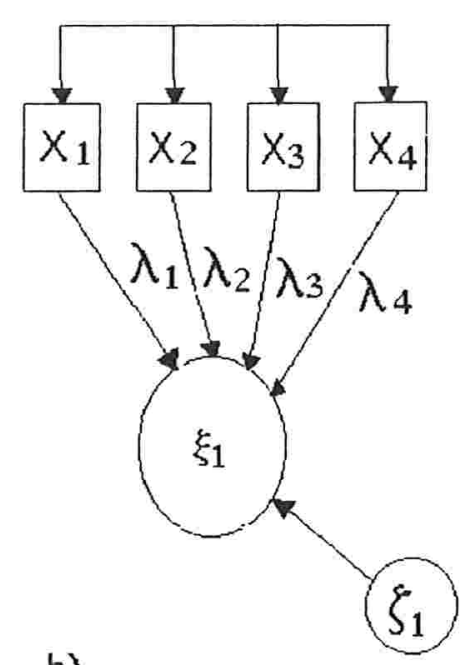

b)

Figura 6.1 - a) Esquema de uma variável latente com quatro indicadores reflexivos e b) Esquema de uma variável latente com quatro indicadores formativos.

Um dos tétrades nulos implicados por este modelo é $\tau_{1234}=\sigma_{12} \sigma_{34}$ $\sigma_{13} \sigma_{24}=0$, como vemos a seguir. Antes de desenvolver toda a expressão para este tétrade nulo, vamos encontrar a expressão das quatro covariâncias usadas em termos de parâmetros do modelo. Temos então:

$$
\sigma_{12}=\operatorname{Cov}\left(X_{1}, X_{2}\right)=\operatorname{Cov}\left(\lambda_{1} \xi_{1}+\delta_{1}, \lambda_{2} \xi_{1}+\delta_{2}\right)=\lambda_{1} \lambda_{2} \phi
$$


em que $\phi=\operatorname{Var}\left(\xi_{1}\right)$, e onde estamos supondo que os erros $\delta_{\mathrm{i}}$ são não correlacionados entre si e com a variável latente $\xi_{1}$. Da mesma forma

$$
\begin{aligned}
& \sigma_{34}=\lambda_{3} \lambda_{4} \phi \\
& \sigma_{13}=\lambda_{1} \lambda_{3} \phi \\
& \sigma_{24}=\lambda_{2} \lambda_{4} \phi
\end{aligned}
$$

e, representado como função dos parâmetros do modelo, o tétrade em questão fica:

$$
\begin{aligned}
\tau_{1234} & =\sigma_{12} \sigma_{34}-\sigma_{13} \sigma_{24} \\
\tau_{1234} & =\lambda_{1} \lambda_{2} \lambda_{3} \lambda_{4} \phi^{2}-\lambda_{1} \lambda_{2} \lambda_{3} \lambda_{4} \phi^{2}=0 .
\end{aligned}
$$

Assim como $\tau_{1234}$, o modelo implica que $\tau_{1342}$ e $\tau_{1423}$ também sejam tétrades nulos. A idéia para se verificar a adequação do modelo consiste, como dissemos, em se testar se esses tétrades diferem significativamente de zero.

Antes, porém, de fazermos os testes, dois assuntos importantes devem ser tratados: como encontrar todos os tétrades nulos implicados pelo modelo e como identificar os tétrades nulos redundantes. Trataremos ambos de forma breve aqui, mas uma abordagem completa pode ser encontrada em Bollen e Ting (1993).

Mostramos que $\tau_{1234}=0$ para o modelo da Figura 6.1a por meio da representação das covariâncias como funções dos parâmetros do modelo. Este é um dos métodos, um método direto, que podemos usar para saber quais dos tétrades devem ser nulos de acordo com um determinado modelo, mas ele pode tornar-se trabalhoso demais quando temos muitos indicadores. Uma regra mais prática para grandes modelos diz que um tétrade é nulo se:

a) nenhuma de suas quatro covariâncias envolve variáveis com erros correlacionados - uma covariância desobedece esta condição se, por exemplo, $\tau_{\mathrm{ij}}=\operatorname{Cov}\left(\mathrm{X}_{\mathrm{i}}, \mathrm{X}_{\mathrm{j}}\right)$ faz parte do tétrade e $\operatorname{Cov}\left(\delta_{\mathrm{i}}, \delta_{\mathrm{j}}\right) \neq 0, \mathrm{e}$, 
b) as variáveis latentes a que estão relacionadas as duas primeiras covariâncias do tétrade são as mesmas a que estão relacionadas as duas outras covariâncias - então, dado $\tau_{i j k l}=\sigma_{i j} \sigma_{k l}-\sigma_{i k} \sigma_{j l}$ e se $\left(X_{i}, X_{j}-\right.$ de $\left.\sigma_{i j}\right)$ são relacionados a $\left(\xi_{1}, \xi_{2}\right)$ e $\left(X_{k_{1}} X_{1}-\right.$ de $\left.\sigma_{k}\right)$ são relacionados a $\left(\xi_{3}, \xi_{4}\right)$, a regra é satisfeita se $\left(X_{i}, X_{k}-\right.$ de $\left.\sigma_{i k}\right)$ e $\left(X_{j}, X_{1}-\right.$ de $\left.\sigma_{j l}\right)$ se relacionarem respectivamente a $\left(\xi_{1}, \xi_{2}\right)$ e $\left(\xi_{3}, \xi_{4}\right)$ obrigatoriamente para que o tétrade seja nulo.

Um último método, que Bollen e Ting (1993) chamam de método empírico, consiste em se usar um software de ajuste de modelos estruturais, e é talvez o mais acessível para grandes modelos. Uma vez definido o modelo, atribuem-se valores arbitrários aos parâmetros e usa-se o modelo para encontrar a matriz de covariância implicada. Então simplesmente calculam-se todos os tétrades e aqueles que foram iguais a zero são os tétrades nulos. Pode acontecer de algum tétrade ser muito próximo de zero, gerando dúvidas se ele é ou não um tétrade nulo. Este caso é improvável, mas se acontecer recomenda-se o uso do método algébrico direto para se assegurar a condição do tétrade em questão.

O outro tema relacionado que vamos comentar aqui são os tétrades redundantes.

No modelo da Figura 6.1a vimos que são implicados três tétrades nulos:

$$
\begin{aligned}
& \tau_{1234}=\sigma_{12} \sigma_{34}-\sigma_{13} \sigma_{24} \\
& \tau_{1342}=\sigma_{13} \sigma_{42}-\sigma_{14} \sigma_{32} \\
& \tau_{1423}=\sigma_{14} \sigma_{23}-\sigma_{12} \sigma_{43} .
\end{aligned}
$$

Mas é fácil ver que $-\left(\tau_{1234}-\tau_{1342}\right)=\tau_{1423}$, ou seja, o terceiro tétrade nulo é uma combinação dos dois primeiros. Na verdade, no caso acima, qualquer dois tétrades que escolhêssemos poderiam ser combinados para se obter 0 terceiro. Isto significa que um dos três tétrades nulos deve ser excluído, pois ele é redundante quando temos os outros dois, que são chamados de tétrades 
independentes, idéia que é muito parecida com a de espaços vetoriais independentes.

Antes de fazer os testes dos tétrades nulos devemos ter o cuidado de eliminar todos os tétrades redundantes. Isto pode ser feito através da comparação dos tétrades dois a dois. Se dois tétrades têm em comum duas covariâncias, então eles implicam num terceiro que é redundante. No exemplo anterior podemos ver que $\tau_{1234}$ e $\tau_{1342}$ têm em comum as covariâncias $\sigma_{13}$ e $\sigma_{24}$. Se somarmos estes dois tétrades de modo a cancelar estas covariâncias, obtemos um terceiro tétrade nulo, que é redundante, e deve ser desconsiderado. Esta parece ser a única forma de se eliminar os tétrades redundantes de um conjunto de tétrades nulos implicados por determinado modelo.

Uma vez que temos os tétrades nulos não redundantes, podemos testar se eles são significativamente diferentes de zero. Bollen (1990) desenvolveu um teste simultâneo para todos os tétrades nulos implicados em um modelo, o qual apresentaremos resumidamente aqui. No entanto, Spearman e Holzinger (1924), Kelley (1928), Wishart (1928) e Kenny (1974) são artigos que desenvolvem testes individuais e assintóticos para tétrades nulos.

O teste a seguir é apropriado para testar $H_{0}: \tau=\tau_{0}$ contra $H_{a}: \tau \neq \tau_{0}$, onde para nós interessa o caso em que $\tau$ é o vetor dos tétrades nulos não redundantes implicados pelo modelo e $\tau_{0}$ é um vetor de zeros, ou seja, nossa hipótese nula é que o vetor de tétrades nulos $\tau$ é igual a zero.

A estatística

$$
T=N \tau^{3} \sum_{t t}^{-1} \tau
$$

Tem, sob $\mathrm{H}_{0}$, uma distribuição assintótica qui-quadrado, com o número de graus de liberdade igual ao número de elementos em $\tau$. Essa distribuição independe da distribuição dos dados - Bollen (1990) e Bollen e Ting (1993). A letra N denota o tamanho da amostra e $\sum_{\mathrm{tt}^{-1}}$ é a inversa da matriz das covariâncias dos tétrades nulos. 
Seguindo os passos de Bollen e Ting (2000) $\sum_{\text {tt }}$ pode ser obtida por intermédio da matriz de covariância das covariâncias que aparecem nos tétrades nulos independentes a serem testados. Cada uma destas covariâncias pode ser chamada de $\delta_{\mathrm{gl}}$ e a matriz de covariâncias entre elas, de $\Sigma_{\mathbf{s s}}$. O estimador de um elemento de $\Sigma_{\mathbf{s s}}$, digamos, $\left[\Sigma_{\mathbf{s s}}\right]_{\text {ef,gh }}$ é dado por

$$
\left[\Sigma_{\mathrm{ss}}\right]_{\mathrm{ef}, \mathrm{gh}}=\delta_{\mathrm{efgh}}-\delta_{\mathrm{ef}} \delta_{\mathrm{gh}}
$$

onde $\delta_{\text {efgh }}$ é o momento de quarta ordem para as variáveis $X_{e}, X_{f}, X_{g}$ e $X_{h}$ cujo estimador é:

$$
\delta_{\text {efgh }}=\frac{1}{N} \sum_{e, f, g, h}\left(x_{e}-\bar{x}_{e}\right)\left(x_{f}-\bar{x}_{f}\right)\left(x_{g}-\bar{x}_{g}\right)\left(x_{h}-\bar{x}_{h}\right)
$$

Tendo estimado $\Sigma_{\mathbf{s s}}, \Sigma_{\mathbf{t t}}$ pode ser estimado pela expressão:

$$
\Sigma_{\mathbf{t t}}=(\partial \tau / \partial \delta)^{\prime} \sum_{\mathbf{s s}}(\partial \tau / \partial \delta)
$$

onde $\partial \tau / \partial \tau$ é a derivada do vetor $\tau$ de tétrades nulos em relação ao vetor $\delta$, das covariâncias que aparecem nestes tétrades nulos.

Uma observação importante a respeito deste teste é que ele pode ser feito sobre um grupo de indicadores, por exemplo, todos os indicadores de uma variável latente, e independe de o modelo ser ou não identificado.

Até agora vimos como testar se determinados tétrades nulos implicados pelo modelo são ou não iguais a zero depois de ajustados aos dados. Se não rejeitarmos a hipótese de que eles são iguais a zero, então temos uma evidência de que o modelo está corretamente especificado. Esta é a base da análise de tétrades, que se assemelha à Análise Fatorial, mas que não é o 
objetivo deste texto. Mostraremos, porém, como Bollen e Ting (2000) propõem usar este teste para a determinação da direção da causa entre uma variável latente e um indicador.

A idéia de se utilizar os tétrades nulos para diferenciar indicadores formativos de indicadores reflexivos é bem simples. Suponha o modelo da Figura $6.1 \mathrm{~b}$, no qual os indicadores são formativos. Neste caso a equação do modelo seria:

$$
\xi_{1}=\lambda_{1} X_{1}+\lambda_{2} X_{2}+\lambda_{3} X_{3}+\lambda_{4} X_{4}+\zeta_{1}
$$

e o modelo não implicaria em nenhum tétrade nulo. Assim, se rejeitarmos a hipótese de que os tétrades nulos implicados pelo modelo com indicadores reflexivos são iguais a zero, temos uma certa evidência de que, na verdade, os indicadores devem ser formativos. Se tivermos evidências de que os tétrades nulos são iguais a zero, então o modelo com indicadores reflexivos está se ajustando bem aos dados e deve ser o mais correto. Mas veja que esta conclusão possibilitada pelo teste só faz sentido se antes de fazer o teste dos tétrades já tivermos certeza de que a estrutura do modelo está correta. Ainda mais que isso, nossa única dúvida deve ser com relação à direção da causa entre a variável latente e os seus indicadores. Devemos, ao decidir fazer o teste, estar seguros de que uma falha no teste só pode ser causada por uma especificação errada da direção da causa.

Mesmo com indicadores formativos poderíamos vir a ter algum tétrade nulo igual a zero, se os indicadores forem não correlacionados ou tiverem correlação próxima de zero. Para saber se isto é o que faz com que os tétrades nulos sejam realmente iguais a zero, Bollen e Ting (2000) sugerem que se faça um teste de hipótese simples de que cada covariância é igual a zero, ou que se verifique se alguns dos coeficientes ou algumas das variâncias das variáveis latentes são significativamente diferentes de zero.

O teste de tétrades somente é possivel quando estamos em dúvida entre dois modelos hierarquicamente relacionados com relação aos tétrades nulos 
implicados. Os dois modelos da Figura 6.1 satisfazem essa condição, já que o modelo em 6.1a implica em três tétrades nulos e o modelo em $6.1 \mathrm{~b}$ não implica em nenhum. Neste caso particular temos apenas que verificar a estatística quiquadrado do modelo em 6.1a porque em $6.1 \mathrm{~b}$ ela é igual a zero. Na verdade estamos comparando então dois modelos, um com quatro indicadores formativos e outro com quatro indicadores reflexivos. Mas pode haver casos em que achamos mais aceitável a hipótese de que há, por exemplo, dois indicadores formativos e dois reflexivos, ao invés de quatro formativos, e um modelo desses não necessariamente implica na ausência de tétrades nulos. Assim temos que verificar a diferença entre as estatisticas qui-quadrado para os dois modelos, e analisar se esta diferença é significativa, considerando que ela tem uma distribuição qui-quadrado com número de graus de liberdade igual a diferença dos graus de liberdade dos modelos usados.

Se a diferença é significativa, devemos ficar com o modelo com menor número de tétrades nulos implicados.

Em Bollen e Ting (2000), página 9, tem-se uma lista bem completa das possíveis configurações com 4 indicadores e um constructo. Os autores mostram quais os tétrades implicados em cada configuração, de forma que, usando esta lista, o pesquisador pode facilmente definir duas configurações em hierarquia, tal que seja possivel verificar com o teste dos tétrades qual é a mais adequada.

De posse de um modelo com apenas quatro indicadores, ou de modelos que podem ser divididos em submodelos menores, onde essas partes menores se encaixam em uma destas configurações, uma consulta a esta lista facilita muito o trabalho se o objetivo é usar essa técnica de análise de tétrades nulos.

Se o modelo tem mais de quatro indicadores, então qualquer combinação de quatro indicadores será um caso particular de um dos casos mostrados em Bollen e Ting (2000) e assim torna-se fácil saber quais e quantos tétrades nulos são implicados em cada uma das possiveis combinações. A soma destes tétrades são os tétrades nulos implicados pelo modelo completo. 
No caso onde um constructo tem apenas três indicadores, não é possivel obviamente que se tenha algum tétrade nulo implicado, pois os tétrades como definimos, são compostos por covariâncias entre quatro variáveis. Um procedimento possivel a ser usado para resolver este problema é tomar emprestado de outro constructo um indicador, como é mostrado na Figura 6.2.

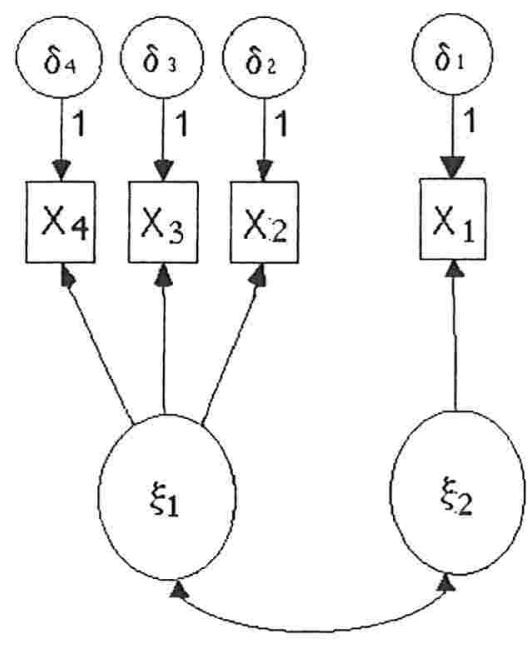

Figura 6.2 - Representação esquemática de uma situação onde toma-se emprestado um indicador de um constructo vizinho para tornar possível a análise de tétrades.

Usando álgebra e as propriedades das covariâncias, pode-se mostrar que o modelo na Figura 6.2 implica em 3 tétrades nulos: $\tau_{1234}, \tau_{1342}$ e $\tau_{1423}$. O teste deste modelo contra um modelo alternativo que esteja em uma escala hierárquica diferente deste (implicando mais ou menos tétrades nulos) pode ser feito normalmente para se concluir qual o melhor modelo.

Para o caso similar onde temos somente dois indicadores em um constructo, a idéia é semelhante: tomam-se dois indicadores emprestados de outra variável latente.

Bollen e Ting (2000) mostram no apêndice, o diagrama de caminho de uma série de configurações possíveis com dois ou três indicadores por variável latente, e seus tétrades nulos implicados. Este apêndice é um guia muito útil para o pesquisador que deseja executar os testes que acabamos de mencionar. 


\section{2 - Modelos para o Relacionamento entre Constructo e Indicador}

Com o argumento de que a especificação do modelo com a determinação de sua estrutura e das direções das relações causais devem ser o primeiro passo a ser tomado antes de qualquer teste post-hoc, Edward e Bagozzi (2000) escreveram um texto que pode ser usado como um guia para a determinação da direção da causa entre constructos e indicadores, e conseqüentemente, diferenciação entre indicadores formativos de reflexivos. Segundo os autores, é de primária importância que o pesquisador encontre a forma de seu modelo inicialmente para só depois se preocupar com assuntos como identificação e estimação.

O fato é que quando estamos falando de direção da causa, Edward e Bagozzi (2000) torna-se uma das referências importantes no assunto, embora seu artigo tenha o objetivo de resolver também o problema da definição da estrutura do modelo no relacionamento constructo-indicador.

Quando outros métodos mais diretos e simples não se aplicam, a direção da causa poderia ser determinada pela classificação do problema em questão em um dos "Modelos de Relação entre Constructo e Indicador" - Edward e Bagozzi (2000).

A princípio podem existir 6 tipos de relações constructo-indicador nas quais qualquer problema deve se encaixar para ser logicamente coerente. Uma vez definida qual das 6 relações é a mais apropriada para o estudo, a direção causal já estaria automaticamente determinada. A seguir comentamos cada um destes tipos.

a) Modelo Reflexivo Direto - É a relação usual entre indicadores e constructos, onde o constructo é responsável pelas mudanças no indicador. Além dos modelos estruturais esta é a relação presente nos modelos de Análise Fatorial Confirmatória. A Figura 6.3 mostra a estrutura deste modelo de relacionamento. 


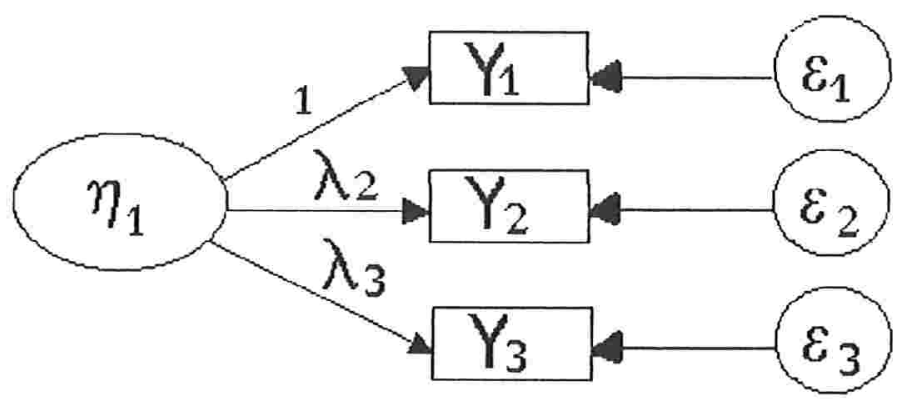

Figura 6.3 - Modelo Reflexivo Direto.

b) Modelo Formativo Direto - É O tipo usual de relação entrie indicadores formativos e variáveis latentes, onde o indicador causa a variável latente. Neste caso não se espera que o constructo explique as variâncias e covariâncias entre as variáveis observadas porque ele não é a causa mas sim é causado por elas. Este modelo é apresentado na Figura 6.4.

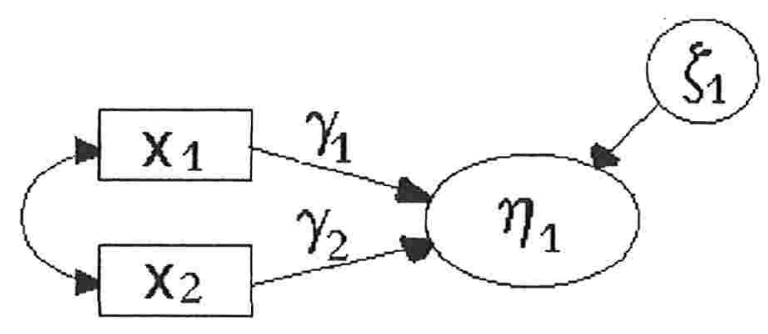

Figura 6.4 - Modelo Formativo Direto.

c) Modelo Reflexivo Indireto - É um tipo de relacionamento análogo aos que existem entre os fatores de segunda ordem e os indicadores. $O$ fator de interesse não causa diretamente o indicador, mas tem seu efeito intermediado por um ou mais fatores que causam diretamente os indicadores. Veja Figura 6.5. 


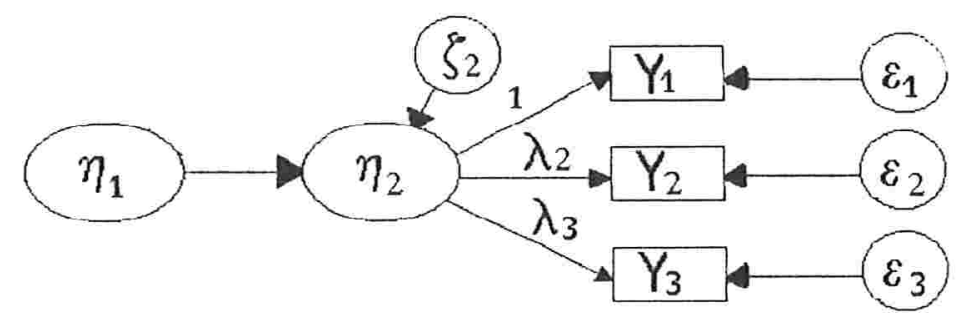

Figura 6.5 - Modelo Reflexivo Indireto - a relaçăo reflexiva indireta é aquela que existe entre os indicadores e $\eta_{1}$.

d) Modelo Formativo Indireto - Neste tipo de relação os indicađórēes formativos não causam diretamente os fatores de interesse. Ao invés disso eles têm sua causa direcionada para um ou mais fatores intermediários que por sua vez causarão diretamente o fator de interesse. A Figura 6.6 mostra um exemplo simplificado deste tipo de modelo.

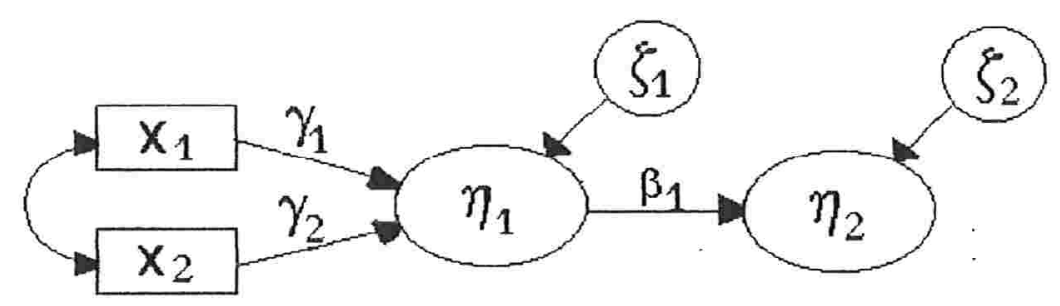

Figura 6.6 - Modelo Formativo Indireto - a relação entre os indicadores e $\eta_{2}$ é formativa indireta.

e) Modelo Espúrio - A relação entre o constructo de interesse e os indicadores reflexivos não é direta nem indireta. Ao invés disso temos um ou mais constructos que causam ambos o constructo de interesse e os indicadores reflexivos. Suponha, por exemplo, que temos um constructo $\xi$ que tem ação de causa nos indicadores $X_{i}, i=1,2,3, \ldots, n$, e também no constructo $\eta$. Como a mesma variável causa os indicadores $X_{i}$ e o constructo $\eta$, existe uma relação entre os indicadores e o constructo $\eta$ que pode ser calculada, e então o caso é de interesse porque estamos falando de tipos possiveis de relação entre constructo e indicador. Se no exemplo anterior tivéssemos $\xi_{1}, \xi_{2}, \ldots, \xi_{p}$, todos com indicadores 
reflexivos e todos causando $\eta$, então teríamos ainda uma forma de modelo espúrio. A Figura 6.7 representa um exemplo de modelo espúrio.

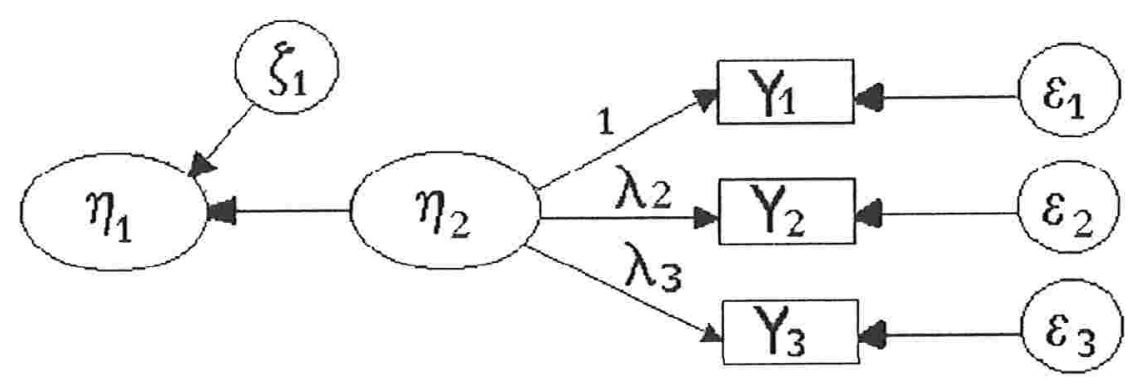

Figura 6.7 - Modelo Espúrio - a relaçäo entre $\eta_{1}$ e os indicadores é considerada espúria.

f) Modelo não Analisável - São tipos bem incomuns de relações entre um constructo e indicadores, onde a relação só existe por causa de uma correlação no diagrama de caminho. Suponha, por exemplo, que temos três variáveis observadas $X_{1}, X_{2}$ e $X_{3}$, e um constructo de interesse $\xi_{1}$, sendo que todos estas quatro variáveis são correlacionadas. Neste caso temos uma relação não analisável entre o constructo e os indicadores, veja Figura 6.8a.

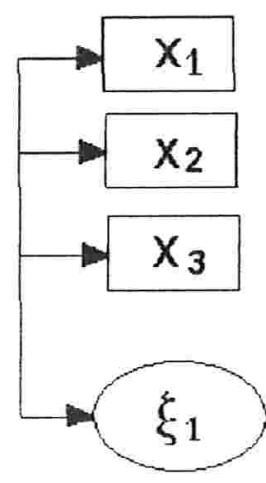

a)

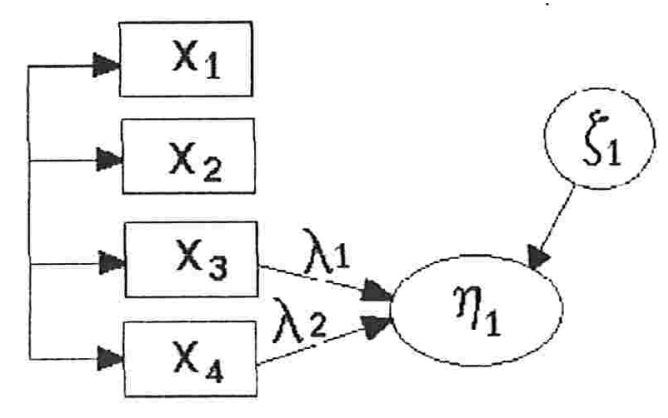

b)

Figura 6.8 - Modelo Não Analisável. a) A relação entre o constructo $\xi_{1}$ e os indicadores é não analisável. b) A relação entre o constructo $\eta_{1}$ e os indicadores $X_{1}$ e $X_{2}$ é não analisável. 
Continuando, suponha que no modelo anterior (Figura 6.8a) o constructo $\xi_{1}$ causa outro constructo $\eta_{1}$ que é o de interesse. A relação entre os indicadores e $\eta_{1}$ também é não analisável. Na Figura $6.8 \mathrm{~b}$ a relação entre os indicadores $X_{1}$ e $X_{2}$ e o constructo de interesse $\eta_{1}$ também é não analisável. Em todos estes casos existem indicadores que não têm relação de causa com nenhum constructo de interesse. Assim estes indicadores são ditos não analisáveis, isto é, não têm ligação causal com constructos de interesse. Estes indicadores não são incluídos nas equações do modelo e não modificam a análise.

Dados estes seis modelos simplificados de relacionamento entre indicadores e constructo, a idéia é usar todo o conhecimento disponível sobre o assunto para classificar o problema em uma dessas estruturas. Como um modelo estrutural completo pode conter mais de um destes tipos de relacionamento, podemos ver estes modelos simplificados como possíveis blocos de relacionamento entre variáveis latentes e observadas. Em alguns casos podemos ter problemas de identificação, mas segundo Edward e Bagozzi (2000) este é um problema secundário que tem solução, sendo que o correto é primeiro definir a estrutura do modelo de acordo com a lógica e só depois pensar na identificação, e não é correto definir a estrutura do modelo da forma mais conveniente para a estimação.

Uma vez que se consegue classificar o problema em uma destas categorias, a direção da relação causal já estará completamente determinada. Edward e Bagozzi (2000) mostram três exemplos na literatura de modelos estruturais onde a estrutura e direção da causa estariam incorretamente especificadas.

Notamos, no entanto, que a classificação dos indicadores e constructos segundo um dos seis tipos de relacionamentos mostrados requer um bom conhecimento do assunto de que se trata o modelo, e é sempre muito subjetivo, deixando grande espaço para o surgimento de divergências quanto à especificação correta. Um dos casos citados em Edward e Bagozzi (2000) cita um estudo onde são considerados o indicador "eu acho que os meus valores são bem parecidos com os da organização" e o constructo "comprometimento 
organizacional" como tendo uma relação reflexiva direta (o constructo causa diretamente o indicador). Edward e Bagozzi acham mais coerente pensar que existe um segundo constructo "senso de identificação com a organização" que causa diretamente ambos o indicador e o constructo e assim, a relação entre o comprometimento organizacional e o indicador seria espúria e não reflexiva direta.

Um artifício utilizado nos exemplos e que julgamos de grande importância para a especificação da direção causal é a precedência temporal. Sempre que possível deve-se tentar imaginar se o constructo acontece antes do indicador ou depois. Muitas vezes é possivel só com isto descobrir qual tipo de relação, se reflexiva ou formativa, é mais adequada porque a precedência temporal é bem evidente. Em outros casos, porém, a precedência temporal não ajuda muito, como no exemplo acima - quem vem primeiro, o comprometimento organizacional ou o sentimento de que meus valores são parecidos com os da organização? Pode haver argumentos em ambos os sentidos. 


\section{Capítulo 7 - Simulações}

No Capítulo 6 tratamos especificamente de métodos para identificação da direção causal, que em muitos casos nos parece ser uma das principais questões a serem respondidas, visto que em situações práticas muitas vezes não é claro se o indicador deve ser tratado como reflexivo ou formativo. No entanto entendemos que a especificação da direção da causa é uma das tarefas do pesquisador ao formular o modelo todo, assim como incluir ou não um indicador, uma correlação, fixar ou não um parâmetro. Enfim, especificar a direção causal é um ato sujeito a erros como qualquer outro na formulação do modelo, e como tal depende sobretudo do conhecimento do pesquisador, o que leva a questão a ser muito específica para cada problema.

Mas além da especificação da direção da causa, uma outra questão nos parece importante e menos relacionada ao conhecimento do pesquisador da área: o que acontece se especificarmos incorretamente um indicador como reflexivo quando ele deveria ser formativo? O fato de esta questão ser mais geral e não específica de cada problema faz com que possamos buscar algum tipo de solução ainda que tentativamente.

A especificação incorreta no sentido contrário, isto é, especificar o indicador como formativo quando ele deveria ser reflexivo nos chama muito menos a atenção porque o padrão amplamente utilizado é especificar o indicador como reflexivo, o que significa que este tipo de erro dificilmente ocorrerá. Na verdade acreditamos que muitos pesquisadores sequer dão atenção à direção causal ao especificar um modelo estrutural; os indicadores são reflexivos simplesmente porque este é o padrão.

Mesmo pesquisadores mais experientes e familiarizados com a teoria podem sentir-se receosos de especificar um indicador formativo, já que falta teoria clara sobre identificação e estimação de modelos com tais indicadores. Assim nos parece importante ter uma idéia do que acontece quando o indicador formativo é substituido pelo reflexivo. 
Neste capítulo tratamos deste assunto através de simulações. Não conseguimos responder todas as questōes, na verdade talvez conseguimos responder apenas uma minoria delas, mas esperamos poder pelo menos dar uma idéia do tamanho do erro que se comete especificando incorretamente a direção causal de indicadores em modelos estruturais.

\section{1 - A Metodologia Utilizada}

A idéia foi gerar dados de acordo com uma determinada estrutura, com coeficientes pré-determinados. Depois usamos um software que ajuste modelos estruturais e testamos se os coeficientes estimados a partir destes dados gerados são os mesmos coeficientes usados para gerar os dados.

Modificamos então a estrutura do modelo, transformando um ou mais indicador formativo em reflexivo, isto é, simulando a situação em que temos dados onde alguns indicadores são formativos, mas o pesquisador especifica incorretamente alguns destes indicadores como reflexivos. Conduzimos um novo processo de estimação para o modelo especificado incorretamente. Nosso objetivo foi comparar valores dos parâmetros e bondade de ajuste do modelo especificado incorretamente com o modelo especificado corretamente.

O software utilizado foi o SAS, que é um dos softwares mais difundidos no mercado para trabalhos com estatística, e também no meio acadêmico. Os motivos para a escolha deste software são:

1) O SAS permite uma programação simples, sendo muito bom para fazer simulações. Para o nosso caso, notamos que ele também é muito rápido;

2) O SAS já tem implementada uma grande quantidade de funções e procedimentos para estimação de modelos estruturais utilizando métodos de especificação matricial dos modelos, de entendimento fácil, e nos permite abandonar os diagramas de caminho. Os diagramas de caminho, embora fáceis de se entender, são um meio um pouco inconveniente para especificação de modelos quando se quer estimar 
repetidamente, como em uma simulação. Neste caso, precisamos de algum outro método de especificação por escrito, por causa dos 'loops' utilizados. Existem três formas de especificar modelos estruturais no SAS, chamadas RAM, LINEQS e COSAN, sendo que no nosso caso escolhemos a forma RAM (Reticular Action Model);

3) A linguagem usada no SAS é amplamente conhecida, de forma que a maioria dos leitores poderá entender como foram feitas as simulações;

4) O SAS, entre os softwares que conhecemos, é o mais completo para se trabalhar com modelos estruturais. Embora não possua os diagramas de caminho, tem implementados muitos métodos de estimação, de otimização, e índices que avaliam a bondade do ajuste;

5) O SAS, em um teste comparativo com o freeware R, mostrou-se mais confiável. Em alguns casos o $\mathrm{R}$ não conseguiu maximizar a função de verossimilhança, às vezes produzindo estimativas com valores não muito coerentes. Nestes mesmos casos, o SAS se saiu bem, com valores das estimativas sempre consistentes, e sempre conseguindo maximizar a verossimilhança sem problemas. Estas comparações foram feitas com dados gerados segundo certo modelo, apenas acrescentando um erro aleatório com distribuição Normal. Repetimos 1000 vezes esta simulação e enquanto os valores estimados dos coeficientes mudavam muito de simulação para simulação no $R$, no SAS os valores estimados eram consistentemente sempre muito próximos. Descobrimos que no $R$ estas grandes variações eram devidas a problemas de otimização de funções, sendo que, quando havia algum problema, os valores estimados apresentavam grande variabilidade. Quando não havia problema, porém, as estimativas do $\mathrm{R}$ e do SAS eram idênticas. Pode ser que alguma opção no $R$ permita melhorar seu desempenho na otimização de funções, devido à grande variedade de alternativas que o $\mathrm{R}$ disponibiliza, mas preferimos optar por trabalhar com o SAS, que também se mostrou bem mais rápido, qualidade importante em simulações que envolvem muitas repetições 
Incluimos no Apêndice o programa completo que utilizamos para a nossa primeira simulação (Seção 7.2.1), com comentários detalhados, de forma que mesmo o usuário não familiarizado com o SAS possa entender o que foi feito. As demais simulações são pequenas modificações deste programa. Optamos por não incluir todos os programas utilizados pela semelhança entre eles e pela extensão dos mesmos.

O SAS possui um procedimento especifico para se trabalhar com modelos estruturais com variáveis observadas e latentes, que é o "PROC CALIS". O SAS só deixa a desejar com relação aos diagramas de caminho, que ainda não estão implementados. Por isso a especificação de modelos sempre deve ser por escrito, em uma das três formas disponiveis: LINEQS, RAM ou COSAN. Utilizamos a forma RAM, que é uma representação matricial dos diagramas de caminho.

Quando rodamos o "PROC CALIS" temos a opção de gravar as saidas em um banco de dados externo. No nosso caso estamos interessados sobretudo nas estimativas dos parâmetros, seus desvios padrões e o valor da estatística qui-quadrado do modelo todo. Muitos outros índices de ajuste poderiam ser comparados, mas isso resultaria num trabalho imenso que evitamos, pois sabemos que não é possível explorar todas as situações. Também por isso, fixamos o método de estimação, como o de máxima verossimilhança, e o método de otimização, como sendo o de Newton-Raphson. Vários outros métodos de estimação e de otimização estão disponiveis no SAS, mas entendemos que devemos fixar estes métodos para que diferenças encontradas não possam ser atribuídas ao método, mas somente à especificação incorreta. Seguindo o raciocínio acima, também fixamos o uso da matriz de covariâncias nos processos, mas o SAS também permite a análise através da matriz de correlações.

\section{2 - Simulações}

Começamos com modelos mais simples, mais fáceis de se gerar dados e a partir daí exploramos modificações deste modelo simples, quer em 
termos apenas de valores dos parâmetros utilizados, quer em termos da estrutura do modelo, sendo que cada nova simulação com novos resultados foi incluída em uma nova subseção desta seção. Como comentamos anteriormente, não temos condições de explorar todos os casos, mas a partir do programa descrito no Apêndice o próprio leitor poderá se aventurar a fazer modificações que julgue interessantes, e tirar suas conclusões.

\subsection{1 - O Modelo MIMIC com Três Indicadores Formativos e Três Indicadores Reflexivos}

Inicialmente consideramos um caso bem simples, onde temos uma única variável latente com três indicadores formativos e três indicadores reflexivos. Este modelo, como vimos no Capítulo 5, é identificado, mesmo se transformarmos um dos indicadores formativos em reflexivo, o que é, na verdade, o nosso objetivo.

Inicialmente, simulamos dados que representassem o modelo MIMIC da Figura 7.1. O segundo passo foi estimar os parâmetros especificando o modelo da forma correta, isto é, como foram gerados os dados. Este é um passo de verificação e controle, queremos ter a certeza que se especificarmos corretamente o modelo, o processo de estimação nos levará aos parâmetros usados para gerar os dados, os erros sendo decorrentes de flutuações amostrais. No caso deste modelo, este segundo passo sempre resultou nas estimativas esperadas, o que também nos dá a confiança de que estamos gerando dados da forma correta. Em todas as simulações foram usadas 1000 repetições de amostras também de tamanho 1000. Acreditamos que 1000 repetições são suficientes para termos uma boa segurança a respeito dos resultados do processo de estimação, mais precisamente, queremos estar seguros de qual o tamanho do efeito da especificação incorreta. É claro que aumentando ainda mais o número de simulações, teríamos ainda mais confiança nos resultados, mas concluímos depois de alguns testes que os resultados são estáveis e o ganho ao aumentar ainda mais o número de simulações é insignificante perto do tempo a mais que se gasta com o procedimento. Não temos muitas razões para ter escolhido o 
tamanho 1000 para as amostras, evitamos uma amostra pequena demais também pelo motivo da estabilidade das estimativas e, conseqüentemente, dos efeitos da especificação incorreta. Mas entendemos que o tamanho da amostra também poderia ter sido uma variável a ser estudada no sentido de sabermos qual seria o efeito do tamanho da amostra no efeito da especificação incorreta. Isto envolveria muitas outras simulações e optamos por deixar este tema de fora dos nossos estudos.

Na Figura 7.1 também mostramos todos os valores dos coeficientes utilizados na geração dos dados. Tanto os erros como as variáveis exógenas $X_{1}$, $\mathrm{X}_{2}$ e $\mathrm{X}_{3}$ foram gerados independentemente, com distribuição Normal padrão.

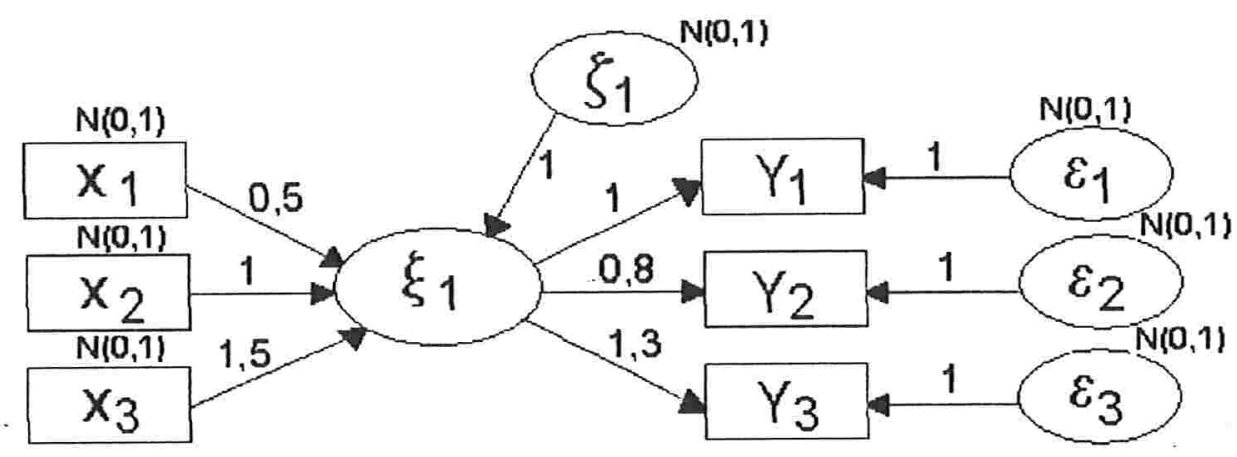

Figura 7.1 - Diagrama de caminho representando o modelo MIMIC a partir do qual foram gerados os dados para a primeira simulação.

Os valores utilizados foram: $\gamma_{11}=0,5, \gamma_{12}=1, \gamma_{13}=1,5, \lambda_{21}=0,8, \lambda_{31}=1,3$ e $\lambda_{11}$ foi fixado em 1 . Nossa primeira análise consiste em avaliar como é o desempenho do processo de estimação quando o modelo é especificado corretamente. Esperamos que os valores estimados sejam muito próximos dos valores usados para gerar os dados, que estão na Figura 7.1. Na verdade isto realmente acontece. Na Tabela 7.1 mostramos os valores médios destes parâmetros para as 1000 repetições do processo de estimação, e adicionalmente as médias para os demais parâmetros estimados. 
Tabela 7.1 - Médias e desvios padrōes das estimativas dos parâmetros do modelo MIMIC da Figura 7.1

\begin{tabular}{|l|c|c|c|c|c|}
\hline Parâmetro & $\mathbf{N}$ & Média & Esperado & Desv. Padräo & Significado \\
\hline lambda21 & 1000 & 0,8003194 & 0,8 & 0,0199016 & \\
\hline lambda31 & 1000 & 1,3005911 & 1,3 & 0,0265856 & \\
\hline gama11 & 1000 & 0,4996424 & 0,5 & 0,0377239 & \\
\hline gama12 & 1000 & 1,0000641 & 1,0 & 0,0388784 & \\
\hline gama13 & 1000 & 1,4993992 & 1,5 & 0,0411404 & \\
\hline phi11 & 1000 & 0,9977091 & 1,0 & 0,0441544 & $\operatorname{Var}\left(X_{1}\right)$ \\
\hline phi12 & 1000 & 0,00062102 & 0,0 & 0,0308212 & $\operatorname{Cov}\left(X_{1}, X_{2}\right)$ \\
\hline phi22 & 1000 & 0,9997173 & 1,0 & 0,0435466 & $\operatorname{Var}\left(\mathrm{X}_{2}\right)$ \\
\hline phi13 & 1000 & $-0,000371694$ & 0,0 & 0,0312268 & $\operatorname{Cov}\left(\mathrm{X}_{1}, \mathrm{X}_{3}\right)$ \\
\hline phi23 & 1000 & 0,0010976 & 0,0 & 0,0324709 & $\operatorname{Cov}\left(\mathrm{X}_{2}, \mathrm{X}_{3}\right)$ \\
\hline phi33 & 1000 & 0,9993818 & 1,0 & 0,0438237 & $\operatorname{Var}\left(\mathrm{X}_{3}\right)$ \\
\hline theta11 & 1000 & 0,9958199 & 1,0 & 0,0612582 & $\operatorname{Var}\left(\varepsilon_{1}\right)$ \\
\hline theta22 & 1000 & 0,9989032 & 1,0 & 0,0538423 & $\operatorname{Var}\left(\varepsilon_{2}\right)$ \\
\hline theta33 & 1000 & 0,9979598 & 1,0 & 0,0777197 & $\operatorname{Var}\left(\varepsilon_{3}\right)$ \\
\hline psi11 & 1000 & 0,9947205 & 1,0 & 0,0640665 & $\operatorname{Var}\left(\zeta_{1}\right)$ \\
\hline
\end{tabular}

Isto quer dizer que temos um conjunto de dados e um modelo que quando especificado corretamente nos leva aos valores reais dos parâmetros, com erros muito pequenos, devidos apenas a flutuações amostrais. Embora tenhamos gerado os indicadores formativos não correlacionados, no procedimento de estimação acima especificamos a correlação entre eles - que foi estimada próxima de zero e não significante - pois geralmente na prática os indicadores formativos são supostos possivelmente correlacionados, visto que são variáveis exógenas das quais não sabemos as causas. Na Figura 7.2 mostramos a distribuição de $\gamma_{11}$. Vemos que é uma distribuição bem centrada no valor real do parâmetro, que é igual a 0,5 .

Assim como $\gamma_{11}$ todos os demais parâmetros estimados apresentaram uma distribuição bem centrada no seu valor real e também simétrica, com pequena dispersão (veja o desvio padrão na Tabela 7.1). Sempre tomamos o cuidado de fazer esta verificação de que o processo de estimação, quando feito com o modelo correto, nos retorna estimativas muito próximas do real valor do parâmetro, não sendo igual por flutuações amostrais. No entanto, nas 
demais simulações não descreveremos aqui os resultados deste passo de verificação do modelo, pois entendemos que este não é o objetivo deste texto além de nos tomar muito espaço.

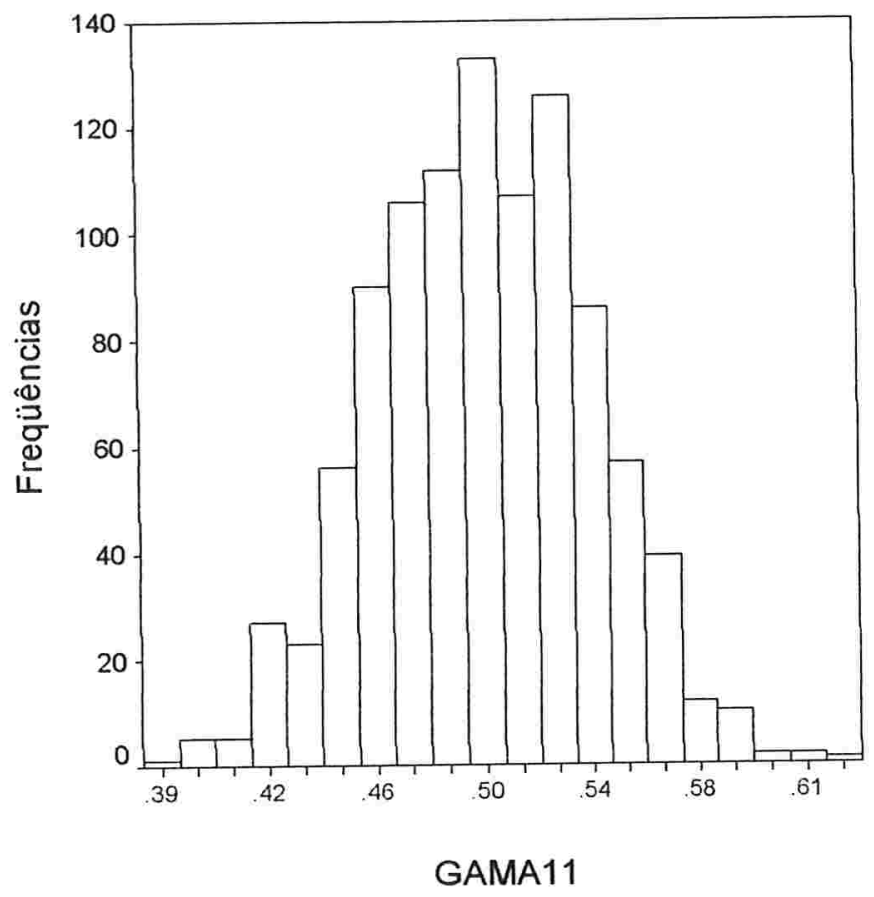

Figura 7.2 - Distribuição de $\gamma_{11}$

Embora existam muitos índices criados para verificar a adequação de um modelo estrutural aos dados, comparamos aqui apenas o valor qui-quadrado, visto que este é o único índice de ajuste do qual conhecemos a distribuição, e também o mais amplamente aceito. O gráfico na Figura 7.3 mostra a distribuição do $p$-valor para a estatística qui-quadrado, considerando as 1000 repetições que foram feitas.

Sob a suposição de que o modelo é adequado, a estatística quiquadrado tem uma distribuição qui-quadrado. Se T é uma variável aleatória com distribuição qui-quadrado, com $F_{T}(t)=P(T \leq t)$, então $W=F_{T}(T)=1$ - $p$-valor, onde estamos considerando o p-valor para o teste unicaudal, usado nos modelos estruturais. Mas $F_{W}(w)=P(W \leq W)=P\left(F_{T}(T) \leq W\right)=P\left(T \leq F^{-1} T(W)\right)=F_{T}\left(F_{T}^{-1}(W)\right)=W$. 
Ou seja, se $F_{W}(W)=w$, então $W \sim U(0,1)$, e 1-W U(0,1). Lembrando que $1-W$ é o $p$ valor, concluímos que o $p$-valor tem distribuição $U(0,1)$.

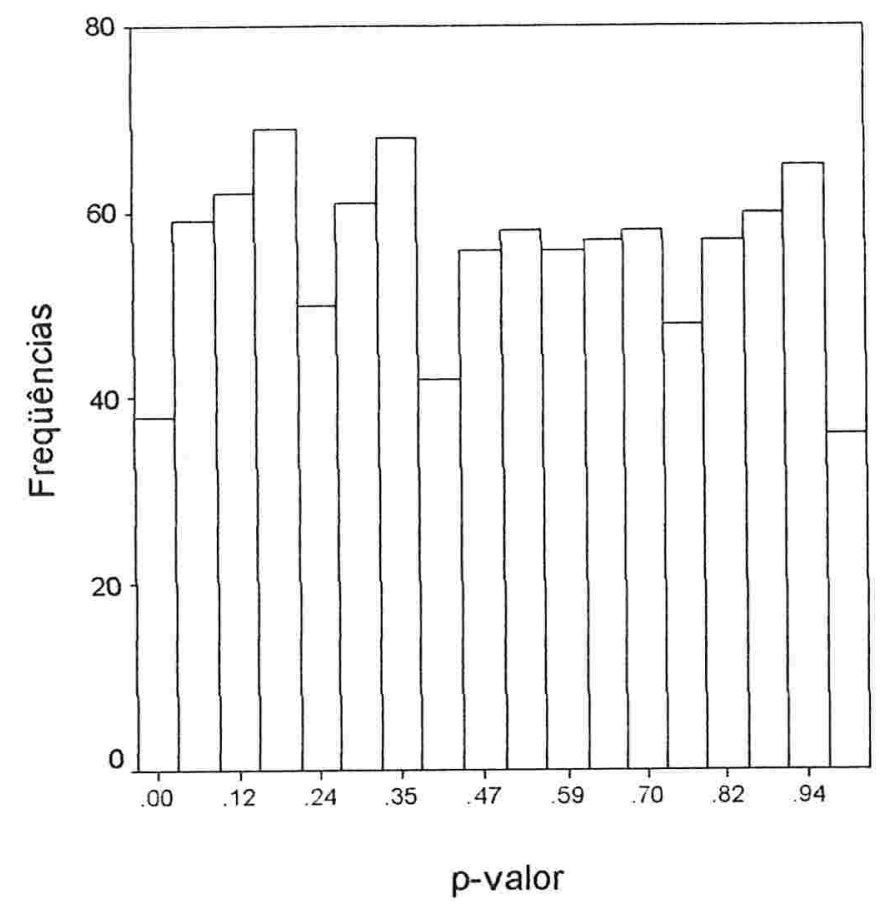

Figura 7.3 - Distribuição do p-valor para a estatística qui-quadrado.

Na Figura 7.3 vemos que a distribuição do $p$-valor é próxima da uniforme, como seria de se esperar no caso de um bom ajuste dos modelos, ou seja, se considerarmos um nível descritivo de $5 \%$, veremos que cerca de $5 \%$ dos modelos são rejeitados (a primeira barra do histograma). Isto nos mostra também que o teste qui-quadrado está sendo adequado para avaliar o ajuste do modelo aos dados.

O terceiro passo em nosso processo de simulações consiste em se especificar um dos indicadores formativos como sendo reflexivo, e re-estimar os parâmetros com este modelo, mas com os dados gerados anteriormente, isto é, geramos os dados de acordo com o modelo da Figura 7.1, mas vamos estimar os parâmetros usando as equações do modelo da Figura 7.4. Neste caso, $X_{1}$ é especificado incorretamente como indicador reflexivo. 
Lembrando das covariâncias especificadas entre os indicadores formativos na estimação do modelo correto, vemos que quando reespecificamos $\mathrm{X}_{1}$ como indicador reflexivo, dois parâmetros deixam de existir $\left(\operatorname{Cov}\left(X_{1}, X_{2}\right)\right.$ e $\operatorname{Cov}\left(\mathrm{X}_{1}, \mathrm{X}_{3}\right)$ ), e como o número de variáveis observadas continua o mesmo, ganhamos dois graus de liberdade. É claro que no modelo inicial já poderíamos ter optado por eliminar as covariâncias entre os indicadores formativos, o que neste caso seria o ideal, visto que os indicadores formativos são gerados independentemente, mas preferimos conduzir o processo de acordo com o que comumente é feito na prática, isto é, supondo os indicadores formativos correlacionados. Acreditamos que assim os resultados podem ser mais úteis.

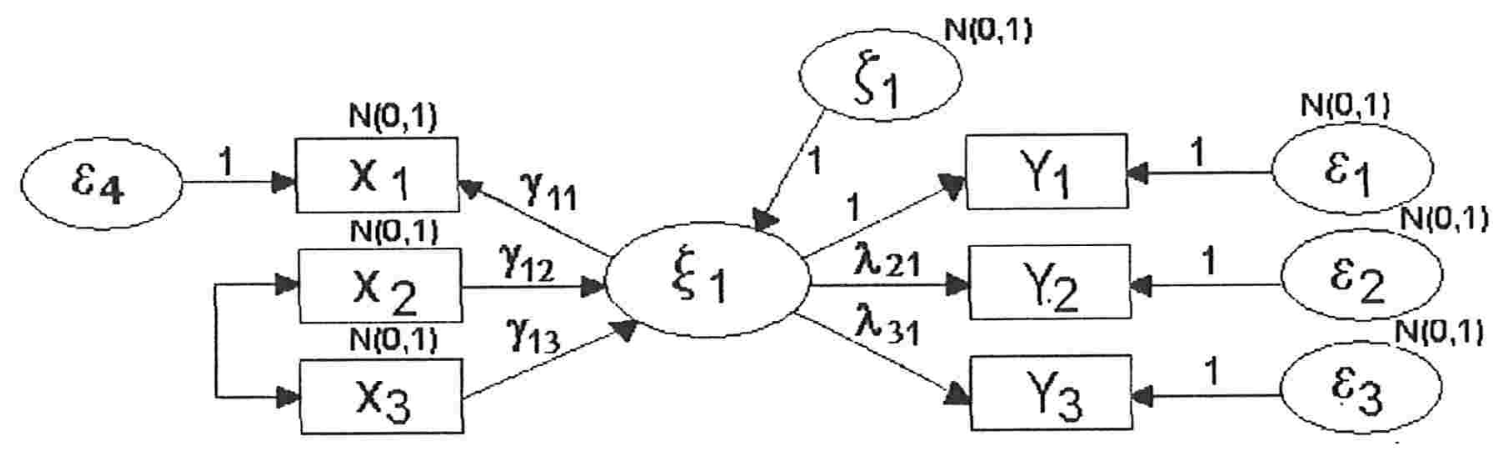

Figura 7.4 - Modelo da Figura 7.1 especificado incorretamente: $X_{1}$ é indicador reflexivo quando deveria ser formativo.

Inicialmente estudamos como foi o ajuste do modelo de uma forma geral pelo valor da estatística qui-quadrado. Ele tende a ser muito alto, geralmente acima de 100, indicando um ajuste muito ruim. O valor médio para as 1000 replicações foi 144,9 e o desvio padrão 22,7 . Todos os p-valores resultantes desta estatística qui-quadrado foram menores que 0,00001, o valor mínimo da estatística qui-quadrado foi de 83,7 , com 8 graus de liberdade, sendo ainda altamente significante. Isto nos faz concluir que para este nosso caso a especificação incorreta resultará primeiramente em um problema de ajuste do modelo aos dados, obrigando o pesquisador a fazer uma reespecificação do modelo. 
Quando o ajuste é ruim como neste caso, geralmente se parte para um novo modelo, sem preocupações em olhar as estimativas dos parâmetros. Mas no nosso caso percebemos que os parâmetros são quase todos estimados corretamente ou quase corretamente, por isso é interessante estudá-los, pois assim podemos ter uma idéia a respeito dos parâmetros que são afetados pela inversão da relação causal, que é a fonte do ajuste muito pobre.

A Tabela 7.2 exibe as médias e desvios padrões calculados sobre as 1000 estimativas dos parâmetros do modelo da Figura 7.4, que foi incorretamente especificado. Apenas o parâmetro $\gamma_{11}$ teve seu valor estimado substancialmente modificado. O valor médio que deveria ser 0,5 agora está próximo de 0,1, sendo que considerando a média dos desvios padrões ele ainda é significantemente diferente de zero.

Tabela 7.2 - Médias e desvios padrões das estimativas do modelo MIMIC com a relação de $X_{1}$ invertida (modelo da Figura 7.4).

\begin{tabular}{|l|c|c|c|c|c|}
\hline Parâmetro & $\mathbf{N}$ & Média & Esperado & Desv. Padrão & Significado \\
\hline gama11 & 1000 & 0,0950448 & 0,5 & 0,0152665 & \\
\hline Lambda21 & 1000 & 0,8013627 & 0,8 & 0,0201895 & \\
\hline Lambda31 & 1000 & 1,3023964 & 1,3 & 0,0266039 & \\
\hline gama12 & 1000 & 0,9960533 & 1,0 & 0,0417306 & \\
\hline gama13 & 1000 & 1,4940262 & 1,5 & 0,0445525 & \\
\hline phi11 & 1000 & 0,9609349 & - & 0,0422199 & $\operatorname{Var}\left(\varepsilon_{4}\right)$ \\
\hline phi22 & 1000 & 0,9991284 & 1,0 & 0,0453919 & $\operatorname{Var}\left(\mathrm{X}_{2}\right)$ \\
\hline phi23 & 1000 & $-0,000533448$ & 0,0 & 0,0307451 & $\operatorname{Cov}\left(\mathrm{X}_{2}, \mathrm{X}_{3}\right)$ \\
\hline phi33 & 1000 & 0,9998208 & 1,0 & 0,045682 & $\operatorname{Var}\left(\mathrm{X}_{3}\right)$ \\
\hline theta11 & 1000 & 0,9957454 & 1,0 & 0,0625222 & $\operatorname{Var}\left(\varepsilon_{1}\right)$ \\
\hline theta22 & 1000 & 0,9949017 & 1,0 & 0,0554031 & $\operatorname{Var}\left(\varepsilon_{2}\right)$ \\
\hline theta33 & 1000 & 0,9787199 & 1,0 & 0,0833918 & $\operatorname{Var}\left(\varepsilon_{3}\right)$ \\
\hline psi11 & 1000 & 1,2715099 & 1,0 & 0,0802922 & $\operatorname{Var}\left(\varsigma_{1}\right)$ \\
\hline
\end{tabular}

A Figura 7.5 apresenta um histograma da distribuição do p-valor para o teste de significância do parâmetro $\gamma_{11}$. Vemos que em metade $(49,5 \%)$ das vezes ele é significante considerando um nivel descritivo de $5 \%$, ou seja, podemos dizer que com uma probabilidade estimada de $50 \%$ temos não só uma mudança 
na ordem de grandeza da estimativa de $\gamma_{11}$, mas também uma mudança inferencial, pois $\gamma_{11}$ deixará de ser significante.

Além disso, duas outras mudanças são observadas: $\theta_{33}$ é um pouco subestimada e $\psi_{11}=\operatorname{Var} \zeta_{1}$ é super-estimada. A mudança no parâmetro $\psi_{11}$ não é pequena e nos mostra o efeito causado na variável latente pela relação causal invertida.

Nesta primeira simulação trabalhamos com uma inversão na relação de causa entre $X_{1}$ e a variável latente, onde $X_{1}$ tinha um coeficiente igual a 0,5. Não tivemos nenhum motivo para escolher este valor, apenas procuramos fazer com que os valores dos parâmetros não fossem iguais, para que o modelo fique mais parecido com uma situação real.

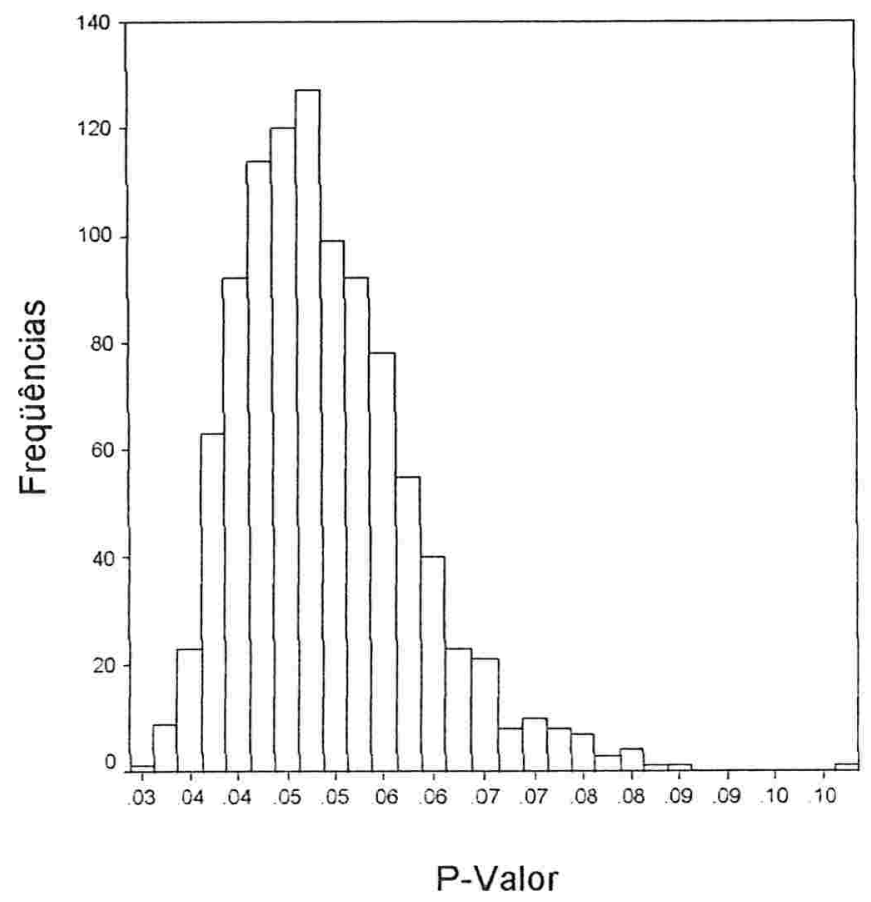

Figura 7.5 - Distribuição do p-valor para o teste de significância para /11

O que vamos fazer agora é deixar a relação de causa entre $X_{1}$ e $\xi_{1}$ na direção correta e inverter a relação entre $X_{2}$ e $\xi_{1}$, tornando $X_{2}$ reflexivo. A intenção é verificar se o fato de $X_{2}$ ter um valor de parâmetro que é o dobro do de 
$X_{1}$ não causará conseqüências diferentes do que quando invertemos a relação de causa de $X_{1}$. Depois faremos o mesmo para a relação entre $X_{3}$ e $\xi_{1}$.

No caso de invertemos a relação causal de $X_{2}$, observamos um efeito ainda mais severo no valor da estatística qui-quadrado. Sua média foi igual a 381,1, com desvio padrão igual a 35,8 . Na Tabela 7.3 mostramos os valores médios das estimativas dos parâmetros. Novamente vemos que $\theta_{33}$ é subestimada e $\psi_{11}=\operatorname{Var}\left(\zeta_{1}\right)$ é super-estimada, mas aqui com mais intensidade do que no caso anterior. A média das estimativas do parâmetro $\gamma_{12}$, da relação invertida é bem menor do que o seu valor real.

\begin{tabular}{|c|c|c|c|c|c|}
\hline Parâmetro & N & Média & Esperado & Desv. Padrão & Significado \\
\hline gama12 & 1000 & 0,206714 & 1,0 & 0,0141555 & \\
\hline lambda21 & 1000 & 0,800086 & 0,8 & 0,0202432 & \\
\hline lambda31 & 1000 & 1,304496 & 1,3 & 0,0268198 & \\
\hline gama11 & 1000 & 0,491865 & 0,5 & 0,0470052 & \\
\hline gama13 & 1000 & 1,476082 & 1,5 & 0,0529503 & \\
\hline phi11 & 1000 & 0,999037 & 1,0 & 0,0449523 & $\operatorname{Var}\left(X_{1}\right)$ \\
\hline phi22 & 1000 & 0,808156 & - & 0,0370086 & $\operatorname{Var}\left(\varepsilon_{4}\right)$ \\
\hline phi13 & 1000 & 0,000305 & 0,0 & 0,0333871 & $\operatorname{Cov}\left(X_{1}, X_{3}\right)$ \\
\hline phi33 & 1000 & 1,000464 & 1,0 & 0,0443693 & $\operatorname{Var}\left(X_{3}\right)$ \\
\hline theta11 & 1000 & 0,992725 & 1,0 & 0,0656621 & $\operatorname{Var}\left(\varepsilon_{1}\right)$ \\
\hline theta22 & 1000 & 0,998406 & 1,0 & 0,0545054 & $\operatorname{Var}\left(\varepsilon_{2}\right)$ \\
\hline theta33 & 1000 & 0,936149 & 1,0 & 0,0870687 & $\operatorname{Var}\left(\varepsilon_{3}\right)$ \\
\hline psi11 & 1000 & 2,083219 & 1,0 & 0,1198724 & $\operatorname{Var}\left(\zeta_{51}\right)$ \\
\hline
\end{tabular}

Quando a relação invertida é a de X3, observamos praticamente as mesmas conseqüências anteriores (veja Tabela 7.4). Os parâmetros $\gamma 11$ e $\theta 33$ são subestimados e $\psi_{11}=\operatorname{Var}(\zeta 1)$ é super-estimada de uma forma ainda mais forte do que nos casos anteriores.

Fizemos adicionalmente uma simulação gerando dados com o coeficiente de $X_{1}$ com sinal negativo. Ao tornar $X_{1}$ reflexivo e re-estimar os parâmetros observamos que o valor médio da estatística qui-quadrado e dos coeficientes estimados são exatamente os mesmos valores obtidos com o 
coeficiente positivo (primeiro caso estudado), apenas invertendo o sinal da estimativa de $\gamma_{11}$

Tabela 7.4 - Médias e desvios padröes das estimativas do modelo com a relaçäo de $X_{3}$ invertida.

\begin{tabular}{|l|c|c|c|c|c|}
\hline Parâmetro & $\mathbf{N}$ & Média & Esperado & Desv . Padrão & Significado \\
\hline gama13 & 1000 & 0,326048 & 1,5 & 0,012536 & \\
\hline lambda21 & 1000 & 0,800976 & 0,8 & 0,0203716 & \\
\hline lambda31 & 1000 & 1,307456 & 1,3 & 0,0268372 & \\
\hline gama11 & 1000 & 0,473669 & 0,5 & 0,0602781 & \\
\hline gama12 & 1000 & 0,940921 & 1,0 & 0,0642136 & \\
\hline phi11 & 1000 & 0,998826 & 1,0 & 0,0444102 & $\operatorname{Var}\left(\mathrm{X}_{1}\right)$ \\
\hline phi12 & 1000 & 0,000621 & 0,0 & 0,0315693 & $\operatorname{Cov}\left(\mathrm{X}_{1}, \mathrm{X}_{3}\right)$ \\
\hline phi22 & 1000 & 0,99832 & 1,0 & 0,0441356 & $\operatorname{Var}\left(\mathrm{X}_{2}\right)$ \\
\hline phi33 & 1000 & 0,521862 & - & 0,0247018 & $\operatorname{Var}\left(\varepsilon_{4}\right)$ \\
\hline theta11 & 1000 & 0,996974 & 1,0 & 0,0660825 & $\operatorname{Var}\left(\varepsilon_{1}\right)$ \\
\hline theta22 & 1000 & 0,998579 & 1,0 & 0,0558838 & $\operatorname{Var}\left(\varepsilon_{2}\right)$ \\
\hline theta33 & 1000 & 0,930539 & 1,0 & 0,0901351 & $\operatorname{Var}\left(\varepsilon_{3}\right)$ \\
\hline psi11 & 1000 & 3,372946 & 1,0 & 0,1781137 & $\operatorname{Var}\left(\zeta_{1}\right)$ \\
\hline
\end{tabular}

Vimos que a inversão da direção causal, pela especificação incorreta do indicador formativo como reflexivo, leva antes de tudo a um ajuste muito ruim, obrigando o pesquisador a reespecificar o modelo. Não vamos fazer aqui uma análise completa de diagnósticos para tentar prever o que o pesquisador mudaria na reespecificação se a situação fosse real, mas escolhemos olhar rapidamente alguns valores úteis para direcionar a reespecificação, como os Índices de Modificação ou Multiplicadores de Lagrange - ML - (ver Seção 1.2.9.2 e Bollen (1989a), pág. 293) e a matriz dos resíduos. Não conseguimos estudar o valor do ML para as 1000 simulações, porque o SAS não o grava em um arquivo externo, mas repetimos o experimento algumas vezes e verificamos que sempre o maior $\mathrm{ML}$ se refere a $\operatorname{Cov}\left(\zeta_{1}, \varepsilon_{4}\right)$, onde $\zeta_{1}$ e $\varepsilon_{4}$ são justamente os termos de erro relacionados às variáveis que tiveram sua relação invertida. Como verificamos a presença deste valor alto para o $\mathrm{ML}$ em todos os modelos incorretamente especificados que testamos (um total de 20 modelos), concluímos que sempre que, em uma situação de reespecificação do modelo, encontrarmos um ML com valor alto entre o erro de um indicador reflexivo e o erro de sua variável latente, 
vale a pena considerar a hipótese de que este indicador reflexivo na verdade seja formativo.

Ainda pensando na reespecificação do modelo, o segundo e o terceiro ML de maior valor também são relacionados ao erro do indicador incorretamente especificado $-\operatorname{Cov}\left(X_{2}, \varepsilon_{4}\right)$ e $\operatorname{Cov}\left(X_{3}, \varepsilon_{4}\right)$, onde $\varepsilon_{4}$ é o erro relacionado a $\mathrm{X}_{1}$, indicador formativo especificado como reflexivo. Por fim, ainda observamos a matriz de resíduos, e os maiores resíduos sempre são aqueles referentes às covariâncias entre o indicador incorretamente especificado e os outros dois indicadores formativos. Vemos que tanto os ML como os resíduos indicam problema com o indicador incorretamente especificado. Neste caso o correto não é incluir uma relação entre os erros, como indica o maior $\mathrm{ML}$, mas inverter a direção causal. É importante ter isto em mente ao fazer exames de diagnóstico de modelos estruturais.

O que aconteceria se seguíssemos a dica do ML e adicionássemos $\operatorname{Cov}\left(\zeta_{1}, \varepsilon_{4}\right)$ como um novo parâmetro livre no modelo? Procuramos esta resposta através de 1000 simulações extras. O modelo passa a se ajustar muito bem aos dados, como se fosse o modelo correto. O coeficiente do indicador incorretamente especificado como reflexivo passa a ser não significante, e a variância do erro $\left(\zeta_{1}\right)$ relacionado à variável latente é super-estimada (média de 1,24 para 1000 simulações com $X_{1}$ especificado incorretamente, quando a média deveria ser próxima de 1). Todos os demais parâmetros, em média, são estimados corretamente. Portanto a reespecificação do modelo segundo o ML, neste caso, levará a um modelo incorreto que se ajusta bem aos dados, problema a que estamos sujeitos sempre que ajustamos um modelo estrutural. No entanto, mesmo com o modelo incorreto, temos a estimativa correta para a maioria dos parâmetros.

Analisamos aqui algumas conseqüências da especificação incorreta de indicadores formativos como reflexivos em um tipo simples de modelo MIMIC com apenas seis indicadores, sendo três de cada tipo. As conclusões são que em todos os casos o ajuste do modelo fica muito ruim, levando necessariamente a 
uma reespecificação, que, se feita através dos Multiplicadores de Lagrange, levará a outro modelo incorreto. Ainda assim os parâmetros são quase todos estimados corretamente, ou quase corretamente, tanto no modelo incorreto que se ajusta mal aos dados quanto naquele reespecificado que se ajusta bem aos dados, sendo que o efeito maior é visto no próprio coeficiente do indicador incorretamente especificado e no erro da variável latente. Esse efeito é maior quanto maior é o valor real do coeficiente do indicador com relação causal invertida. É importante então verificar sempre as direções das relações causais entre variáveis latentes e indicadores sempre que reespecificamos um modelo, pois pode estar aí a fonte do ajuste ruim.

Vamos agora fazer simulações com um MIMIC um pouco maior. Daqui em diante seremos mais objetivos no texto, visto que o método usado será basicamente o mesmo descrito acima.

\subsection{2 - O Modelo MIMIC com Três Indicadores Formativos e Cinco Indicadores Reflexivos}

Nosso objetivo nesta seção é verificar quais são as alterações com relação aos resultados da simulação anterior quando temos mais indicadores reflexivos. Adicionamos então dois indicadores reflexivos $\left(\mathrm{Y}_{4}\right.$ e $\left.\mathrm{Y}_{5}\right)$ no modelo da Figura 7.1, com coeficientes respectivamente iguais a 1,7 e 2,2. Este novo modelo ficou sendo o padrão para a geração de dados. Invertemos a relação do indicador formativo $X_{1}$ e ficamos com o modelo especificado incorretamente, o qual teve seus parâmetros estimados 1000 vezes. Os novos erros $\varepsilon_{4}$ e $\varepsilon_{5}$ foram gerados com distribuição $\mathrm{N}(0,1)$, independentes.

A especificação incorreta da direção causal de $X_{1}$ neste modelo tem conseqüências praticamente idênticas às que observamos ao ajustar o modelo da Figura 7.4, com apenas dois indicadores reflexivos a menos. O valor médio da estatística qui-quadrado para os 1000 modelos foi de 174,6 (contra 144,9 para o caso anterior, com apenas três indicadores reflexivos), mas lembramos que, dado que agora temos 19 graus de liberdades (contra apenas 8 no caso anterior), este 
aumento no valor qui-quadrado seria de se esperar. Assim os dados são muito mal-ajustados por este modelo, mas apenas o coeficiente de $X_{1}$ e a variância de $\zeta_{1}$ têm suas estimativas bastante alteradas.

Quando observamos os Multiplicadores de Lagrange e a matriz dos resíduos, nossas conclusões são exatamente as mesmas já relatadas na seção

anterior: $\operatorname{Cov}\left(X_{1}, \zeta_{1}\right)$ é o parâmetro com maior $M L$, sendo que $\operatorname{Cov}\left(X_{1}, X_{2}\right)$ e $\operatorname{Cov}\left(X_{1}, X_{3}\right)$ também apresentam valores elevados para o $M L$, bem como para os resíduos. Ao reajustarmos o modelo incluindo o termo $\operatorname{Cov}\left(X_{1}, \zeta_{1}\right)$, obtemos um ajuste muito bom, sendo que o coeficiente de $X_{1}$ torna-se não significante e a variância de $\zeta_{1}$ é super-estimada.

Somos levados a concluir que neste caso MIMIC com apenas um constructo, o número de indicadores reflexivos não parece ser relevante para os efeitos que a especificação incorreta causa no modelo. E mais uma vez, usar diretamente $\circ \mathrm{ML}$ para reespecificar o modelo resolverá o problema do mau ajuste, mas não da forma correta.

\subsection{3 - O Modelo MIMIC com Cinco Indicadores Formativos e Três Indicadores Reflexivos}

Após alterar o número de indicadores reflexivos, tentamos fazer o mesmo com o número de indicadores formativos. Ao invés de apenas três indicadores formativos, geramos dados de acordo com o modelo da Figura 7.1, mas com cinco indicadores formativos, todos eles independentes, com distribuição $\mathrm{N}(0,1)$. O fato de que a parcela da variável latente formada pelo indicador formativo incorretamente especificado - $X_{1}$ - é agora bem menor, nos leva a pensar que o efeito da especificação incorreta também deve ser menor. Os efeitos de $X_{4}$ e $X_{5}$ são respectivamente iguais a 2 e 2,5.

Após ajustar o modelo incorreto 1000 vezes e verificar os resultados, notamos que não temos muitas mudanças em relação ao que vínhamos observando nos casos anteriores. A média da estatística qui-quadrado foi igual a 
178,43, com 14 graus de liberdade, o valor mínimo foi igual a 101,5 indicando que em todas as 1000 simulações tivemos ajustes muito ruins. $\mathrm{Na}$ Tabela 7.5 mostramos as médias das estimativas dos parâmetros do modelo:

Tabela 7.5 - Médias e desvios padröes das estimativas do modelo MIMIC com cinco indicadores formativos e três indicadores reflexivos.

\begin{tabular}{|l|c|c|c|c|c|}
\hline Parâmetro & $\mathbf{N}$ & Média & Esperado & Desv. Padrão & Significado \\
\hline Gama11 & 1000 & 0,027484 & 0,5 & 0,0081512 & \\
\hline lambda21 & 1000 & 0,799971 & 0,8 & 0,0105536 & \\
\hline Iambda31 & 1000 & 1,3001425 & 1,3 & 0,0131682 & \\
\hline Gama12 & 1000 & 1,0007428 & 1,0 & 0,0409965 & \\
\hline Gama13 & 1000 & 1,5014144 & 1,5 & 0,0407942 & \\
\hline Gama14 & 1000 & 1,9990072 & 2,0 & 0,0413233 & \\
\hline Gama15 & 1000 & 2,5004002 & 2,5 & 0,0420421 & \\
\hline phi11 & 1000 & 0,9893412 & - & 0,0436728 & $\operatorname{Var}\left(\varepsilon_{4}\right)$ \\
\hline phi22 & 1000 & 0,9996233 & 1,0 & 0,0437173 & $\operatorname{Var}\left(\mathrm{X}_{2}\right)$ \\
\hline phi23 & 1000 & 0,0014991 & 0,0 & 0,0312812 & $\operatorname{Cov}\left(\mathrm{X}_{2}, \mathrm{X}_{3}\right)$ \\
\hline phi33 & 1000 & 0,9990942 & 1,0 & 0,0432497 & $\operatorname{Var}\left(\mathrm{X}_{3}\right)$ \\
\hline phi24 & 1000 & $-0,0011212$ & 0,0 & 0,0314958 & $\operatorname{Cov}\left(\mathrm{X}_{2}, \mathrm{X}_{4}\right)$ \\
\hline phi34 & 1000 & 0,000768636 & 0,0 & 0,0312768 & $\operatorname{Cov}\left(\mathrm{X}_{3}, \mathrm{X}_{4}\right)$ \\
\hline phi44 & 1000 & 0,9990989 & 1,0 & 0,0457438 & $\operatorname{Var}\left(\mathrm{X}_{4}\right)$ \\
\hline phi25 & 1000 & $-0,0014408$ & 0,0 & 0,0320688 & $\operatorname{Cov}\left(\mathrm{X}_{2}, \mathrm{X}_{5}\right)$ \\
\hline phi35 & 1000 & $-0,0017603$ & 0,0 & 0,0318637 & $\operatorname{Cov}\left(\mathrm{X}_{3}, \mathrm{X}_{5}\right)$ \\
\hline phi45 & 1000 & 0,000531295 & 0,0 & 0,0330227 & $\operatorname{Cov}\left(\mathrm{X}_{4}, \mathrm{X}_{5}\right)$ \\
\hline phi55 & 1000 & 0,999755 & 1,0 & 0,0423735 & $\operatorname{Var}\left(\mathrm{X}_{5}\right)$ \\
\hline theta11 & 1000 & 1,0014234 & 1,0 & 0,0606251 & $\operatorname{Var}\left(\varepsilon_{1}\right)$ \\
\hline theta22 & 1000 & 0,9994886 & 1,0 & 0,0534584 & $\operatorname{Var}\left(\varepsilon_{2}\right)$ \\
\hline theta33 & 1000 & 0,9923668 & 1,0 & 0,0802416 & $\operatorname{Var}\left(\varepsilon_{3}\right)$ \\
\hline psi11 & 1000 & 1,252648 & 1,0 & 0,0724002 & $\operatorname{Var}\left(\zeta_{1}\right)$ \\
\hline
\end{tabular}

Vemos que apenas as médias das estimativas de $\gamma_{11}$ e de $\operatorname{Var}\left(\zeta_{1}\right)$ têm valores estimados diferentes dos seus valores reais. Enquanto o valor médio da estimativa de $\operatorname{Var}\left(\zeta_{1}\right)$ é praticamente igual ao encontrado nas simulações anteriores, o da estimativa de $\gamma_{11}$ é bem menor, embora significantemente diferente de zero. Essa foi a principal mudança que encontramos após a adição de mais dois indicadores formativos no modelo. 
Olhando os valores dos Multiplicadores de Lagrange (ML), novamente chegamos à conclusão imediata que devemos incluir um parâmetro de covariância entre o erro de $X_{1}$ e o erro de $\xi_{1}$, e ao incluir este parâmetro, novamente o modelo revela um ajuste muito bom aos dados, porém com estimativas de $\gamma_{11}$ não significantemente diferente de zero e de $\operatorname{Var}\left(\zeta_{1}\right)$ maior do que o real.

Assim, de uma forma geral a conclusão até o momento é que a especificação incorreta gera um ajuste muito ruim do modelo aos dados e a reespecificação do modelo pode facilmente levar a um modelo que tem um bom ajuste, mas também incorretamente especificado. Visto isso, nossa recomendação é que sempre que encontrarmos um ML alto para a covariância entre um erro de um indicador reflexivo e o erro relacionado a seu constructo, que seja levada em conta a reespecificação do modelo com a relação causal entre este indicador e o constructo invertida.

A seguir tentamos verificar os efeitos da especificação incorreta no caso em que os indicadores formativos são correlacionados entre si.

\subsection{4 - O Modelo MIMIC com Indicadores Formativos Correlacionados}

Nos casos anteriores geramos dados nos quais os indicadores formativos eram não correlacionados, embora no processo de estimação supusemos a existência da correlação entre eles. Agora nossa idéia é gerar indicadores formativos correlacionados e comparar a influência da especificação incorreta da direção causal nesse caso com os casos anteriores, onde os indicadores foram gerados como sendo independentes uns dos outros.

A Tabela 7.6 exibe os parâmetros estimados de acordo com 0 modelo correto, isto é, a média de 1000 simulações com estimativas calculadas com o modelo especificado exatamente como foi gerado. Os valores médios são iguais aos usados na geração dos dados, exceto pelo pequeno erro devido a flutuações amostrais, que geralmente está na segunda ou terceira casa decimal. 
O valor médio da estatística qui-quadrado para este ajuste foi igual a 6,08 , com 6 graus de liberdade, indicando um bom ajuste. Para gerar indicadores formativos correlacionados, simplesmente fizemos com que um deles fosse função dos outros. No caso acima, geramos $a, b$ e $c$ com distribuição $\mathrm{N}(0,1)$, e fizemos $X_{1}=a, X_{2}=1,5 X_{1}+b$ e $X_{3}=0,5 X_{2}+c$. Se calcularmos algebricamente as covariâncias entre $X_{1}, X_{2}$ e $X_{3}$, veremos que elas são praticamente iguais às médias das covariâncias estimadas na Tabela 7.6.

Tabela 7.6 - Médias e desvios padröes das estimativas do modelo MIMIC com três indicadores formativos correlacionados e três indicadores reflexivos.

\begin{tabular}{|l|c|c|c|c|c|}
\hline Parâmetro & $\mathbf{N}$ & Média & Esperado & Desv. Padrão & Significado \\
\hline lambda21 & 1000 & 0,8007406 & 0,8 & 0,0104859 & \\
\hline lambda31 & 1000 & 1,3005682 & 1,3 & 0,0136609 & \\
\hline gama11 & 1000 & 0,4980743 & 0,5 & 0,0640298 & \\
\hline gama12 & 1000 & 1,0018066 & 1,0 & 0,0420368 & \\
\hline gama13 & 1000 & 1,4997406 & 1,5 & 0,037534 & \\
\hline phi11 & 1000 & 0,998933 & 1,0 & 0,0490735 & $\operatorname{Var}\left(X_{1}\right)$ \\
\hline phi12 & 1000 & 1,4992144 & 1,5 & 0,0746583 & $\operatorname{Cov}\left(X_{1}, X_{2}\right)$ \\
\hline phi22 & 1000 & 3,2481881 & 3,25 & 0,1489269 & $\operatorname{Var}\left(X_{2}\right)$ \\
\hline phi13 & 1000 & 0,7504528 & 0,75 & 0,048997 & $\operatorname{Cov}\left(X_{1}, X_{3}\right)$ \\
\hline phi23 & 1000 & 1,6247701 & 1,6 & 0,0930474 & $\operatorname{Cov}\left(X_{2}, X_{3}\right)$ \\
\hline phi33 & 1000 & 1,8124553 & 1,8 & 0,0825802 & $\operatorname{Var}\left(X_{3}\right)$ \\
\hline theta11 & 1000 & 0,9973908 & 1,0 & 0,0601026 & $\operatorname{Var}\left(\varepsilon_{1}\right)$ \\
\hline theta22 & 1000 & 0,9998186 & 1,0 & 0,0529963 & $\operatorname{Var}\left(\varepsilon_{2}\right)$ \\
\hline theta33 & 1000 & 0,9978619 & 1,0 & 0,0807425 & $\operatorname{Var}\left(\varepsilon_{3}\right)$ \\
\hline psi11 & 1000 & 0,9957746 & 1,0 & 0,0637964 & $\operatorname{Var}\left(\zeta_{1}\right)$ \\
\hline
\end{tabular}

Depois disso o modelo foi reespecificado com a relação entre $X_{1}$ e $\xi_{1}$ invertida, ou seja, $X_{1}$ como indicador reflexivo. $\mathrm{Na}$ Tabela 7.7 estão as médias das estimativas dos parâmetros dos 1000 modelos gerados e ajustados com especificação incorreta.

Neste caso observamos uma mudança significativa não só no valor de $\gamma_{11}$, que foi subestimado, mas também nos valores de $\gamma_{12}$ (super-estimado) e $\gamma_{13}$ (subestimado). Isso era esperado pois agora $X_{1}, X_{2}$ e $X_{3}$ são correlacionados. Além disso o valor de $\psi_{11}=\operatorname{Var}\left(\zeta_{1}\right)$ parece também um pouco super-estimado, 
porém bem menos do que no caso dos modelos com indicadores formativos não correlacionados. Na verdade, se atentarmos para o seu desvio padrão médio, não temos evidências para dizer que ele é maior do que 1.

É interessante notar a grande influência em $\gamma_{12}$ e também a influência em $\gamma_{13}$ da especificação incorreta da direção causal, já que esta influência não acontecia no caso de indicadores formativos não correlacionados. Esta especificação incorreta afeta diretamente o indicador $X_{1}$ que tem uma certa relação com $X_{2}$ e $X_{3}$.

Tabela 7.7 - Médias e desvios padrōes das estimativas do modelo MIMIC com três indicadores formativos correlacionados, sendo $\mathrm{X}_{1}$ com a direção causal invertida.

\begin{tabular}{|c|c|c|c|c|c|}
\hline Parâmetro & $\mathbf{N}$ & Média & Esperado & Desv. Padrão & Significado \\
\hline gama11 & 1000 & 0,1953224 & 0,5 & 0,0053833 & \\
\hline 1ambda21 & 1000 & 0,8002713 & 0,8 & 0,0101708 & \\
\hline 1ambda31 & 1000 & 1,3001113 & 1,3 & 0,0132986 & \\
\hline gama12 & 1000 & 1,2632545 & 1,0 & 0,0300272 & \\
\hline gama 13 & 1000 & 1,4566105 & 1,5 & 0,0383793 & \\
\hline phi11 & 1000 & 0,386235 & - & 0,0183415 & $\operatorname{Var}\left(\varepsilon_{4}\right)$ \\
\hline phi22 & 1000 & 3,2469089 & 3,25 & 0,1397086 & $\operatorname{Var}\left(X_{2}\right)$ \\
\hline phi23 & 1000 & 1,6243451 & 1,6 & 0,0891888 & $\operatorname{Cov}\left(X_{2}, X_{3}\right)$ \\
\hline phi33 & 1000 & 1,8123267 & 1,8 & 0,0823979 & $\operatorname{Var}\left(X_{3}\right)$ \\
\hline theta11 & 1000 & 1,007052 & 1,0 & 0,0602944 & $\operatorname{Var}\left(\varepsilon_{1}\right)$ \\
\hline theta22 & 1000 & 0,9986571 & 1,0 & 0,0521843 & $\operatorname{Var}\left(\varepsilon_{2}\right)$ \\
\hline theta33 & 1000 & 1,016023 & 1,0 & 0,0760125 & $\operatorname{Var}\left(\varepsilon_{3}\right)$ \\
\hline psi11 & 1000 & 1,0506637 & 1,0 & 0,0627961 & $\operatorname{Var}\left(\zeta_{1}\right)$ \\
\hline
\end{tabular}

O valor médio da estatística qui-quadrado para o modelo especificado incorretamente foi de 317,47 , com 8 graus de liberdade, que é muito significante e indica um ajuste muito ruim. O valor mínimo da estatística quiquadrado foi de 217,95 , ou seja, em todas as 1000 simulações o ajuste foi muito ruim.

Se fôssemos pensar em reespecificar este modelo usando como guia o Índice de Modificação ou Multiplicador de Lagrange (ML), chegaríamos à conclusão que deveriamos incluir dois parâmetros: uma correlação entre $X_{1}$ e $X_{2}$ e uma correlação entre $X_{1}$ e $X_{3}$, nesta ordem de importância. No entanto ao 
incluirmos o parâmetro $\phi_{12}=\operatorname{Cov}\left(X_{1}, X_{2}\right)$ já obtivemos um ajuste muito bom. $A$ Tabela 7.8 mostra as médias das estimativas dos parâmetros após a inclusão de $\phi_{12}$, para 1000 repetições do processo.

Tabela 7.8 - Médias e desvios padröes das estimativas do modelo MIMIC com três indicadores formativos correlacionados, sendo $X_{1}$ com a direção causal invertida, reespecificado segundo $\circ \mathrm{ML}$ com inclusão de $\phi_{12}=\operatorname{Cov}\left(X_{1}, X_{2}\right)$.

\begin{tabular}{|l|c|c|c|c|c|}
\hline Parâmetro & $\mathbf{N}$ & Média & Esperado & Desv. Padrão & Significado \\
\hline gama11 & 1000 & 0,1573375 & 0,5 & 0,0057055 & \\
\hline lambda21 & 1000 & 0,800595 & 0,8 & 0,0101065 & \\
\hline lambda31 & 1000 & 1,301003 & 1,3 & 0,0133369 & \\
\hline gama12 & 1000 & 1,229281 & 1,0 & 0,0295318 & \\
\hline gama13 & 1000 & 1,5005495 & 1,5 & 0,038682 & \\
\hline phi11 & 1000 & 0,4141513 & 1,0 & 0,0204014 & $\operatorname{Var}\left(\varepsilon_{4}\right)$ \\
\hline phi12 & 1000 & 0,4818966 & - & 0,0340264 & $\operatorname{Cov}\left(\mathrm{X}_{1}, \mathrm{X}_{2}\right)$ \\
\hline phi22 & 1000 & 3,2391515 & 3,25 & 0,1494412 & $\operatorname{Var}\left(\mathrm{X}_{2}\right)$ \\
\hline phi23 & 1000 & 1,6170649 & 1,6 & 0,093244 & $\operatorname{Cov}\left(\mathrm{X}_{2}, \mathrm{X}_{3}\right)$ \\
\hline phi33 & 1000 & 1,8156126 & 1,8 & 0,0820185 & $\operatorname{Var}\left(\mathrm{X}_{3}\right)$ \\
\hline theta11 & 1000 & 1,0010932 & 1,0 & 0,0607329 & $\operatorname{Var}\left(\varepsilon_{1}\right)$ \\
\hline theta22 & 1000 & 0,9995302 & 1,0 & 0,0542681 & $\operatorname{Var}\left(\varepsilon_{2}\right)$ \\
\hline theta33 & 1000 & 1,0041952 & 1,0 & 0,0769028 & $\operatorname{Var}\left(\varepsilon_{3}\right)$ \\
\hline psi11 & 1000 & 1,0690335 & 1,0 & 0,0642228 & $\operatorname{Var}\left(\zeta_{1}\right)$ \\
\hline
\end{tabular}

Notamos que somente $\gamma_{11}, \gamma_{12}$ e $\phi_{12}$ estão com estimativas significativamente diferentes dos valores usados na geração dos dados, embora no caso de $\phi_{12}$ (assim como $\phi_{11}$ ) a comparação com o valor gerado seja questionável porque há um termo de erro ligado a $\mathrm{X}_{1}$, responsável por uma parte da variância de $X_{1}$. O próprio valor de $\gamma_{13}$, que estava um pouco subestimado, agora está com estimativa igual ao valor gerado. O valor médio da estatística quiquadrado para estas 1000 simulações foi de 7,499, com 7 graus de liberdade, ou seja, a considerar pela média, o ajuste foi bom. A Figura 7.6 mostra a distribuição da estatística qui-quadrado e lembramos que para 7 graus de liberdade e nível de significância igual a 0,05 temos que encontrar um valor acima de 14,1 para rejeitar a hipótese de que o modelo está correto. 
O gráfico da Figura 7.6 mostra que o modelo especificado incorretamente será aceito como correto na maior parte das vezes, na verdade, será rejeitado em apenas $7,4 \%$ das vezes. Isto mostra que, novamente, a especificação incorreta pode levar a uma outra especificação incorreta que, no entanto, ajusta bem os dados.

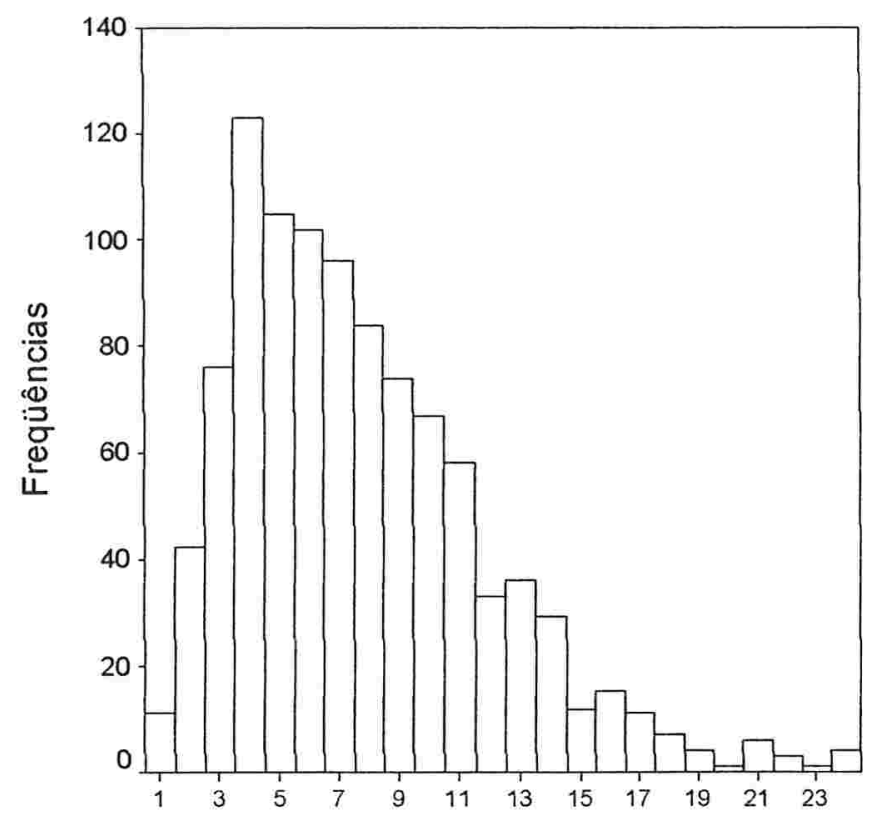

Estatística Qui-Quadrado

Figura 7.6 - Distribuição dos valores da estatística qui-quadrado para as 1000 simulaçöes do modelo reespecificado com o parâmetro $\operatorname{Cov}\left(X_{1}, X_{2}\right)$.

Neste ponto os modelos MIMIC com um constructo já foram bastante explorados e optamos por incluir mais um constructo nas simulações. Com a inclusão de um novo constructo as possibilidades de modelos diferentes para simulações se multiplicam e testar em simulações todas as possibilidades torna-se impossivel. Por isso escolheremos um caso mais simples. 


\subsection{5 - Modelo com Dois Constructos, sendo um sem Indicador Formativo e Causado pelo Outro}

Neste primeiro momento, nossa opção para um modelo de dois constructos foi simplesmente utilizar a estrutura dos modelos MIMIC das simulações anteriores e nela incluir uma nova variável latente. Neste caso a variável latente adicional é causada pela variável latente do modelo MIMIC antigo e tem três indicadores reflexivos. A Figura 7.7 mostra o diagrama de caminho deste novo modelo quando corretamente especificado, inclusive com os valores dos coeficientes usados para a geração dos dados.

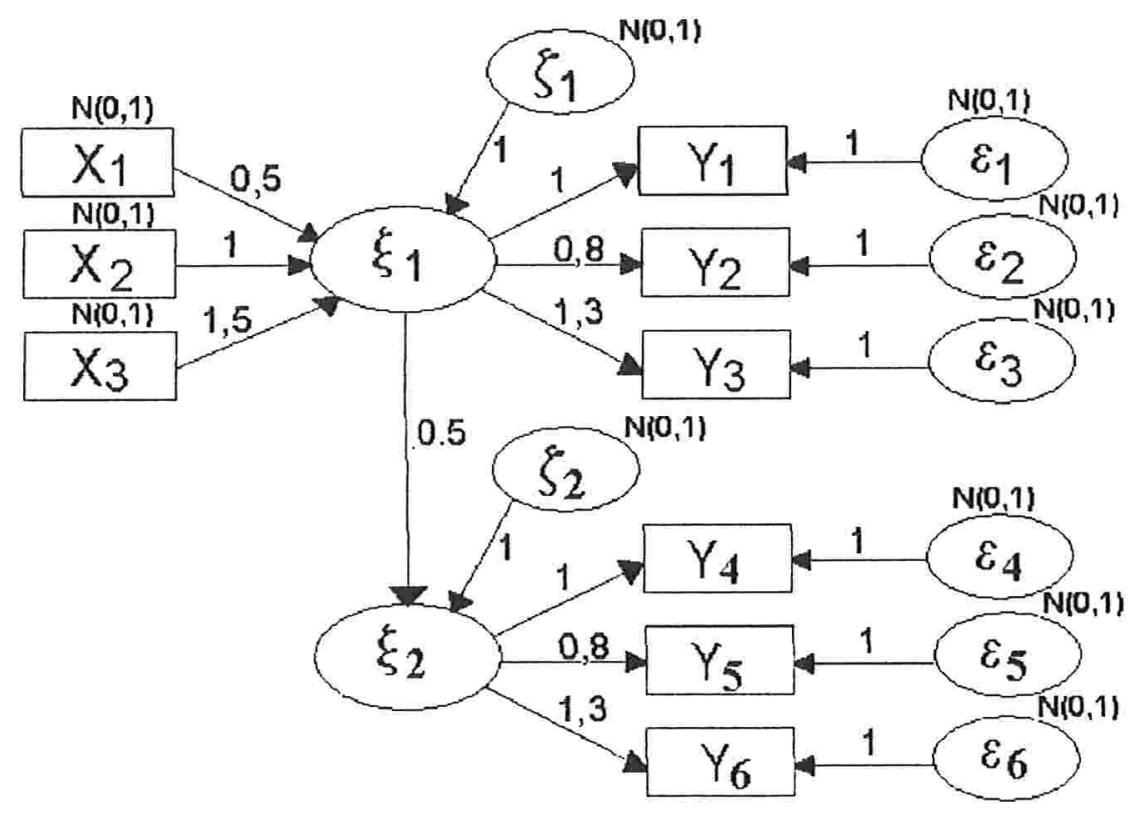

Figura 7.7 - Modelo estrutural com dois constructos corretamente especificado.

Da forma como mostrado na Figura 7.7 este modelo tem 23 graus de liberdade $e$ as simulações feitas com o modelo corretamente especificado resultaram em estimativas muito próximas dos valores reais, que podem ser vistas na Figura 7.7. O valor da estatística qui-quadrado foi, em média, igual a 23,35 , ou seja, em média o ajuste pode ser considerado muito bom, indicando que realmente estamos gerando dados que seguem o modelo da Figura 7.7. 
Após a verificação desta consistência dos dados, invertemos a direção da relação de causa do indicador $X_{1}$, e tornamos este indicador reflexivo. Foram feitos os 1000 ajustes com esta relação de causa incorretamente especificada, e a média das 1000 estimativas para cada parâmetro é mostrada na Tabela 7.9 .

Tabela 7.9 - Médias e desvios padröes das estimativas do modelo MIMIC com dois constructos, cada um com três indicadores reflexivos, sendo $\xi_{1}$ com três indicadores formativos dos quais $X_{1}$ com relaçäo causal invertida.

\begin{tabular}{|l|c|c|c|c|c|}
\hline Parametro & $\mathbf{N}$ & Média & Esperado & Desv. Padrão & Significado \\
\hline gama11 & 1000 & 0.0961246 & 0,5 & 0.0151709 & \\
\hline lambda21 & 1000 & 0.8003145 & 0,8 & 0.0197123 & \\
\hline lambda31 & 1000 & 1.3017716 & 1,3 & 0.0258131 & \\
\hline Lambda52 & 1000 & 0.7992173 & 0,8 & 0.0306337 & \\
\hline Lambda62 & 1000 & 1.3013552 & 1,3 & 0.0436568 & \\
\hline gama12 & 1000 & 0.9985085 & 1,0 & 0.0411458 & \\
\hline gama13 & 1000 & 1.4961124 & 1,5 & 0.0447741 & \\
\hline beta1 & 1000 & 0.50004 & 0,5 & 0.0221111 & \\
\hline phi11 & 1000 & 0.9549673 & - & 0.0432771 & $\operatorname{Var}\left(\varepsilon_{7}\right)$ \\
\hline phi22 & 1000 & 1.0008579 & 1,0 & 0.0449764 & $\operatorname{Var}\left(\mathrm{X}_{2}\right)$ \\
\hline phi23 & 1000 & -0.00027613 & 0,0 & 0.0337013 & $\operatorname{Cov}\left(\mathrm{X}_{2}, \mathrm{X}_{3}\right)$ \\
\hline phi33 & 1000 & 0.997376 & 1,0 & 0.0457803 & $\operatorname{Var}\left(\mathrm{X}_{3}\right)$ \\
\hline theta11 & 1000 & 1.0005539 & 1,0 & 0.0626101 & $\operatorname{Var}\left(\varepsilon_{1}\right)$ \\
\hline theta22 & 1000 & 1.0007533 & 1,0 & 0.0535463 & $\operatorname{Var}\left(\varepsilon_{2}\right)$ \\
\hline theta33 & 1000 & 0.9773481 & 1,0 & 0.0783099 & $\operatorname{Var}\left(\varepsilon_{3}\right)$ \\
\hline theta44 & 1000 & 0.9973776 & 1,0 & 0.0640325 & $\operatorname{Var}\left(\varepsilon_{4}\right)$ \\
\hline theta55 & 1000 & 0.9999654 & 1,0 & 0.0534296 & $\operatorname{Var}\left(\varepsilon_{5}\right)$ \\
\hline theta66 & 1000 & 0.9997119 & 1,0 & 0.0874613 & $\operatorname{Var}\left(\varepsilon_{6}\right)$ \\
\hline psi11 & 1000 & 1.2705066 & 1,0 & 0.0790609 & $\operatorname{Var}\left(\zeta_{51}\right)$ \\
\hline psi22 & 1000 & 0.9978414 & 1,0 & 0.0734988 & $\operatorname{Var}\left(\zeta_{2}\right)$ \\
\hline
\end{tabular}

O valor da estatística qui-quadrado para este modelo foi em média de 162,96 , com o valor mínimo igual a 91,29 , o que indica que todos os 1000 ajustes foram muito ruins, já que temos 25 graus de liberdade neste modelo. Apesar disso podemos ver acima que quase todos os parâmetros foram estimados corretamente, a não ser pelo erro amostral muito pequeno. O coeficiente da relação de $X_{1}$ em $\xi_{1}$, que teve sua direção invertida, foi o que mais sofreu com a especificação incorreta. Outro parâmetro que sofreu alteração com a 
especificação incorreta foi $\psi_{11}=\operatorname{Var}\left(\zeta_{1}\right)$, que passou de 1 para 1,27 . É interessante notar que o parâmetro $\theta_{33}$ também parece ter sofrido uma pequena influência, embora praticamente insignificante.

Se pensarmos em reespecificar este modelo seguindo o Multiplicador de Lagrange, somos levados a incluir uma correlação entre $\varepsilon_{7}$ (erro associado ao indicador formativo que está incorretamente especificado $X_{1}$ ) e $\zeta_{1}$ (erro associado à variável latente $\xi_{1}$ ), e esta reespecificação resolverá o problema do mau ajuste.

A conclusão é que a inclusão de um novo constructo da forma como foi feita aqui não afeta os resultados da especificação incorreta de forma diferente do que no modelo MIMIC sem esse novo constructo. Na verdade é bastante intuitivo que este novo constructo, da forma como foi incluído, exerça papel similar a um novo indicador reflexivo. 


\section{Capítulo 8 - Conclusões}

Até o Capítulo 6 fizemos um apanhado geral do pouco que existe na literatura relacionada a indicadores formativos. Acreditamos que alguns pontos são bastante importantes e merecem destaque, outros ainda ficaram de certa forma sem respostas. A seguir listamos brevemente estes pontos, seguido de rápido comentário. Alguns referem-se à situação atual do uso de modelos estruturais considerando os indicadores formativos, situação esta que fomos conhecendo no decorrer do desenvolvimento deste texto, e que é mais prática do que teórica. Outros referem-se ao aprendizado que conseguimos com a própria pesquisa, pontos estes que são mais teóricos.

a) A Causa - Os modelos estruturais são construidos de relações causais. A causa tem obrigatoriamente os componentes associação, isolamento e direção. A direção da causa, que é o nosso ponto de interesse, algumas vezes é difícil de ser determinada, e aqui a precedência temporal, embora possa ser um pouco subjetiva, é no nosso ponto de vista a melhor forma de se tentar especificar a direção da causa. No Capítulo 6 mostramos duas maneiras de ajudar o pesquisador a determinar a direção causal, mas ainda assim a percepção subjetiva, a experiência desenvolvida no assunto que se está modelando e a precedência temporal são, a nosso ver, insubstituíveis. Aqui fica claro que modelar não é apenas conhecer a teoria matemática do modelo, mas é também conhecer profundamente o assunto com o qual se está trabalhando.

b) A Análise Fatorial - Seja exploratória ou confirmatória, a Análise Fatorial sempre se valeu de indicadores reflexivos, causados pelo constructo, e padronizou o uso deste tipo de indicador nos modelos estruturais. O uso dos modelos estruturais como técnica de análise segue então muitas vezes este modelo 'padrão' sem questionamento quanto à real direção causal. A Análise Fatorial deve ser entendida melhor bem como as relações de causa implicadas. Dar mais ênfase à Análise Fatorial Confirmatória seria uma forma de trabalhar mais com modelos especificados a priori, e desta forma, também dar mais 
importância às relações causais. A Análise Fatorial Exploratória é uma forma fácil de especificar um modelo que se "ajusta sempre", e onde as relações causais são praticamente ignoradas.

c) Os Softwares - O avanço tecnológico torna o computador um instrumento de uso cada vez mais fácil. Os programas para modelos estruturais não são diferentes, sendo ainda mais atrativos pela facilidade que proporcionam os diagramas de caminho. Os seus usuários muitas vezes não conhecem adequadamente a teoria dos modelos estruturais, e os tutoriais dos softwares também não costumam chamar a atenção para os indicadores formativos, nem apresentar exemplos que os apliquem. A nossa experiência mostra que neste ponto estamos longe do ideal. Está cada vez mais fácil especificar e ajustar modelos estruturais conhecendo cada vez menos $O$ assunto.

d) A Identificação do Modelo - A utilização de modelos com indicadores formativos geralmente causa problemas de identificação, o que também contribui para que estes indicadores sejam menos atrativos. A identificação em si é um dos problemas mais evitados quando se fala em modelos estruturais, porque sua teoria é difícil, e o próprio entendimento do seu significado é pesado para o pesquisador menos preparado. A adição de indicadores formativos exige mais conhecimento da teoria dos modelos estruturais, o que muitas vezes torna preferivel ajustar o modelo incorretamente com indicadores reflexivos do que parar o procedimento para consultar a literatura especializada.

e) A Literatura Especializada - Notamos que a literatura disponivel sobre Modelos de Equações Estruturais não só é escassa, como também é deficiente na cobertura de temas como indicadores formativos. A maioria dos livros dedicados a usuários mais leigos destes modelos nem sequer menciona a existência destes indicadores. Os tutoriais dos softwares seguem o mesmo caminho. O leitor interessado em entender mais os indicadores formativos tem que recorrer a textos mais teóricos e acadêmicos, que nem sempre estão facilmente disponiveis. 
f) O Estudo de Modelos não Identificados - Existem métodos para o tratamento de modelos não identificados com indicadores formativos que permitem estimar muitos dos parâmetros e até fazer teste de bondade de ajuste do modelo. A teoria não é extensa nem difícil e foi tratada com certo detalhe no Capitulo 5. O problema aqui é mais encontrar a literatura do que entendê-la.

g) A Variável Latente - A especificação de indicadores formativos ou reflexivos trazem conseqüências para o significado da variável latente. Indicadores formativos causam o constructo e como os indicadores são observáveis, então o constructo causado por eles também deve ser, pois o constructo neste caso nada mais é do que uma função dos seus indicadores. Já os constructos que causam indicadores reflexivos são mesmo não observáveis.

h) A Consistência Interna - Os indicadores reflexivos devem ser correlacionados por terem uma causa comum: o constructo. Já os indicadores formativos têm sua causa geralmente fora do modelo e desconhecida, por isso é impossivel dizer algo a respeito da correlação entre eles. A não correlação entre indicadores de um mesmo constructo pode ser uma indicação de que os indicadores são formativos.

i) A Especificação Incorreta - Constatamos que a literatura deixa um problema em aberto sobre os indicadores formativos, que talvez seja o principal e mais importante - quais as conseqüências de se especificar incorretamente indicadores formativos como reflexivos, ou vice-versa? Visto que o uso predominante é o de indicadores reflexivos, a especificação incorreta que mais interessa é a do indicador formativo como reflexivo. O caso oposto provavelmente ocorre com muita raridade.

Os itens citados acima são assuntos que consideramos relevantes depois de termos concluído este texto até o Capítulo 6. Os itens de a a $h$ refletem um pouco do que aprendemos até aqui, são nossas conclusões sobre 0 assunto discutido até o Capítulo 6. Já o item i é diferente, em nenhum momento chegamos a discuti-lo, não encontramos literatura a respeito e não tínhamos até então idéia do quão grande é o preço pago por especificar indicadores incorretamente. O modelo conceitualmente estará errado, mas isto pode ter uma 
conseqüência muito pequena para merecer preocupação se ainda assim os parâmetros forem estimados corretamente e as inferências não mudarem. Neste caso continuar especificando o modelo reflexivo poderia até ser justificável pela ampla teoria existente e pelo afastamento de muitos problemas de identificação. Especificar a direção causal incorretamente poderia ser então uma aproximação bastante razoável. Se, no entanto, parâmetros e inferências mudam muito com a mudança da direção causal, então a especificação incorreta pode ter graves conseqüências e uma atenção maior deve ser dada à direção sempre que se constrói um modelo estrutural com variáveis latentes.

No Capítulo 7 tentamos dar uma idéia de qual seria a resposta para a pergunta do item i: Quais as conseqüências de se usar o tipo errado de indicador, invertendo assim a direção da causa entre ele e o constructo? Sabemos que é muito difícil responder esta questão devido à grande generalidade dos modelos estruturais, que permite que uma quantidade teoricamente infinita de modelos estruturais possam ser postulados. E para cada modelo diferente pode-se ter um efeito diferente da especificação incorreta da direção causal.

Como nenhuma literatura aborda o assunto explicitamente, resolvemos tentar obter pelo menos algumas respostas para situações mais simples, através de simulações.

Os modelos utilizados nas simulações foram os do tipo MIMIC mais simples. Estudamos principalmente os efeitos da variação da magnitude dos coeficientes, da variação do número de indicadores de ambos os tipos, e também da existência de correlações entre os indicadores formativos.

De uma forma geral podemos dizer que não encontramos grandes variações nas conclusões para os diversos tipos de modelos MIMIC estudados. Quando se especifica a direção causal como indo do constructo para o indicador quando deveria ser o contrário, o modelo sempre se ajusta muito mal aos dados. Apesar disso, a maioria dos coeficientes e parâmetros são estimados corretamente. 
Apenas o coeficiente da relação causal invertida e a variância do termo de erro relacionado ao respectivo constructo acabam sendo estimadas com bastante erro com relação ao valor que elas deveriam ter. Mas o ajuste é tão ruim que $\circ$ pesquisador certamente se verá obrigado a reespecificar 0 modelo. O Índice de Modificação ou Multiplicador de Lagrange é uma das ferramentas mais utilizadas para se reespecificar modelos estruturais. E se ele for usado, indicará logo onde estará o problema de mau ajuste, mostrando que se deve incluir um termo de correlação entre o erro relacionado ao indicador incorretamente especificado e o erro relacionado ao respectivo constructo. Isso por si só resolve o problema do mau ajuste do modelo, mas deixa o pesquisador com um modelo incorreto, que embora ajuste-se bem aos dados, não é o modelo mais adequado para representar a situação.

Este, aliás, é um dos grandes problemas dos modelos estruturais. O fato de um modelo ajustar-se bem aos dados não significa que ele é o modelo correto, pois nada impede que haja inúmeros modelos que apresentam um bom ajuste aos dados.

Visto isso, nosso aprendizado com todo o texto e finalmente com as simulações nos permite aconselhar que sempre que em um modelo estrutural mal-ajustado o Índice de Modificação apontar para a inclusão de um coeficiente de correlação entre o termo de erro de um indicador reflexivo e o termo de erro do respectivo constructo, deve ser feita uma verificação extra: será que este indicador reflexivo não é de fato formativo? A verificação desta possível especificação incorreta da direção causal deve ser feita tanto do ponto de vista da reespecificação e reajuste do modelo com a direção causal invertida, como do ponto de vista do significado do indicador em questão, se faz ou não sentido prático que ele seja formativo ao invés de reflexivo.

Muitas simulações ainda poderiam ser feitas, outras variáveis poderiam ser abordadas, como por exemplo, a ausência de normalidade dos erros, o tamanho da amostra, o número de indicadores formativos especificados incorretamente como reflexivos, o número de constructos, modelos que não sejam do tipo MIMIC, etc... Modelos muito mais complexos poderiam ser 
estudados. Sabemos que não respondemos todas as questões e que não exaurimos todo o assunto, mas estamos satisfeitos por termos abordado um tema que percebemos ser muitas vezes ignorado pelos usuários dos modelos estruturais e mesmo da própria Análise Fatorial, e assim sendo, mesmo o simples esclarecimento do significado da relação causal já é um grande passo. 


\section{APÊNDICE}

\section{Programa utilizado no SAS System para a primeira simulação da seção 7.3.1}

Apresentamos aqui a rotina usada no SAS para a nossa primeira simulação. Incluímos comentários para que seja fácil o entendimento, ainda que o leitor não esteja muito familiarizado com o SAS.

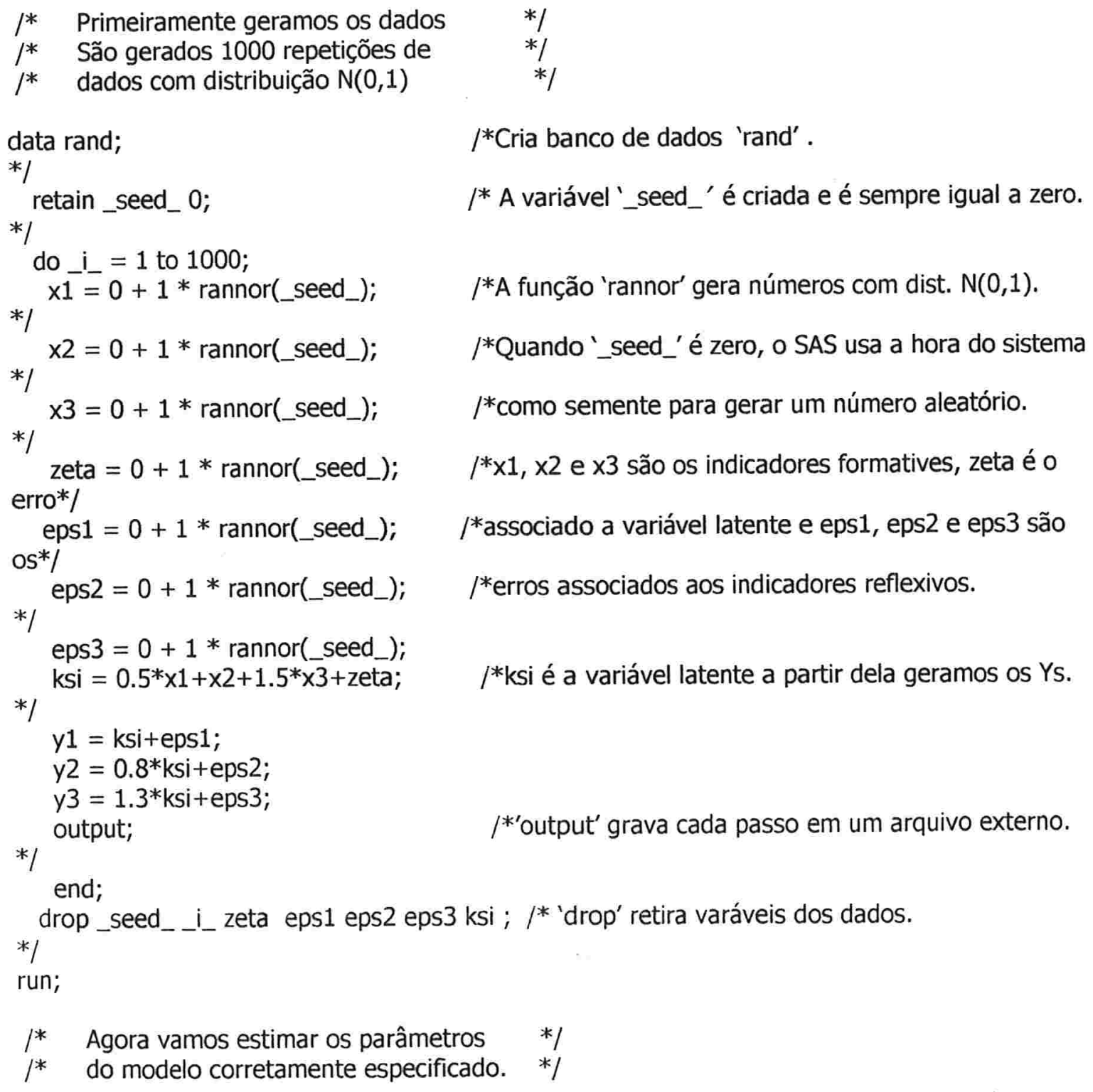


proc calis cov data $=$ rand tech $=n r$ outest=est_par outram=ram_par noprint ;

Ram

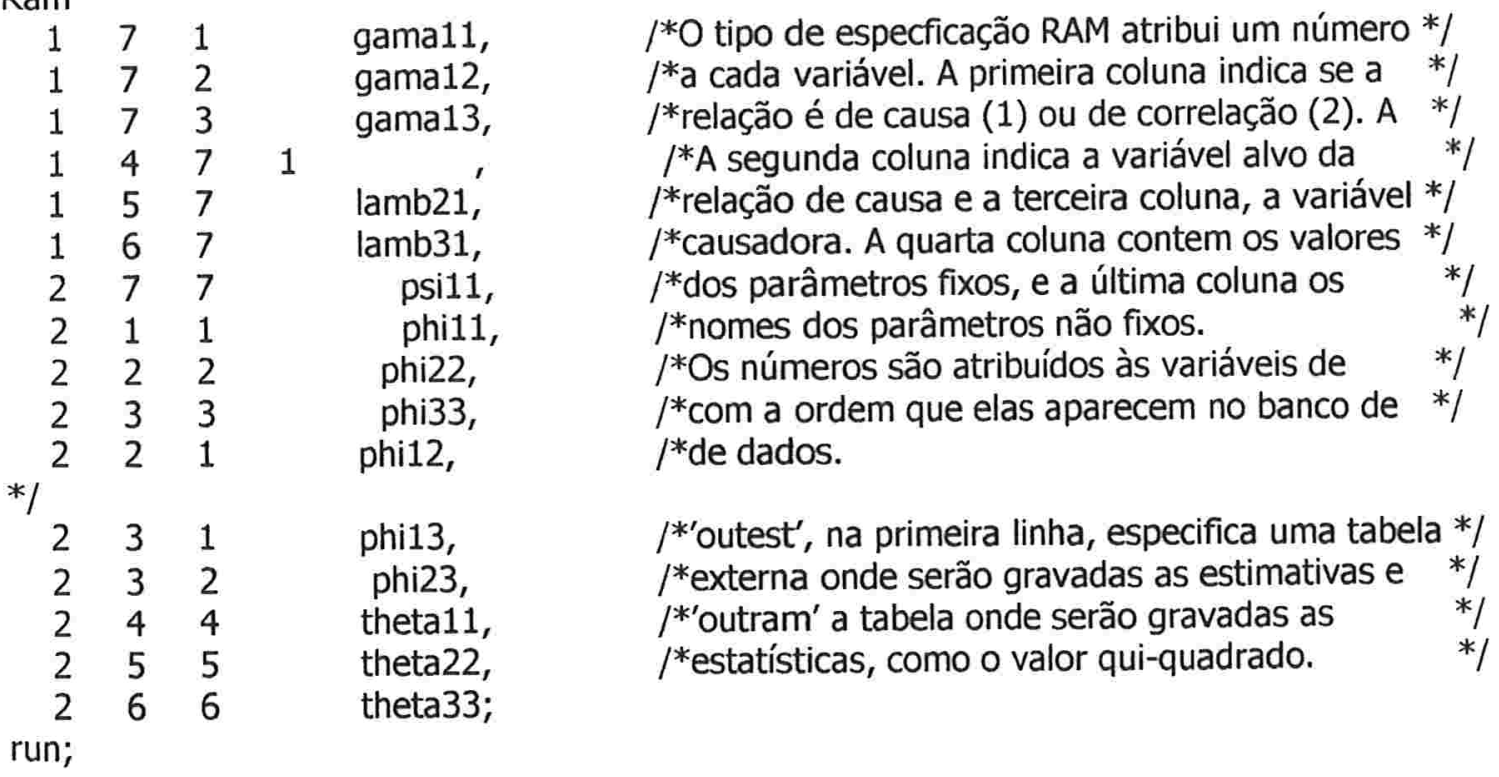

$\begin{array}{ll}* & \text { Agora vamos estimar os parâmetros } \quad * / \\ / * & \text { do modelo incorretamente especificado. } * /\end{array}$

proc calis cov data=rand tech=nr outest=est_parw outram=ram_parw noprint; Ram

$\begin{array}{rrrrr}1 & 1 & 7 & & \text { gama11, } \\ 1 & 7 & 2 & & \text { gama12, } \\ 1 & 7 & 3 & & \text { gama13, } \\ 1 & 4 & 7 & 1 & \\ 1 & 5 & 7 & & \text { lamb21, } \\ 1 & 6 & 7 & & \text { lamb31, } \\ 2 & 7 & 7 & & \text { psi11, } \\ 2 & 1 & 1 & & \text { phi11, } \\ 2 & 2 & 2 & & \text { phi22, } \\ 2 & 3 & 3 & & \text { phi33, } \\ 2 & 3 & 2 & & \text { phi23, } \\ 2 & 4 & 4 & & \text { theta11, } \\ 2 & 5 & 5 & & \text { theta22, } \\ 2 & 6 & 6 & & \text { theta33; } \\ \text { un; } & & & \end{array}$

/*Vamos limpar os bancos de dados criados, mentendo apenas algumas */ $/$ *linhas que nos interessam. Tanto para o ajuste especificado corretamente */ ${ }^{*}$ como para o especificado incorretamente, vamos manter apenas as /*estimativas dos parâmetros, seus desvios padrões e o valor qui-quadrado */ /* do ajuste do modelo.

/*A relação causal é invertida.

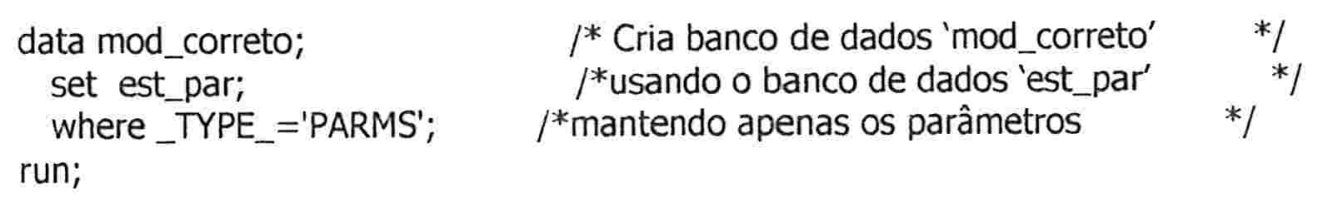




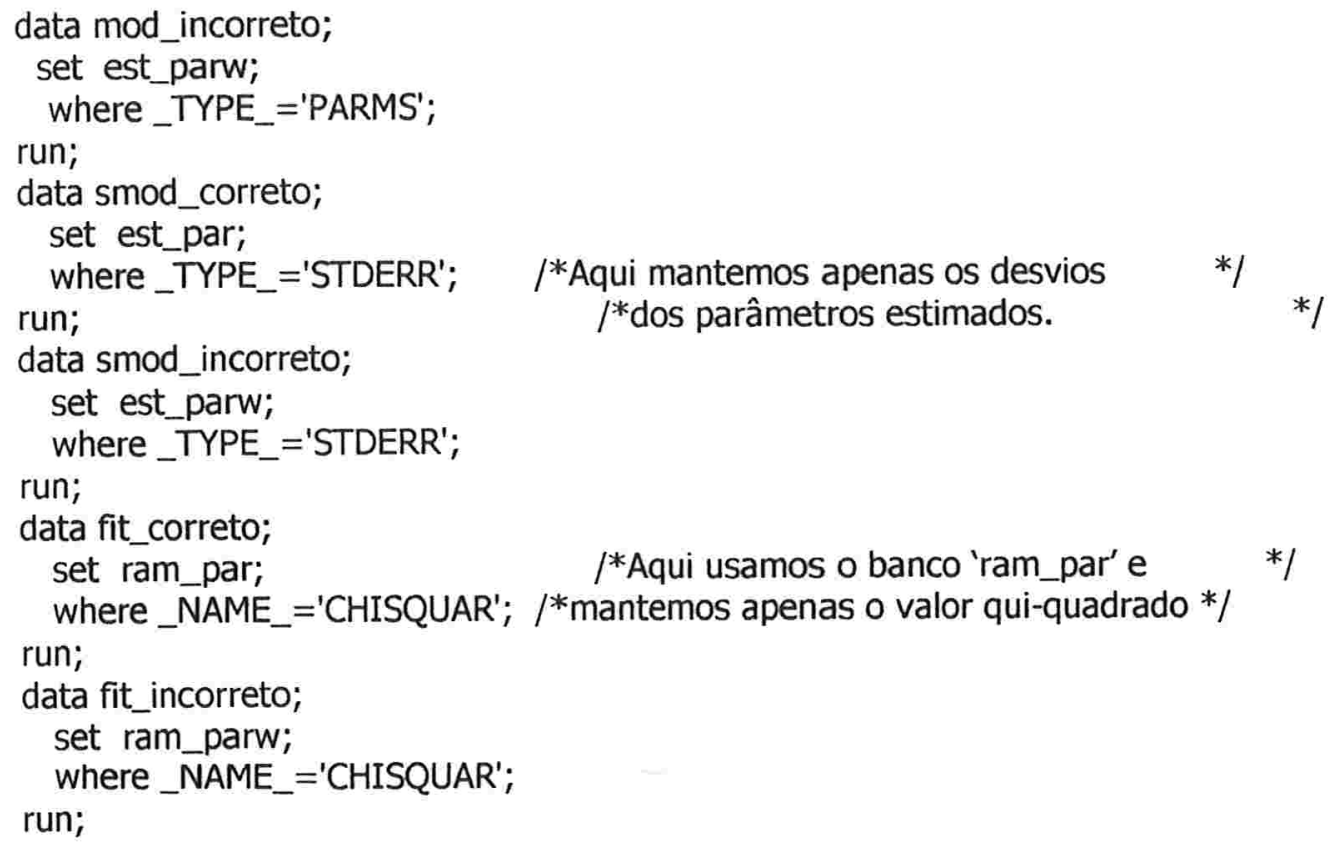

/*Acima foi feito um passo do processo de geração de dados e estimação */ /*de parâmetros. Agora precisamos repetir esse processo mais 999 vezes */ /*para termos no total 1000 replicações, e adicionalmente precisamos criar */ /*um novo banco de dados que receberá as novas estimativas de cada */ /*replicação. Isso é feito pela macro abaixo /*O primeiro passo deve ser fora da macro para inicializarmos os bancos que */ /*armazenarão os valores estimados.

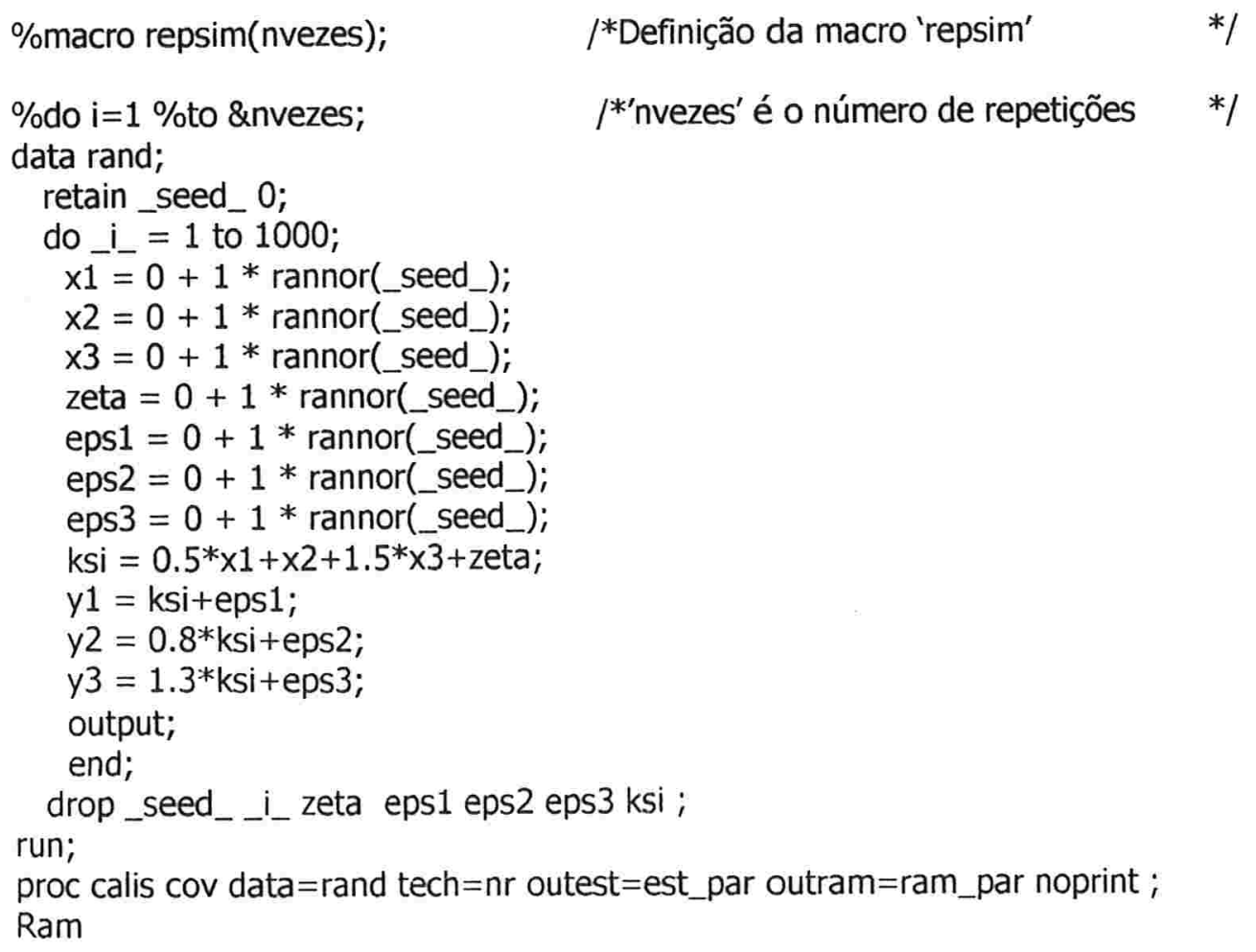




$\begin{array}{rrrrr}1 & 7 & 1 & & \text { gama11, } \\ 1 & 7 & 2 & & \text { gama12, } \\ 1 & 7 & 3 & & \text { gama13, } \\ 1 & 4 & 7 & 1 & \\ 1 & 5 & 7 & & \text { lamb21, } \\ 1 & 6 & 7 & & \text { lamb31, } \\ 2 & 7 & 7 & & \text { psi11, } \\ 2 & 1 & 1 & & \text { phi11, } \\ 2 & 2 & 2 & & \text { phi22, } \\ 2 & 3 & 3 & & \text { phi33, } \\ 2 & 2 & 1 & & \text { phi12, } \\ 2 & 3 & 1 & & \text { phi13, } \\ 2 & 3 & 2 & & \text { phi23, } \\ 2 & 4 & 4 & & \text { theta11, } \\ 2 & 5 & 5 & & \text { theta22, } \\ 2 & 6 & 6 & & \text { theta33; }\end{array}$

run;

proc calis cov data=rand tech=nr outest=est_parw outram=ram_parw noprint;

Ram

$\begin{array}{rrrrr}1 & 1 & 7 & & \text { gama11, } \\ 1 & 7 & 2 & & \text { gama12, } \\ 1 & 7 & 3 & & \text { gama13, } \\ 1 & 4 & 7 & 1 & \\ 1 & 5 & 7 & & \text { lamb21, } \\ 1 & 6 & 7 & & \text { lamb31, } \\ 2 & 7 & 7 & & \text { psi11, } \\ 2 & 1 & 1 & & \text { phi11, } \\ 2 & 2 & 2 & & \text { phi22, } \\ 2 & 3 & 3 & & \text { phi33, } \\ 2 & 3 & 2 & & \text { phi23, } \\ 2 & 4 & 4 & & \text { theta11, } \\ 2 & 5 & 5 & & \text { theta22, } \\ 2 & 6 & 6 & & \text { theta33; } \\ & & & \end{array}$

run;

data mod_correto;

set mod_correto

/*Aqui incluímos o novo valor de 'est_par' enquanto */ est_par; $\quad / *$ mantemos as estimativas dos passos anteriores, em */ run; where_TYPE_='PARMS'; $/{ }^{* \prime}$ mod_correto'.

data mod_incorreto;

set mod_incorreto

est_parw;

where _TYPE_='PARMS';

run;

data smod_correto;

set smod_correto

est_par;

run;

where _TYPE_='STDERTR';

data smod_incorreto;

set smod_incorreto

est_parw; 
run;

where _TYPE_='STDERR';

data fit_correto;

set fit_correto

ram_par;

where NAME_='P_CHISQ';

run;

data fit_incorreto;

set fit_incorreto

ram_parw;

where_NAME_='P_CHISQ';

run;

$\%$ end;

\%mend repsim;

I*Aqui termina a macro

\%repsim(999);

/*Aqui chamamos a macro, com 999 repetições.

$*$ / 


\section{Referências}

Arbuckle, J. L. (1999). AMOS 4.0 User's Guide. SmallWaters Corporation.

Asher, H. B. (1983). Causal Modelling - Sage University Paper Series on Qauntitative Aplication on Social Sciences, series $n^{\circ} 07-003$. Newbury Park, CA.

Bagozzi, R. P. e Fornell, C. (1982). Theroretical concepts, measurements and meaning. In C. Fornell (Ed.), A second Generation of Multivariate Analysis: Vol. 2. Measurement and Evaluation, 24-38. New York: Praeger.

Bentler, P. M. (1985). Theory and implementation of EQS: A structural equation program. Los Angeles: BMDP Statistical Software.

Bentler, P. M. (1990). Comparative fit index in structural models. Psychological Bulletin, 107: 238-246.

Bentler, P. M. e Bonett, D. G. (1980). Significance tests and goodness of fit in the analysis of covariance structures. Psychological Bulletim, 88: 588-600.

Bentler, P. M. e Freeman, E. H. (1983). Tests for stabilityin linear structural equation systems. Psychometrika, 48: 143-145.

Blalock, H. M. (1964). Causal inferences in nonexperimental research. Chapell Hill: University of Noth Carolina Pres.

Bollen, K. A. (1984). Multiple indicators: Internal consistency or no necessary relationship? Quality and Quantity, 18: 377-385.

Bollen, K. A. (1989a). Structural Equations with Latent Variables. New York: Wiley.

Bollen, K. A. (1989b). A new incremental fit index for general structural models. Sociological Methods \& Research, 17: 303-316.

Bollen, K. A. (1990). Outlier screening and distribution free test for vanishing tetrads. Sociological Methodology and Research, 19: 80-92.

Bollen, K. A. e Davis, W. R. (1994a). Causal Indicator models: Identification, estimation and testing. Paper presented at the 1993 American Sociological Association Convention, Miami, FL. 
Bollen, K. A. e Davis, W. R. (1994b). The extended MIMIC and 2+ emitted paths rules of identification. Umpublished manuscript - Chapel Hill: University of Noth Caroline.

Bollen, K. A., e Lennox, R. (1991). Conventional wisdom on measurement: A structural equation perspective. Psychological Bulletin, 110: 305-314.

Bollen, K. A. e Ting, K. F. (1993). Confirmatory Tetrad Analysis. Sociological Methodology, 23: 147-175.

Bollen, K. A e Ting, K. F. (2000). A tetrad test for causal indicator, Psychological Methods, 5: 3-22.

Bridgman, P. (1927). The Logic of Modern Physics. New York: Macmillan.

Brief, A. P., Butcher, A. H., e Roberson, L. (1995). Cookies, disposition and job attitudes: the effect of positive mood-nducing events and negative affectivity in job satisfaction in a field experiment. Organizational Behavior and Human Decision Process, 62: 55-62.

Browne, M. W. (1982). Covariance structures. In D. M. Hawkins, ed., Topics in Multivariate Analysis. Cambridge: Cambridge University Press, pg 72-91.

Browne, M. W. (1984). Asymptotic distribution free methods in analysis of covariance structures. British Journal of Mathematical and Statistical Psychology, 37: 62-83.

Browne, M. W. e Cudeck, R. (1993). Aternative ways of assessing model fit. In Bollen, K. A. \& Long, S. , Testing Structural Equation Models, Newbory Park, CA: SAGE.

Byrne, B. M (2001). Structural Equation Modeling with AMOS: basic concepts, applications and programming. New Jersey: Lawrence Erlbaum Associates.

Curtis, R. F. e Jackson, E. F. (1962). Multiple indicators in survey research American Journal of Sociology, 68: 195-204.

Diamantopoulos, A. (1999). Export performance measurement: reflective versus formative indicators. International Marketing Review, 16: 444-457.

Diamantopoulos, A., e Winklhofer, H. M. (1999). Index construction with formative indicators: An alternative to scale development. Journal of Marketing Research, 38: 269-277.

Diamantopoulos, A., e Winklhofer, H. M. (2001). Index Construction With Formative Indicators: An Alternative to Scale Development. Journal of Marketing Research, 37: 269-277. 
Edward,J. R. e Bagozzi, R. P. (2000). On the nature and direction of relationship between constructs and measures. Psychological Methods, 5: 155-174.

Felson, R. B. e Bohrnstedt, G. W. (1979). "Are the good beautiful or the beautiful good?". The relationship between children's perception of ability and perceptions of physical attractiveness. Social Psychology Quarterly, 42: 386-392.

Finkel, S. E. (1995). Causal Analysis eith Panel Data. Sage University Paper Series on Qauntitative Aplication on Social Sciences, series $n^{\circ}$ 07-105. Newbury Park, CA. SAGE.

Fornell, C. e Bookstein, F. L. (1982). Two structural equation models: LISREL and PLS applied to consumer exit-voice theory, Journal of Marketing Research, 19: 440- 452.

Fox, J. (1980). Effect analysis in structural equation model. Sociological Methods and Research, 9: 3-28.

Fox, J. (1984). Linear Statistical Models and Related Methods. New York: Wiley.

Glymour, C., Scheines, R., Spirtes, P. e Kelly, K. (1987). Discovering causal structure. Orlando, FL. Academic Press.

Hauser, R. M., e Goldberger, A. S. (1971). The treatment of unobservable variables in path analysis. In H. L. Costner (Ed.), Sociological Methodology (pp. 81-117). San Francisco: Jossey-Bass.

Hu, L. T. e Bentler, P. M. (1995). Evaluating model fit. In R. H. Royle, Ed., Structural Equation Modeling: Concepts, issues and applications, Thousand Oaks, CA: Sage. pg. 76-99.

Hu, L. T. e Bentler, P. M. (1999). Cutoff criteria for fit index in covariance structure analysis: Conventional criteria versus new alternatives. Structural Equation Modeling: A Multidisciplinary Journal, 6: 1-55.

Johnson, R. A. e Wichern, D. W (1992). Applied Multivariate Statistical Analysis, New York: Prentice-Hall, Inc.

Jonhston, J. (1984). Econometric Methods. New York: McGraw - Hill.

Jöreskog, K. G. (1967). Some contributions to maximum likelihood factor analysis. Psychometrika, 32: 443-482. 
Jöreskog, K. G (1973). A general method for estimating a linear structural equation system. In A. S. Goldberger, and O. D. Duncan, eds., Structural Equation Models in the Social Sciences. New York: Academic Press, pg. 85-112.

Jöreskog, K. G. e Goldberger, A. S. (1975). Estimation of a model with multiple indicator and multiple causes of a single latent variable. Journal of the American Statistical Association, 10: 631-639.

Jöreskog, K. G. e Lawley, D. N. (1968). New methods in maximum likelihood factor analysis. British Journal of Mathematical Statistics, 21: 85-96.

Jöreskog, K. G. e Sörbom, D. (1989). LISREL-7 user's reference guide. Mooresville, IN: Scientific Software.

Keesling, J. W. (1972). Maximum Likelihood Approach to Causal Analysis. Department of Education: University of Chicago.

Kelley, T. L. (1928). Crossroads in the Mind of Man. Stanford, Calig. Stanford University.

Kenny, D. A. (1974). A test for vanishing tetrad: The second canonical correlation equals zero. Social Science Research, 3: 83-87.

Lawley, D. N. (1940). The estimation of factor loadings by the method of maximum likelihood. Proceedings of the Royal Society of Edinburgh, 60: 6482.

Liebetrau, A. M. (1983). Measures of association. Sage University Paper Series on Qauntitative Aplication on Social Sciences, series $n^{\circ}$ 07-032. Newbury Park, CA. SAGE.

MacCallum, R. C., e Browne, M. W. (1993). The use of causal indicators in covariance structure models: Some practical issues. Psychological Bulletin, 114: $533-541$.

MacCallum, R. C., Browne, M. W. e Sugawara, H. M. (1996). Power analysis and determination of sample size for covariance structure modeling. Psychological Methods, 1: 130-149.

Mardia, K. V. (1970). Measures of multivariate skewness and kurtosis with applications, Biometrika, 57: 519-530. 
Mardia, K. V. (1974). Applications of some measures of multivariate skewness and kurtosis in testing normality and robustness studies. Sankhya, B, 36: 115-128.

Mardia, K. V. (1985). Mardia's test of Multinormality.In S. Kotz and N. L. Jonhson, cds., Ecyclopedia of Statistical Sciences, Vol. 5, New York: Wiley, pg. 217-221.

Menardi, S. (1991). Longitudinal Research - Sage University Paper Series on Qauntitative Aplication on Social Sciences, series $n^{\circ}$ 07-076. Newbury Park, CA. SAGE.

Nunnally, J. C. (1978). Psychometric Theory ( $2^{\text {nd }}$ ed.). New York, McGraw_Hill.

Pearl, J. (2000). Causality - Models, Reasoning, and Inference. Cambridge University Press - New York.

Pedhazur, E. J. (1991). Measurement, design and analysis - an integrated approach. Hillsdale, New Jersey, Lawrence Erlbaum Associates Inc.

Rindskopf, D. (1984). Using phantom and imaginary latent variables to parameterize constraints in linear structural models. Psychometrika, 49: 3747.

Sarris, W. E., Satorra, A. e Sörbom D. (1987). The detection and correction of specifcation errors in structural equation models. Sociological Methodology1987: $105-130$.

Satorra, A. e Sarris, W. E. (1985). Power of the likelihood ratio test in covariance structure analysis. Psychometrika, 53: 83-90.

Simon, H. (1957). Spurious correlations: a causal interpretation. In Mode/s of Man, pag 37-49. New York, John Wiley.

Spearman, C. (1904). General Intelligence, Objectively Determined and Measured. American Journal of Psychology, 15: 201-293.

Spearman, C. (1927). The abilities of Man. New York, Macmillan.

Spearman, C. e Holzinger, K. (1924). The sampling error in the theory of two factor. British Journal of Psychology, 15: 17-19.

Steiger, J. H. (1990). Structural model evaluation and modification: An interval estimation approach, Multivariate Behavioral Research, 25: 173-180.

Steiger, J. H. e Lind, J. C. (1980). Statistically based test for the number of commum factors. Paper presented at the Psychometric Society Annual Meeting, lowa City, IA. 
Wiley, D. E. (1973). The identification problem for structural equation models with unmeasured variables. In A. S. Goldberger, and O. D. Duncan, eds., Structural Equation Models in the Social Sciences. New York: Academic Press, pg. 69-83.

Wishart, J. (1928). Sampling errors in the theory of two factors. British Journal of Psychology, 19: 180-187.

Wonnacott, R. J. e Wonnacott, T. H. (1979). Econometrics. New York: Wiley.

Wright, S. (1918). On the Nature of Size Factors. Genetics, 3: 367-374.

Wright, S. (1921). Correlation and Causation. Journal of Agricultural Research, 20: $557-582$.

Wright, S. (1934). The method of path coefficients. Annals of Mathematical Statistics, 5: 161-215.

Wright, S. (1960). Path coefficients and path regressions: Alternatives or Complementary Concepts: Biometrics, 16: 189-202. 